PROGRAMA DE DOCTORADO EN INGENIERIA

TERMODINAMICA DE LOS FLUIDOS

TESIS DOCTORAL:

\title{
DESARROLLO DE UNA BIORREFINERIA DE SUBPRODUCTOS DEL TABACO MEDIANTE FLUIDOS SUPERCRITICOS
}

Presentada por Gerardo Joaquin Tita para optar al grado de Doctor por la Universidad de Valladolid

Dirigida por:

Prof. Maria Jose Cocero Alonso

Dr. Alexander Navarrete Muñoz 

DESARROLLO DE UNA BIORREFINERIA DE SUBPRODUCTOS DEL TABACO MEDIANTE FLUIDOS SUPERCRITICOS 



\section{Índice de Contenidos}

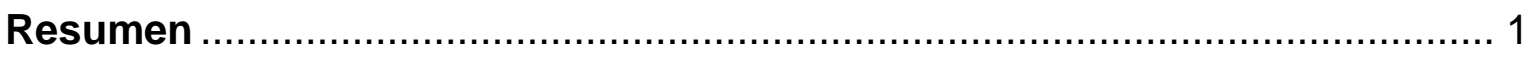

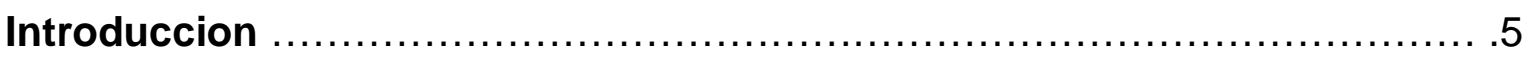

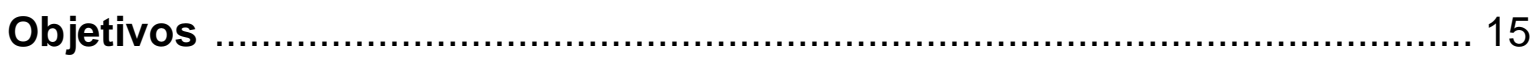

Capítulo I: Tabaco. Consideraciones para su uso como materia prima en una

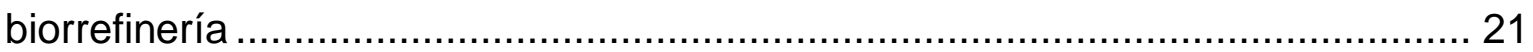

Capítulo II: Separación de la fracción extraíble del scrap de tabaco Virginia con

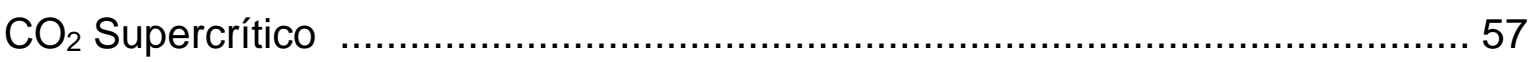

Capitulo III. Hidrólisis ultrarrápida en Agua Supercrítica (ASC) de la fracción lignocelulósica del scrap de tabaco Virginia. 83

Capítulo IV: Estudio sobre el uso del solanesol extraído de scrap de tabaco como

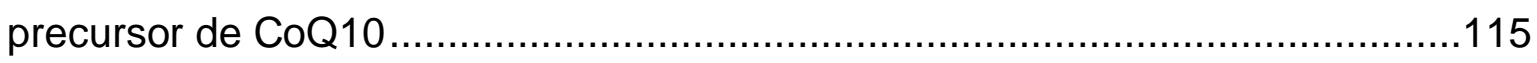

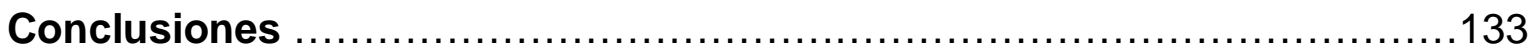

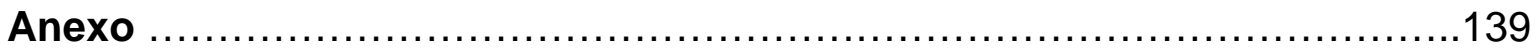

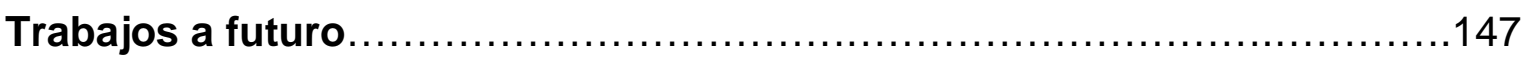

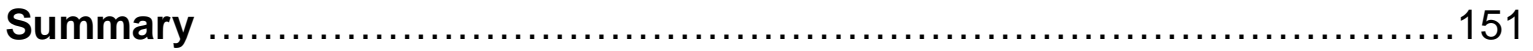

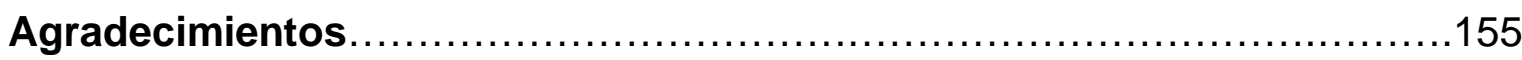

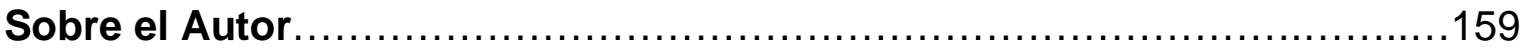



Resumen 
La producción de tabaco en Argentina se concentra en las provincias del norte del país, debido a las condiciones climáticas favorables. Entre las provincias de Salta y Jujuy se producen en promedio unos 70.000 tn/año de láminas de FCV, que generan 35.000 th de subproductos o residuos. En este trabajo se aportan estudios para desarrollar una biorrefinería sostenible con los subproductos de la industria tabacalera, utilizando fluidos supercríticos como $\mathrm{CO}_{2}$ y $\mathrm{H}_{2} \mathrm{O}$ como disolventes y medio de reacción. Se propone valorizar los subproductos, expandiendo la cadena de valor actual y contribuyendo a la sostenibilidad de esta importante industria en las provincias del noroeste argentino.

Entre las fortalezas identificadas para valorizar estos subproductos están la composición química, alto rendimiento de biomasa en $\mathrm{kg} / \mathrm{ha}$, alto nivel de conocimiento en el cultivo agrícola, abundantes antecedentes de investigaciones en usos alternativos al actual, la economía de escala en la producción industrial y el acceso a subproductos y residuos en volumen, y centralizado en centros de acopio, lo que favorece la homogeneidad y accesibilidad del producto. La memoria presenta las características de los subproductos generados en la industria de procesado de tabaco, para su uso como materia prima en una biorrefinería.

La tesis aporta los resultados experimentales que demuestran la viabilidad de la extracción de solanesol y nicotina de los subproductos obtenidos en el procesado del scrap de tabaco, con $\mathrm{CO}_{2} \mathrm{SC}$. Se ha analizado el efecto de las variables de operación (presión, temperatura, tiempo de extracción) y se aplicó un modelo fenomenológico de la extracción para obtener los coeficientes de solubilidad y transferencia de masa. Además, se fraccionó los extractos obtenidos mediante extracción líquido-líquido para conseguir una fracción con alto contenido en solanesol y otra con alto contenido en nicotina. Los resultados muestran que se requieren diferentes condiciones según el propósito de la extracción: baja presión (15 MPa) para aumentar el rendimiento de los extractos en solanesol, y alta presión (37 MPa) para promover la extracción de nicotina, mientras que los resultados del modelo indican que los mejores resultados se obtuvieron en condiciones en las que la extracción fue controlada por los parámetros de solubilidad. Estos resultados aportan la información necesaria para la valorización de los compuestos extractivos en $\mathrm{CO}_{2} \mathrm{SC}$ de los residuos producidos por la industria tabacalera.

El subproducto obtenido de la etapa de extracción con $\mathrm{CO}_{2} \mathrm{SC}$, contiene una fracción próxima al $60 \%$ de compuestos solubles en agua, como azucares libres, pectina, y otros. Además de $10 \%$ de proteínas, $10 \%$ de celulosa, $6 \%$ de lignina, $10 \%$ de 
humedad y en menor proporción hemicelulosas y cenizas. El scrap de la planta de tabaco procedente de la etapa de extracción con $\mathrm{CO}_{2} \mathrm{SC}$, se ha tratado en un proceso de hidrólisis en ASC tanto a escala laboratorio como de planta piloto. Las condiciones de operación han sido temperaturas entre $374-400^{\circ} \mathrm{C}$, presiones de $25 \mathrm{MPa}$.

Los resultados muestran que la etapa limitante de este proceso es la de transferencia de materia. Así, en la planta laboratorio que se ha operado con un tamaño de partícula de $150 \mathrm{~mm}$, se ha obtenido una concentración de azucares de 38,5\% y de sus productos de hidrolisis, aldehídos 42,4 \% y ácidos de 35,2\%. El fácil acceso del ASC promueve la hidrólisis de los azucares. En la planta piloto, se ha operado con un tamaño de partícula de hasta $500 \mu \mathrm{m}$ y tiempo de residencia de $180 \mathrm{~ms}$, se da una mayor resistencia a la transferencia del agua en la partícula y disminuye significativamente el contenido de aldehídos al 2,1\% y de ácidos al 20,8\%, aumentando la concentración de azucares al $49,1 \%$.

El último capítulo de la tesis está dedicado a estudiar una aplicación del solanesol obtenido del scrap de tabaco, mediante extracción supercrítica en el capítulo 2. Su utilización como precursor en un cultivo de Rhizobium radiobacter para obtener la CoQ10. El solanesol se encapsula en N-Lok formando una emulsión que facilita su disolución en el medio de cultivo. Los resultados muestran que se consigue multiplicar por 10 la producción de CoQ10 sobre la obtenida en el control.

Los resultados de este estudio permiten proponer una refinería en cascada. La fracción de extractivos se puede valorizar por extracción con agua y posterior etapa de fermentación. La concentración de proteínas permite su valorización, y el residuo remanente se fracciona mediante un proceso de hidrólisis en ASC, produciendo un efluente liquido rico en azucares que se valoriza por fermentación. 
Introducción 


\section{Bioeconomía y Biorrefinerías}

A nivel mundial hay una creciente necesidad de transformar el sistema productivo actual, en un sistema basado en la sustentabilidad económica, ambiental y social. Este nuevo enfoque da origen al concepto de bioeconomía. La cantidad de definiciones de bioeconomía es abundante, fue evolucionando a lo largo de los últimos años, y actualmente tiene diferentes perspectivas y visiones [1]. En el año 2015, la Cumbre Mundial de Bioeconomía publicó una definición de este concepto [2], desde una perspectiva global y en términos generales:

"Bioeconomía es la producción, utilización y conservación de los recursos biológicos, incluidos los conocimientos relacionados, la ciencia, la tecnología y la innovación, para proporcionarle información, productos, procesos y servicios a todos los sectores económicos, con el objetivo de avanzar hacia una economía sostenible".

La Organización de las Naciones Unidas para la alimentación y la Agricultura (FAO) coordina el trabajo internacional sobre bioeconomía y viene trabajando desde la cumbre mencionada anteriormente, en establecer directrices que permitan desarrollar la bioeconomía manera sostenible. Los principales desafíos sociales interconectados que identificó la FAO son: la seguridad alimentaria, dependencia de los recursos fósiles, escasez de recursos naturales y el cambio climático. Recientemente, la FAO publicó 10 principios para ayudar a los países, productores y usuarios de biomasa y bioproductos en el desarrollo de estrategias, políticas y programas de bioeconomía sostenibles. En la Tabla 1 se presentan estos 10 principios. En la misma línea, en diciembre de 2015, la Unión Europea comenzó a trabajar en un plan de acción [3] para cerrar el ciclo de vida de algunos productos (actualmente lineal) en un ciclo de vida circular. Básicamente, reutilizando, reciclando y volviendo a la economía. A esto se lo llama economía circular. Tres años después de este documento, se publicó la visión 2050 de la unión europea sobre lo que esperan ser para ese año :

Europa contará con una industria de base biológica sostenible y competitiva que proporcionará empleos y crecimiento que contribuirán a una bio-sociedad circular. En esta bio-sociedad circular, los ciudadanos informados eligen un modo de vida sostenible, apoyando una economía que combina el crecimiento económico con el bienestar de la sociedad y el respeto por el medio ambiente [4]. 
Tabla 1. Principios para una bioeconomía sostenible [5]

Principio 1: El desarrollo de la bioeconomía sostenible debe apoyar la seguridad alimentaria y la nutrición en todos los niveles.

Principio 2: La bioeconomía sostenible debe asegurarse que los recursos naturales estén conservados, protegidos y mejorados.

Principio 3: La bioeconomía sostenible debe apoyar el crecimiento económico, competitivo e inclusivo.

Principio 4: La bioeconomía sostenible debe hacer comunidades más saludables, más sostenibles y aprovechar la resiliencia social y del ecosistema.

Principio 5: La bioeconomía sostenible debe confirmarse en la mejora de la eficiencia y en el uso de recursos y biomasa.

Principio 6: Mecanismos de gobierno responsables y efectivos deben apuntalar la bioeconomía sustentable.

Principio 7: La bioeconomía sostenible debe hacer un buen uso de los conocimientos relevantes existentes y tecnologías sólidamente probadas, y cuando sea apropiado promover la investigación y la innovación.

Principio 8: La bioeconomía sostenible debe utilizar y promover el comercio y las prácticas de mercado sostenible.

Principio 9: La bioeconomía sostenible debe dirigirse a las necesidades sociales y fomentar el consumo sostenible.

Principio 10: La bioeconomía sostenible debe promover la cooperación, la colaboración y el compartir entre grupos de interés interesados y preocupados en todos los niveles pertinentes

La bioeconomía, entre otras cosas, exige la creación de procesos sostenibles integrados, basados en la utilización de biomasa como materia prima. Estos procesos que se llevan a cabo en las denominadas biorrefinerías. El National Renewable Energy Laboratory (NREL) de los EE.UU. define una biorrefinería como: "una instalación que integra procesos y equipos de conversión de biomasa, para producir combustibles, energía, y productos químicos a partir de biomasa. El concepto de biorrefinería es análogo a las actuales refinerías de petróleo que producen múltiples combustibles y productos a partir del petróleo" (NREL).

La Agencia Internacional de Energía (www.iea.org) elaboró una clasificación de las biorrefinerías [6], en función de las siguientes características:
a. Plataforma
b. Producto
c. Materia prima
d. Proceso 
La combinación de estas cuatro características puede describir distintos tipos de biorrefinerías. La más importante, es el tipo plataforma usada. Las plataformas son grupos de productos intermedios de los cuales se pueden obtener distintos productos finales desde materias primas. Una biorrefinería puede tener una o más plataformas. Un ejemplo de esto, son las biorrefinerías de plataforma de azúcares. Que, partiendo de la hidrólisis de biomasa lignocelulósica, almidón o sacarosa obtienen azúcares de 5 y 6 carbonos que son materia prima de procesos de fermentación. El tipo de producto se refiere a energía (etanol, biodiesel, electricidad, calor, etc.) o bioproductos (materiales, químicos, alimentos, etc.). Los tipos de materia prima pueden ser: cultivos agrícolas (maíz, forestales, cereales, etc.), residuos de la industria agrícola (subproductos, residuos forestales, residuos urbanos, etc.). En la Tabla 2 se presentan los distintos subgrupos de cada una de las características de esta clasificación.

Argentina dispone de la capacidad científico-tecnológica necesaria para avanzar hacia esa transformación, sin embargo, hay escasos antecedentes que se enmarquen en el desarrollo de procesos bioeconómicos. Un estudio realizado por la FAO presenta un análisis del balance de energía derivada de biomasa en la Argentina [7]. De acuerdo con este informe la biomasa accesible y potencialmente disponible podría satisfacer el $47 \%$ de la demanda energética primaria del país. En el apartado dedicado a la provincia de Salta [8], considera a los residuos de la industria tabacalera como una oferta importante de biomasa para energía.

El desarrollo de biorrefinerías sostenibles requiere que se tengan en cuenta los principios de la ingeniería sostenible recogidos por Anastas y Zimmerman $[9,10]$. 
Plataformas

\begin{tabular}{ll}
\hline I.) Azúcares C5 & $\begin{array}{l}\text { I.) Productos energéticos } \\
\text { I.1) Biodiesel }\end{array}$ \\
II.) Azúcares C6 & $\begin{array}{l}\text { I.2) Bioetanol } \\
\text { I.3) Biometano }\end{array}$ \\
III.) Aceites & I.4) Biocombustibles \\
& I.6) Electricidad y calor
\end{tabular}

IV.) Biogás

\section{II.) Productos Materiales}

V.) Gas de síntesis
II.1) Alimentos
II.2) Alimentación animal
II.3) Fertilizante
II.4) Glicerina
II.5) Biomateriales
II.6) Productos químicos
II.7) Bloques de construcción
II.8) Polímeros y resinas
II.9) Biohidrógeno

VII.) Solución

orgánica

VIII.) Líquido

pirolítico
Materias primas
I.) Biomasa forestal
I.1) Cultivos forestales
I.2) Aprovechamientos forestales
I.3) Residuos forestales

\section{II.) Biomasa agrícola}

II.1) Cultivos agrícolas

\section{III.) Biomasa ganadera}

III.1) Estiércol

III.2) Purines y otros

\section{IV.) Biomasa industrial}

IV.1) Subproductos y residuos forestales

IV.2) Subproductos y residuos

alimenticios

\section{V.) Biomasa doméstica}

IV.1) Residuos orgánicos biodegradables

\section{I.) Físicos}

I.1) Adsorción

I.2) Centrifugación

I.3) Cristalización

1.4) Densificado

1.5) Destilación

I.6) Extracción

I.7) Filtración

I.8) Fraccionamiento

I.9) Humectación

I.10) Molienda

I.11) Prensado

I.12) Secado/deshidratación

I.13) Refrigerado/calentado

I.14) Tamizado

\section{III.)Termo - Químicos}

III.1) Pirólisis

III.2) Reformado con vapor

III.3) Licuefacción

III.4) Esterificación

III.5) Pirólisis

III.6) Reformado con vapor

III.7) Torrefacción
Procesos

II.) Químicos

II.1) Craqueo

II.2) Des lignificación

II.3) Epoxidación

II.4) Esterificación

II.5) Eterificación

II.6) Explosión con amoniaco

II.7) Explosión con $\mathrm{CO}_{2}$

II.8) Explosión con vapor

II.9) Hidrogenación

II.10) Hidrólisis

II.11) Hidrólisis ácida

II.12) Hidrólisis alcalina

II.13) Isomerización

II.14) Oxidación-reducción

II.15) Polimerización

II.16) Pretratamiento químico

II.17) Procesos hidrotérmicos

II.18) Purificación

\section{IV.) Biotecnológicos}

IV.1) Des lignificación enzimática

IV.2) Digestión anaerobia

IV.3) Esterificación enzimática

IV.4) Fermentación

IV.5) Hidrólisis enzimática 


\section{El $\mathrm{CO}_{2}$ Supercrítico $\left(\mathrm{CO}_{2} \mathrm{SC}\right)$ como disolvente}

La utilización de $\mathrm{CO}_{2}$ como disolvente se basa en las propiedades físicas que tiene cuando se encuentra en condiciones de presión y temperatura superiores a su punto crítico. Concretamente, su densidad reducida mayor que 1 hace que tenga un comportamiento como disolvente. Este poder disolvente varia con la densidad, comportándose como disolvente a densidades próximas a la de los líquidos y como antidisolvente a densidades próximas a la de los gases. Brunner presenta un detallado estudio de las propiedades de los fluidos supercríticos en su libro "Gas Extraction" [11].

La extracción supercrítica se basa en las propiedades físicas de los fluidos en condiciones supercríticas, el fluido más utilizado es el $\mathrm{CO}_{2} \mathrm{SC}$. El proceso de separación se basa en la utilizando $\mathrm{CO}_{2} \mathrm{SC}$ en la etapa de extracción y reduciendo la presión hasta fase gas, en la etapa de separación del soluto. En la extracción de un soluto de una matriz sólida, el proceso se pude describir mediante etapas de transporte del $\mathrm{CO}_{2}$, disolución, y transporte del soluto disuelto en el $\mathrm{CO}_{2}$ desde la matriz a la fase global. El efecto de las variables de operación tanto en las etapas de transporte como en la solubilidad en el $\mathrm{CO}_{2}$ están bien descritas en la bibliografía [11].

El proceso está desarrollado a escala industrial desde el año 1978 [12]. La primera instalación fue una planta de producción de café descafeinado, seguida de plantas multipropósito para la extracción de compuestos con alto valor añadido, como aditivos alimentarios, especies, aromas etc. Actualmente el proceso que está más desarrollado a escala industrial es la extracción de TCA del corcho, con plantas industriales en España y Francia [13]. Recientemente la extracción de compuestos del cannabis con fines medicinales está abriendo una nueva aplicación industrial [14].

\section{El Agua Supercrítica (ASC) como disolvente y medio de reacción}

El agua tanto en condiciones subcríticas como supercríticas se ha utilizado como disolvente y medio de reacción en los procesos de despolimerización-reacciónseparación de biomasa. Las principales ventajas que hacen que los medios hidrotermales sean una alternativa prometedora para el procesamiento de la biomasa son: 1) Utilización directa de la materia prima independientemente de su contenido de agua, lo que implica un importante ahorro de energía; 2) El mismo medio de reacción Se puede utilizar para la transformación de diferentes fracciones de biomasa; 3) Reduce 
significativamente las limitaciones de transferencia de materia, con lo que las velocidades de reacción son más altas [15].

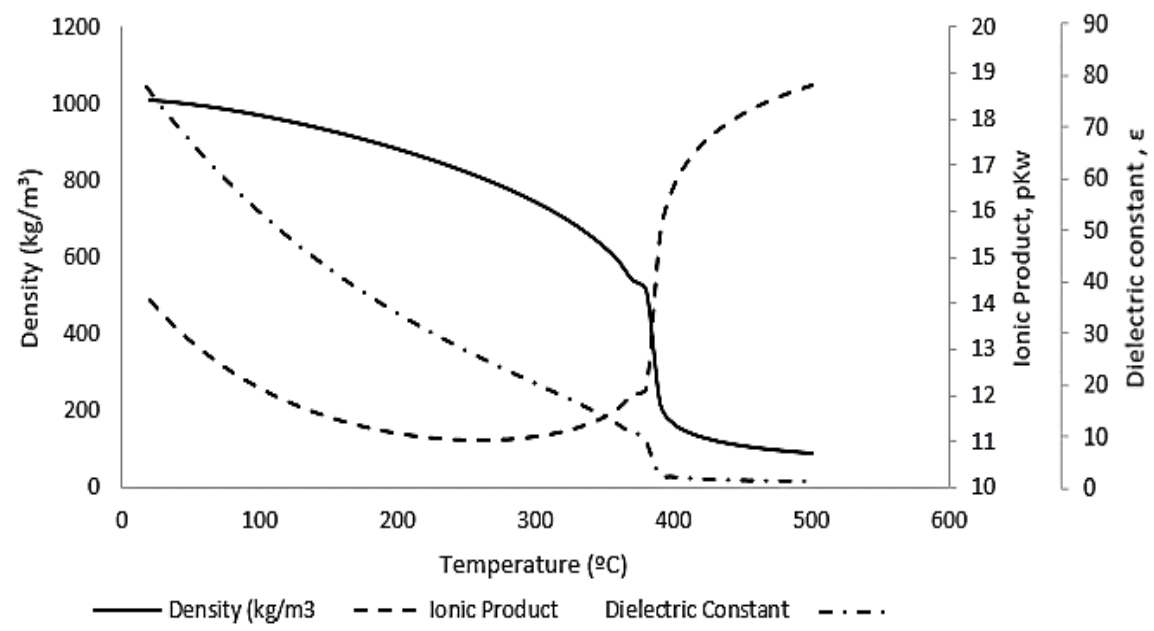

Figura 1 Propiedades del agua a presión de $25 \mathrm{MPa}$

Las propiedades del ASC permiten que actúe como un buen disolvente y medio de reacción. Disuelve la celulosa, por ejemplo, y controlar la selectividad de las reacciones de hidrolisis. El producto iónico del agua (Kw). a una temperatura de $300^{\circ} \mathrm{C}$ es de $\mathrm{KW}=10-11$. Esto permite tener un medio con altas concentraciones de $\mathrm{H}^{+} \mathrm{y} \mathrm{OH}^{-}$, favoreciendo de esta manera las reacciones catalíticas ácido/base. Por encima de la temperatura crítica del agua $\left(374^{\circ} \mathrm{C}\right)$, el $\mathrm{Kw}$ disminuye drásticamente a valores de $\mathrm{Kw}=$ 10-19, estas condiciones minimizan las reacciones con mecanismo de tipo iónico favoreciendo los mecanismos radicalarios. La Fig. 2, presenta las propiedades del agua en medio sub/supercrítico [16]. La combinación de las propiedades del ASC con las altas velocidades de reacción asociadas a las altas temperaturas, hace del agua un excelente disolvente para el desarrollo de procesos compatibles con el medio ambiente. Permitirá, llegar a un uso sostenible de las materias primas, energía, y a la reducción del coste de los equipos, ya que consigue una elevada intensificación de los procesos con la drástica reducción del tiempo de reacción $[17,18]$

El objetivo de esta tesis es valorizar los subproductos de la industria de procesado de tabaco, que presenta buenas perspectivas por su producción centralizada, composición, y cantidad producida para desarrollar una biorrefinería. Esta valorización se tiene que realizar en el medio rural donde se producen, por lo que se propone utilizar tecnologías limpias, como son la extracción con $\mathrm{CO}_{2} \mathrm{SC}$ y la valorización de la fracción lignocelulósica mediante hidrolisis ultra-rápida en ASC. El grupo de investigación ingeniería de procesos a presión tiene experiencia e instalaciones a escala piloto para realizar la investigación necesaria. La tesis se va a desarrollar de acuerdo con los objetivos que se presentan a continuación. 


\section{Bibliografía}

[1] Birner R, «Bioeconomy Concepts», en Bioeconomy, I. Lewandowski, Ed. Cham: Springer International Publishing, 2018, pp. 17-38.

[2] German Bioeconomy Council, «Comunicado Cumbre Global de Bioeconomía 2018». Disponible en https://gbs2018.com/resources/gbs2018-documentation/ [Accedido: 20-nov-2019].

[3] European Commission «Helping consumers choose sustainable products and services».Disponible en: https://ec.europa.eu/commission/publications/helpingconsumers-choose-sustainable-products-and-services_en. [Accedido: 20-nov2019].

[4] SamDB, «Home», Biosociety Vision. Disponible en: https://biosocietyvision.eu/. [Accedido: 20-nov-2019].

[5] FAO, Climate and Environment Division, «Towards sustainable bioeconomy guidelines Brief». Disponible en http://www.fao.org/3/ca5145en/ca5145en.pdf [Accedido: 07-sept-2020].

[6] Cherubini, F., Jungmeier, G., Wellisch, M., Willke, T., Skiadas, I., Van Ree, R., de Jong, E., 2009. Toward a common classification approach for biorefinery systems. Biofuels, Bioprod. Bioref. 3, 534-546.

[7] Organización de las Naciones Unidas para la Alimentación y la Agricultura, Análisis espacial del balance energético derivado de biomasa en Argentina. Metodología Wisdom. Food \& Agriculture Org., 2009.

[8] Organización de las Naciones Unidas para la Alimentación y la Agricultura, Análisis espacial del balance energético derivado de biomasa. Metodología Wisdom. Provincia de Salta: Colección Documentos Técnicos $N^{\circ} 2$. Food \& Agriculture Org., 2016.

[9] Anastas PT, Zimmerman J B. Through the 12 Principles GREEN Engineering Environmental science \& technology, 95-101, 2003

[10] Zimmerman J B, Anastas PT, Erythropel H C, Leitner W , Designing for a green chemistry future, Science (80-. ). 367 397-400 (2020)

[11] Brunner, G. Gas extraction. An introduction to fundamentals of supercritical fluids and the application to separation processes. Ed. Springer. 1994. ISBN 978-3-66207380-3.

[12] Eggers R. Design and operation of the pressure vessels used in near-critical extraction processes. Publicado en Extration of Natural Products using near critical Solvents. M.R. King, R.R. Bott. Editores. Blackie Academic. 1994. 
[13] Eduard L, Helmut S. industrial cleaning of cork with supercritical $\mathrm{CO}_{2}$. 3rd International Meeting on High Pressure Chemical Engineering, 10.-12. May 2006, Erlangen Alemania.

[14] Baldino, L., Scognamiglio, M., \& Reverchon, E. . Supercritical fluid technologies applied to the extraction of compounds of industrial interest from cannabis sativa $L$. and to their pharmaceutical formulations: A review. Journal of Supercritical Fluids, $165(2020)$

[15] Cocero M.J., Supercritical water processes. Future prospects. (2018) J supercritical fluids,134, 124-132.

[16] Cocero, M.J., Cabeza, Á., Abad, N., Adamovic, T., Vaquerizo, L., Martínez, C.M., Pazo-Cepeda, M.V. Understanding biomass fractionation in subcritical \& supercritical water. Journal of Supercritical Fluids, 133: 550-565, 2018.

[17] Cantero, D., Jara, R., Navarrete, A., Pelaz, L., Queiroz, J., Rodríguez-Rojo, S., \& Cocero, M. J. Pretreatment processes of biomass for biorefineries: Current status and prospects. Annual Review of Chemical and Biomolecular Engineering, 10, 289-310. (2019).

[18] Cantero, D.A., Vaquerizo, L., Mato, F., Bermejo, M.D., Cocero, M.J. Energetic approach of biomass hydrolysis in supercritical water. Bioresource Technology, 179: 136-143, 2015. 


\section{Objetivos}


En este trabajo se aportan los estudios para desarrollar una biorrefineria con los subproductos de la industria tabacalera, utilizando fluidos supercríticos como $\mathrm{CO}_{2}$ y $\mathrm{H}_{2} \mathrm{O}$ como disolventes y medio de reacción. Se propone valorizar los subproductos, expandiendo la cadena de valor actual y contribuyendo a la sostenibilidad de esta importante industria en la provincias del noroeste argentino.

Para cumplir con esta propuesta se plantean los siguientes objetivos específicos:

1. Tabaco. Consideraciones para su uso como materia prima en una biorrefinería. Analisis de los subproductos de la industrialización primaria del tabaco Virgina como materia prima de una biorrefineria.

a. Caracterización del scrap, subproductos del tabaco Virgina.. Identificación y cuantificación de principios activos de interés.

2. Extracción y separación de la fracción extraíble mediante $\mathrm{CO}_{2}$ supercritico. Se propone el uso del $\mathrm{CO}_{2}$ supercrítico como alternativa a los disolventes organicos, por la ubicación de estas biorrefinerias en el medio urbano donde se encuentra la biomasa.

Se propone desarrollar un modelado fenomenológico del proceso de extracción, que permita determinar los parámetros de las etapas de disolución y transferencia de materia, para realizar el escalado del proceso. Para alcanzar este objetivo se evaluará:

a. Análisis de las variables y de la cinética de extracción con $\mathrm{CO}_{2}$ supercrítico

b. Cuantificación y caracterización del extracto obtenido. Rendimiento de la extracción

c. Separación de los componentes de interés. Evaluación del rendimiento.

3. Valorización de la fracción lignocelulósica de los subproductos mediante la hidrólisis con agua supercrítica (ASC) Se propone una biorrefinería a base de los subproductos de tabaco, en dos etapas: i) obtención de los extraíbles, compuestos con un alto valor añadido mediante $\mathrm{CO}_{2} \mathrm{SC}$, en una primera etapa y ii) fraccionamiento de la fracción lignocelulósica con ASC para obtener azúcares fermentables y lignina. Para conseguir este objetivo, se realizará la:

a. Caracterización de los carbohidratos estructurales

b. Cuantificación de los productos obtenidos de la hidrólisis

c. Evaluación de las variables del proceso de hidrólisis con ASC. 
d. Evaluación del rendimiento de conversión de los carbohidratos estructurales en azucares fermentables.

4. Valorización del solanesol obtenido de la extracción con $\mathrm{CO}_{2}$ supercrítico. Se comprobará la efectividad del solanesol obtenido como precursor en la biosíntesis de CoQ10, realizando:

a. Cultivos de bacterias comunmente conocidas como productoras de CoQ10

b. Evaluación de distintas formas de incorporar solanesol al caldo de cultivo.

c. Cuantificación del aumento de la producción de CoQ10 debido al uso de solanesol como precursor.

5. Propuesta de una biorefineria de subproductos de tabaco Virginia. Diagrama de flujo, balance de masa y energético del escenario propuesto para la biorrefineria.

El desarrollo de estos objetivos en la tesis se ha realizado en cuatro capítulos. En cada uno de ellos se presentan los objetivos específicos, una revisión de los antecedentes de cada tema, los resultados experimentales y discusión para contribuir al desarrollo de la biorrefinería propuesta.

En el Capítulo I: Tabaco. Consideraciones para su uso como materia prima en una biorrefinería, se desarrollan los aspectos positivos y relevantes con los que cuenta esta biomasa, como potencial materia prima para una biorrefineria. Además, se enmarcan estos aspectos en un contexto mas global, como los desafios y objetivos propuestos por la Unión Europea para alcanzar una bioeconomía circular en las próximas décadas. Se presentan los datos de los volúmenes y las características socioeconómicas de la producción tabacalera en el noroeste argentino, como la cantidad de empleo que genera, la cantidad de recursos económicos que genera y la cadena de valor actual y ampliada. Por último, se introduce el tema de la compleja y amplia composicion química de la planta de tabaco, presentando los dos principios activos de interés de esta tesis: solanesol y nicotina, junto con la composicion lignocelulósica. Estos datos, aportan fortalezas al objetivo de este capítulo que es, demostrar que los subproductos de tabaco Virginia, son una excelente potencial materia prima de una biorrefineria.

En el Capítulo II: Separación de los extraíbles de scrap de tabaco Virginia con $\mathbf{C O}_{2}$ supercrítico, se presentan los datos de la cinética de extracción y un modelado fenomenológico de la extracción supercrítica del scrap de tabaco Virginia. Se evalúa y 
verifica, las propiedades del $\mathrm{CO}_{2}$ como solvente selectivo en función de su densidad. Se utiliza una planta piloto de extracción supercrítica, desarrollada en la Universidad de Valladolid. Esta escala permite obtener los parámetros para un posterior escalado del proceso. Se estudia la influencia de la densidad en el rendimiento obtenido de solanesol y nicotina. Se realiiza una simulación del comportamiento del $\mathrm{CO}_{2}$ como solvente y del extracto de tabaco como soluto, a lo largo dl extractor y con el tiempo de extracción. Además, se desarrolla un procedimiento sencillo y efectivo de separación del extracto de tabaco en dos fracciones, una con alto contenido de solanesol y la otra con alto contenido de nicotina. Esta separación permite tener solanesol para usar en otras aplicaciones y una solucion con alto contenido de nicotina que simplifica su posterior purificación.

En el Capítulo III: Hidrólisis de scrap de tabaco Virginia con agua supercrítica, se estudió la composición de los carbohidratos estructurales como celulosa, hemicelulosa y lignina, del scrap y de los palos del tabaco Virginia. Se analizaron los resultados obtenidos de la hidrólisis de esta biomasa con agua supercrítica $\left(400{ }^{\circ} \mathrm{C}, 25\right.$ $\mathrm{MPa}$ ), en un proceso desarrollado por investigadores del mismo grupo que controla la selectividad de la hidrolisis mediante el tiempo de residencia, operando a tiempos inferiores a $1 \mathrm{~s}$, proceso FASTSUGARS. Se analizaron y cuantificaron los productos de la hidrólisis de la celulosa, hemicelulosa y lignina de la biomasa como azúcares C-5 y C-6, aldehídos y ácidos. Además, se realizaron experiencias en un planta escala laboratorio, con un tamaño pequeño de partícula y experiencias en una planta escala piloto con un tamaño de partícula mayor y se compararon los resultados. Este capítulo, complementa el anterior en el escenario propuesto de una biorrefineria de tabaco, donde se propone un proceso en cascada comenzaando con la extracción de principios activos de alto valor seguido del proceso de hidrólisis de la fracción lignocelulósica.

Se propone un diagrama de flujo, con los balances de materia y energia de la biorefineria de scarp de tabaco con $\mathrm{CO}_{2} \mathrm{SC}$ y ASC.

En el Capítulo IV: Estudio preliminar del uso del solanesol extraído de scrap de tabaco como precursor de CoQ10, se buscó valorizar la fracción con alto contenido de solanesol del extracto de tabaco obtenido con $\mathrm{CO}_{2}$ supercrítico. Utilizando el solanesol como precursor de la biosíntesis de un principio activo de alto valor, como la Coenzima Q10. Se desarrollaron formulaciones que permitieron dosificar un producto lipofídico como el solanesol en una solucion acuosa como el caldo de cultivo de Rhizobium radiobacter. Se llevaron a cabo experiencias de cultivo de una cepa de Rhizobium radiobacter, al que se la agregó la formulación de solanesol hidrosoluble y 
se comprobó la eficacia del solanesol como precursor, obteniéndose un considerable aumento de la producción específica de Coenzima Q10.

Por último, en Trabajos a Futuro, se presentan los aspectos que surgieron de los resultados de esta tesis para complementar, enriquecer y aumentar el escenario propuesto para una biorrefineria sostenible de subproductos de la fabricación de tabaco. 
Capítulo I.

Tabaco. Consideraciones para su uso como materia prima en una biorrefinería 


\section{Breve reseña histórica del tabaco}

Los primeros antecedentes del uso de la planta de tabaco se remontan al año 6.000 a.C. con las primeras civilizaciones mesoamericanas. En los hallazgos arqueológicos se identificaron pipas de piedra con restos de tabaco. Se cree que el cultivo de la planta de tabaco por parte de las culturas americanas comenzó cerca del año 1 d.C. para uso ceremonial y medicinal. Hasta la llegada de los españoles, el tabaco era cultivado por los nativos desde América del Norte hasta Perú. Los Mayas y los Arawak (Caribe) enrollaban las hojas de tabaco para fumarlo de una manera similar a los actuales cigarros, los Aztecas rellenaban juncos con tabaco y las culturas del norte usaban pipas [1].

Cuando Cristobal Colón llegó a las costas de las islas Bahamas el 12 de octubre de 1492 fue recibido por los Arawak quienes le entregaron hojas de tabaco como ofrenda. En la primera mitad del siglo XVI fue introducido por los portugueses en África del Sur y Europa, por los españoles en Filipinas, otros países de América del Sur y las Indias, y por los ingleses en Oriente Medio y China [10]. Un hito importante se produjo cuando en el año 1560, el embajador francés en Portugal, Jean Nicot le envió semillas de tabaco a la reina consorte de Francia Catarina de Medici para cultivar las plantas y utilizar las hojas de tabaco para curar sus migrañas[11], tuvo buenos resultados y su uso como medicina se expandió rápidamente en Europa. Debido a esto, la corte francesa propuso llamar Nicotiane a la planta, en honor a Jean Nicot. El nombre botánico actual Nicotiana tabacum fue publicado y descripto en 1753 por Carlos Linneo [12]

En el año 1612 se inicia el primer cultivo comercial de tabaco en Jamestown (la primera ciudad inglesa fundada en América) y dos años después se realizó el primer envío a Inglaterra [11]. Desde el descubrimiento de América, solo pasaron 150 años hasta que el tabaco se empezó a utilizar en todo el mundo

La producción de tabaco se fue expandiendo desde Jamestown a otros estados hasta convertir en la actualidad a los Estados Unidos en el mayor exportador de tabaco y a China en el mayor productor del mundo. Las tendencias del mercado y de la producción fueron creciendo y solo se vieron afectadas considerablemente después de la primera y de la segunda guerra mundial [13]. Estos hechos históricos generaron un aumento considerable del consumo. 


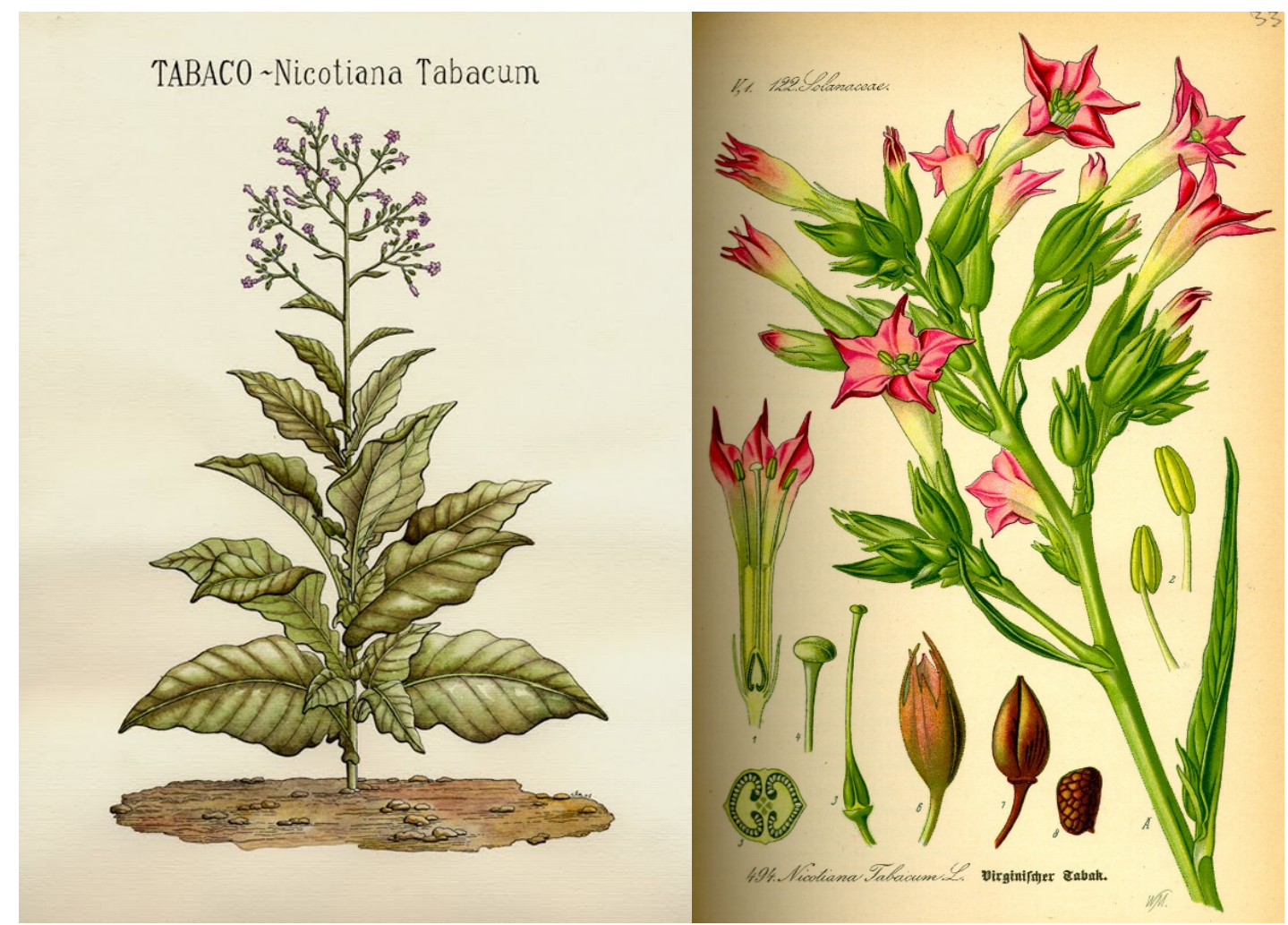

Figura 1. . Planta de tabaco, pintura en acuarela de la artista sevillana Cristina Luengo Acosta (izq.) Ilustración de 1855 de las flores y semillas de la planta de tabaco [14] (der) 


\section{Producción mundial de tabaco}

Según datos de la FAO [7], hasta el año 2018, el volumen total producido alcanzó un volumen de 6,1 millones de toneladas. De los 136 países de los que se tiene registro de la producción de tabaco, el 80\% del volumen se concentra en 10 países: China, Brasil, India, EE. UU, Indonesia, Zimbabwe, Malawi, Argentina, Pakistán y Zambia. En la Figura 2 se presentan los valores de la producción mundial de tabaco desde el año 2008 hasta el año 2018, y la cantidad producida por cada uno de los 10 principales productores del mundo.

La principal diferencia entre China y los siguientes países en orden de volumen de producción es que prácticamente todo el volumen producido en el gigante asiático es para consumo interno y el resto de los países exportan la mayor parte de su producción. Como es el caso de Argentina, quien exporta el 80\% del tabaco.

Un aspecto importante de analizar en cuanto a la producción de tabaco en el mundo es el impacto del Convenio Marco para el Control de Tabaco (CMCT) [8] impulsado por la Organización Mundial de la Salud en el año 2003. Este convenio establece una serie de pautas que los gobiernos que firmen deben cumplir para disminuir la demanda y la oferta de tabaco para fumar. Entre las pautas para disminuir la demanda están el aumento de los impuestos, protección contra la exposición del humo de tabaco, empaquetado y etiquetado de los productos de tabaco, entre otras acciones. Y para disminuir la oferta de tabaco propone erradicar el comercio ilícito, restringir la venta a menores de edad y apoyo a actividades alternativas de producción a los cultivadores. Con respecto a este último punto, China firmo el CMCT en el año 2003 y lo ratifico en el 2005. Sin embargo, no tomó acciones hasta el año 2014 cuando se convirtió en el primer país del mundo en generar una política nacional para la sustitución del cultivo de tabaco por otros cultivos[9]. No se encontró información actualizada pero la disminución del volumen producido por China es constante desde el año 2014 y podría continuar con esa tendencia.

En el caso de Brasil e India, la producción fue aumentando en los últimos años, en ambos países la mayor parte de lo producido se exporta a países asiáticos. En EE. UU., la cantidad de tabaco producido si bien fluctúa se mantiene dentro de un mismo rango desde varias décadas.

Por último, se estima que, si China disminuye su volumen de producción, la diferencia entre la oferta y la demanda en ese país será sustituida por tabaco proveniente de otros países como Brasil y Argentina. 


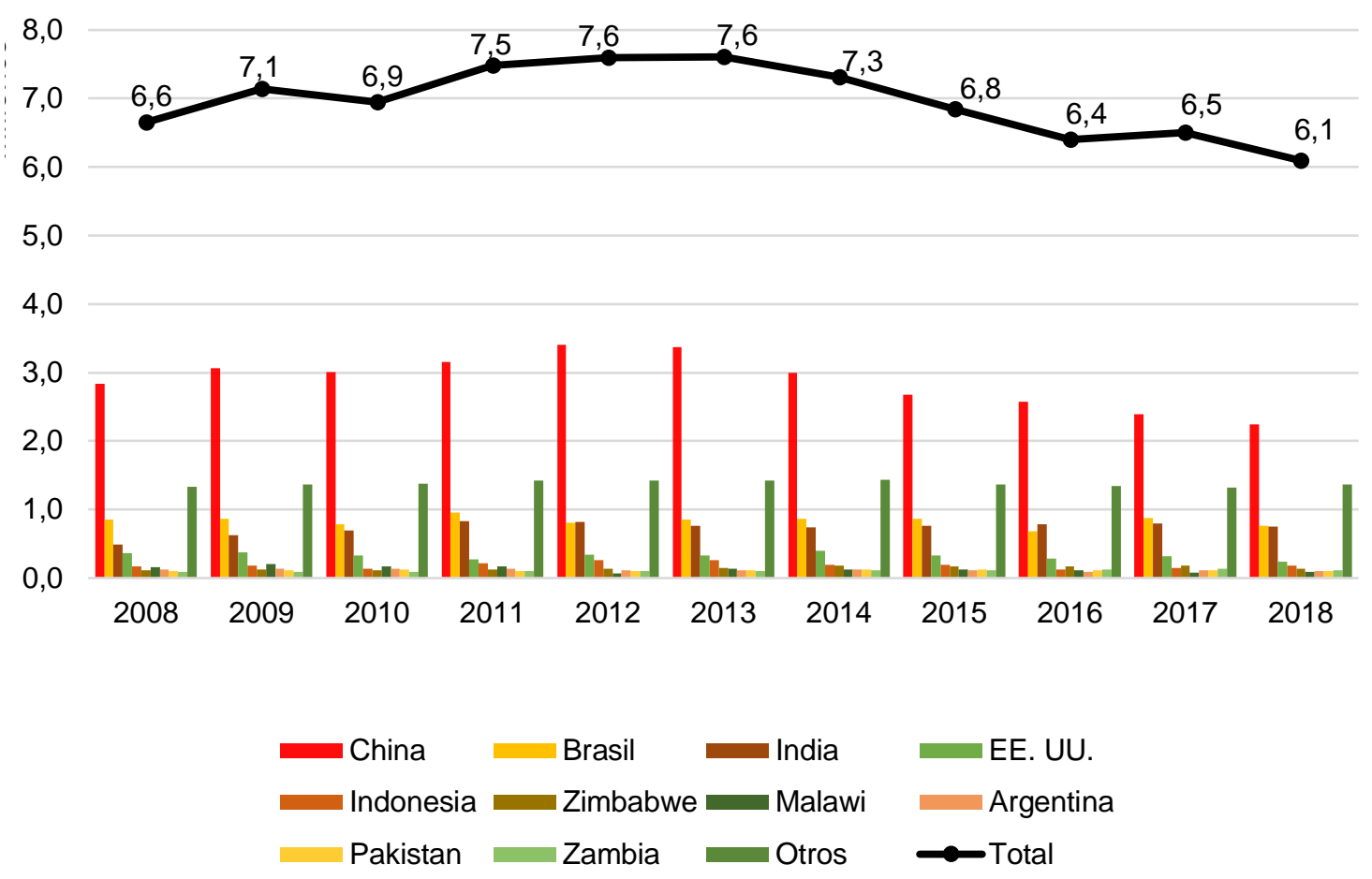

Figura 2. Participación de los principales países productores de tabaco en relación con el volumen total producido en el mundo.

\section{Producción de tabaco en Argentina}

La producción de tabaco en Argentina se concentra en las provincias del norte del país (ver Figura 3), debido a las condiciones climáticas favorables. Las principales variedades cultivadas son tabaco Virginia y tabaco Burley, y en menor medida tabacos criollos. En la Figura 4 se presentan los valores de producción interanual en millones de kilogramos de los últimos diez años en Argentina. Para la campaña 2016/2017 el tabaco Virginia representó un $63 \%$ del total de la producción nacional, este porcentaje equivale un valor aproximado de 73 millones de kilogramos y 273 millones de USD [20].

Las provincias de Jujuy y Salta producen el $99 \%$ del total de tabaco Virginia nacional, y se reparten esta producción en un $55 \%$ para Jujuy y un $44 \%$ para Salta. En Tabla 3 están los valores que corresponden a estos porcentajes. Es importante aclarar que los valores de kilogramos producidos corresponden al producto final de la cadena primaria de producción que es la lámina de tabaco para la producción de cigarrillos. Uno de los aspectos más relevantes de la producción de tabaco en la región del noroeste es el alto grado de conocimiento en el manejo del cultivo, en la campaña 2016/2017 el rendimiento de hojas de tabaco Virginia fue de 2,3 t/ha en Salta y 2,8 t/ha en Jujuy [11]. Además, la concentración de los cultivos en la región tiene la ventaja de que los costos 
de transporte y logística son bajos para los productores en comparación con otras producciones agrícolas como los de la soja, que para ser rentables deben tener volúmenes muy grandes para poder compensar los costos de transporte hacia los puertos. La producción primaria, con menor margen de ganancia, tiene bajos costos de transporte. La industrialización primaria (acopio), le agrega valor, suma volumen entre todos los productores y disminuye los costos unitarios de transporte.
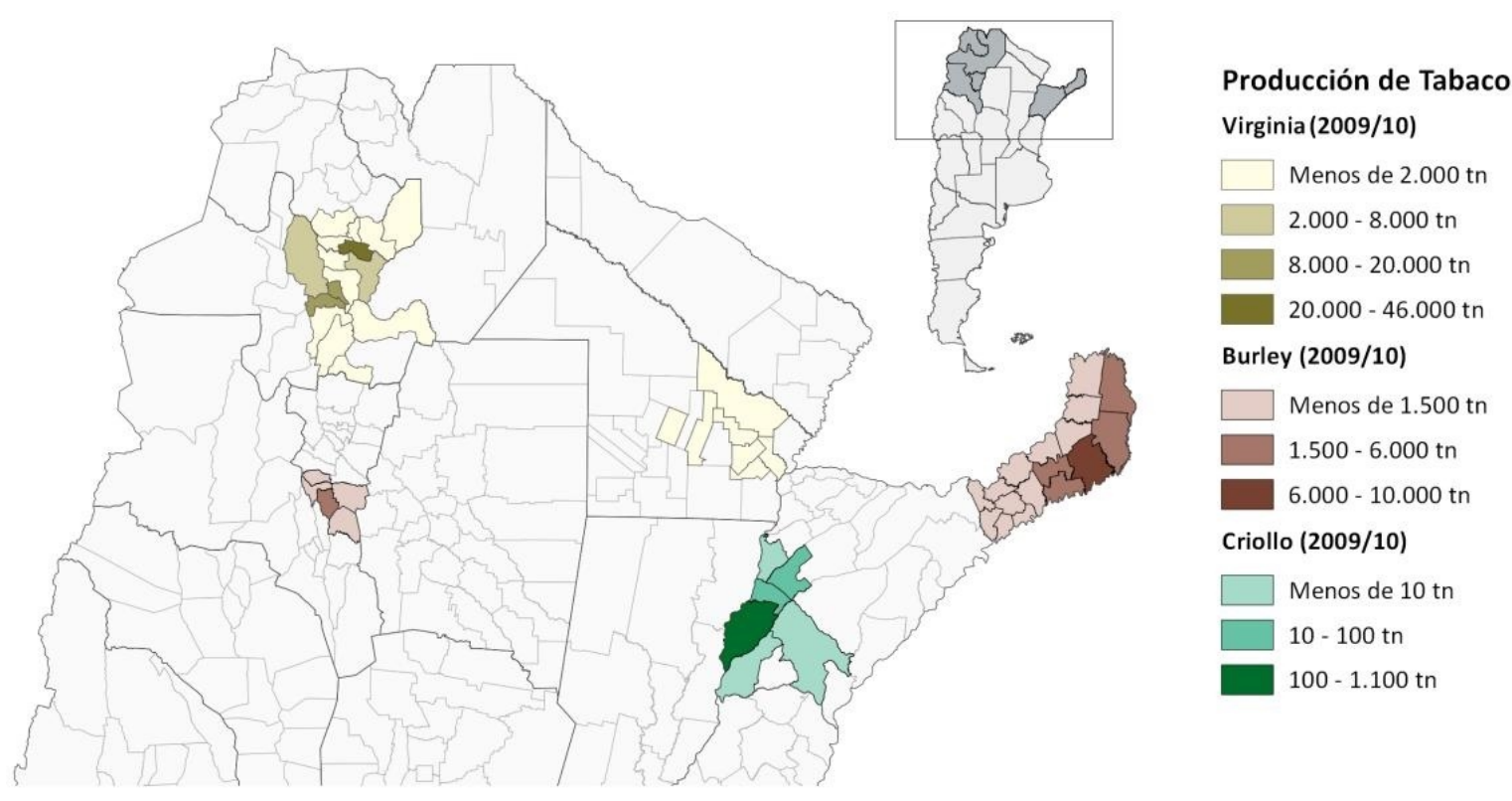

Figura 3. Mapa de localización de la producción tabacalera en Argentina[12]

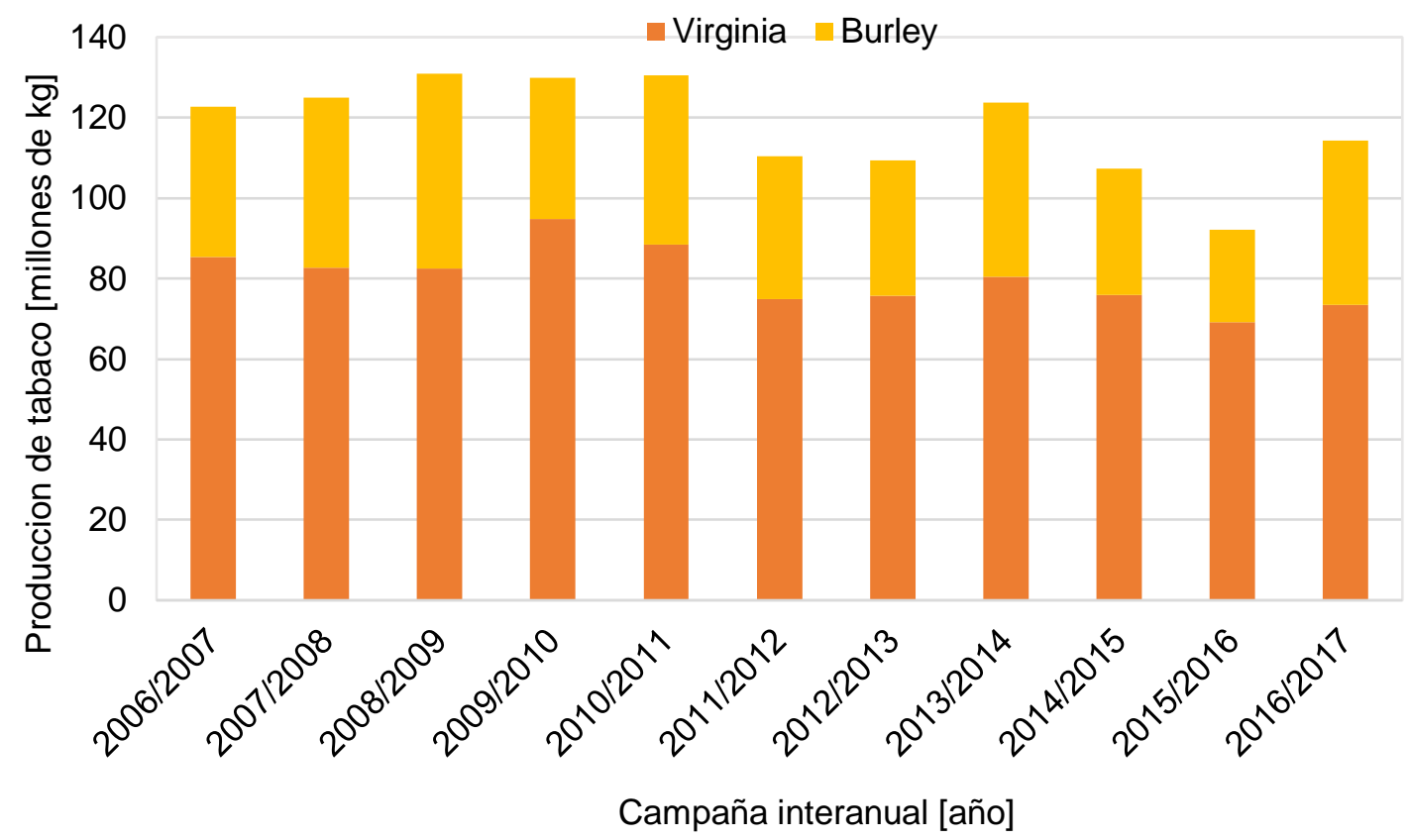

Figura 4. Producción de tabaco en miles de toneladas en Argentina por tipo de tabaco y por campaña interanual. 


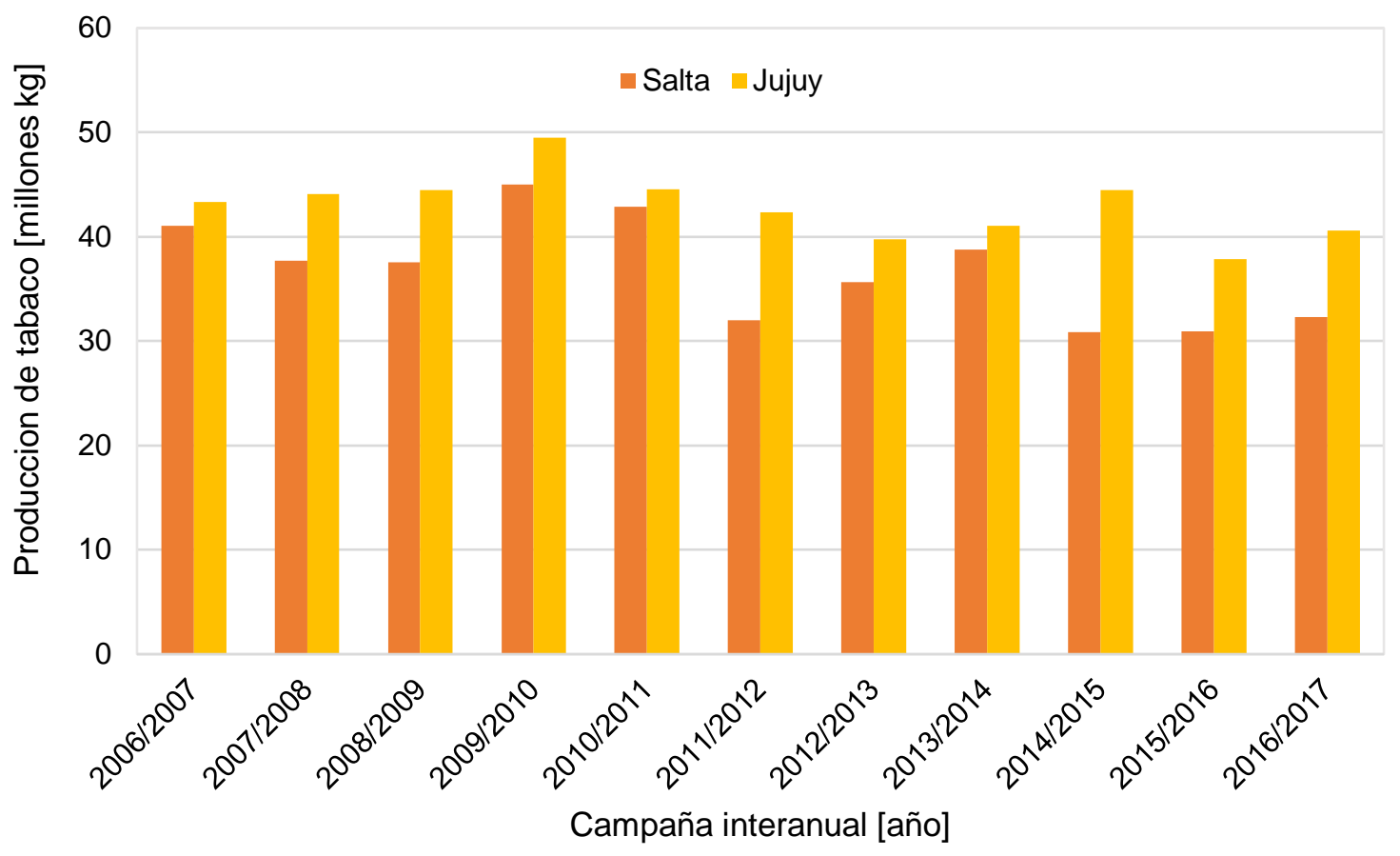

Figura 5. Producción de tabaco Virginia en las provincias de Salta y Jujuy

Tabla 3. Kilogramos de tabaco producido en las provincias de Salta y Jujuy.

\begin{tabular}{cccccc}
\hline \multirow{2}{*}{ Campaña } & \multicolumn{3}{c}{ Tipo de tabaco } & \multicolumn{3}{c}{ Tabaco Virginia por provincia } \\
\cline { 2 - 6 } & Virginia & Burley & Criollo & Salta & Jujuy \\
\hline $2006 / 2007$ & 85.299 .773 & 37.458 .035 & 4.981 .699 & 41.076 .267 & 43.313 .839 \\
$2007 / 2008$ & 82.654 .006 & 42.377 .611 & 5.349 .516 & 37.707 .438 & 44.059 .350 \\
$2008 / 2009$ & 94.913 .748 & 48.501 .101 & 3.807 .849 & 37.531 .002 & 44.438 .596 \\
$2009 / 2010$ & 94.913 .748 & 35.004 .318 & 2.951 .922 & 44.982 .556 & 49.461 .487 \\
$2010 / 2011$ & 88.360 .739 & 42.230 .451 & 4.616 .305 & 42.880 .645 & 44.566 .124 \\
$2011 / 2012$ & 74.908 .685 & 35.500 .729 & 3.674 .102 & 32.038 .762 & 42.320 .963 \\
$2012 / 2013$ & 75.742 .911 & 33.606 .560 & 2.998 .237 & 35.654 .017 & 39.779 .575 \\
$2013 / 2014$ & 80.406 .361 & 43.272 .511 & 3.406 .542 & 38.786 .475 & 41.074 .979 \\
$2014 / 2015$ & 75.832 .388 & 31.607 .360 & 1.666 .239 & 30.883 .226 & 44.503 .582 \\
$2015 / 2016$ & 69.208 .441 & 23.008 .911 & 1.453 .515 & 30.955 .772 & 37.845 .331 \\
$2016 / 2017$ & 73.386 .763 & 40.848 .860 & 2.918 .802 & 32.330 .198 & 40.586 .210 \\
\hline
\end{tabular}

\section{Cadena de Valor del tabaco actual y cadena de valor ampliada}

La cadena de valor del tabaco en Argentina fue relevada en el año 2016 por el Ministerio de Hacienda de la Nación [20]. En ese trabajo, se destaca que la etapa primaria de producción (producción agrícola) hay un número significativo de 18.526 
productores, en su mayoría, minifundistas. En Jujuy, Salta y Tucumán, la cantidad de productores registrados es 902, 1.599 y 1.255 respectivamente. Lo que representa el $20 \%$ de los productores que generan el $80 \%$ del volumen. El empleo directo de esta actividad se calculó en 50.000 personas[13]. Este número corresponde al 1,9\% del total de empleo y al 2,2 \% del total de empleo privado en las provincias productoras de tabaco.

En la Figura 6 se presenta la cadena actual del tabaco en Argentina y la cadena de valor ampliada según el enfoque de este trabajo. En el esquema actual, los productores tabacaleros solo pueden vender su producción a la industria de fabricación de cigarrillos y no se comercializa el tallo que queda en las fincas. En la cadena de valor ampliada, los productores pueden vender el tabaco y los tallos a una biorrefinería. Este aspecto tiene una vital relevancia, ya que es una alternativa viable ante la propuesta de erradicar el cultivo de tabaco mediante cultivos alternativos del Convenio Marco para el control del Tabaco de la OMS. Permitiendo a los productores seguir haciendo lo que saben y hacer y sin cambiar su infraestructura. Esta ampliación de los mercados a los que pueden acceder los productores tabacaleros no presenta ninguna amenaza a las acopiadoras ya en el sistema actual las tabacaleras adjudican cupos de producción a cada productor asegurando las ventas a futuro y el $50 \%$ del volumen producido en el total de las acopiadoras pertenece a 2 cooperativas de productores.

Existen varios potenciales impactos sobre las acopiadoras. Uno es el aumento de la cartera de clientes y otro es que, al darle valor a los subproductos o residuos como los palos, fibra y scrap se soluciona el problema de la disposición final y esto generaría un incremento de las ganancias. 


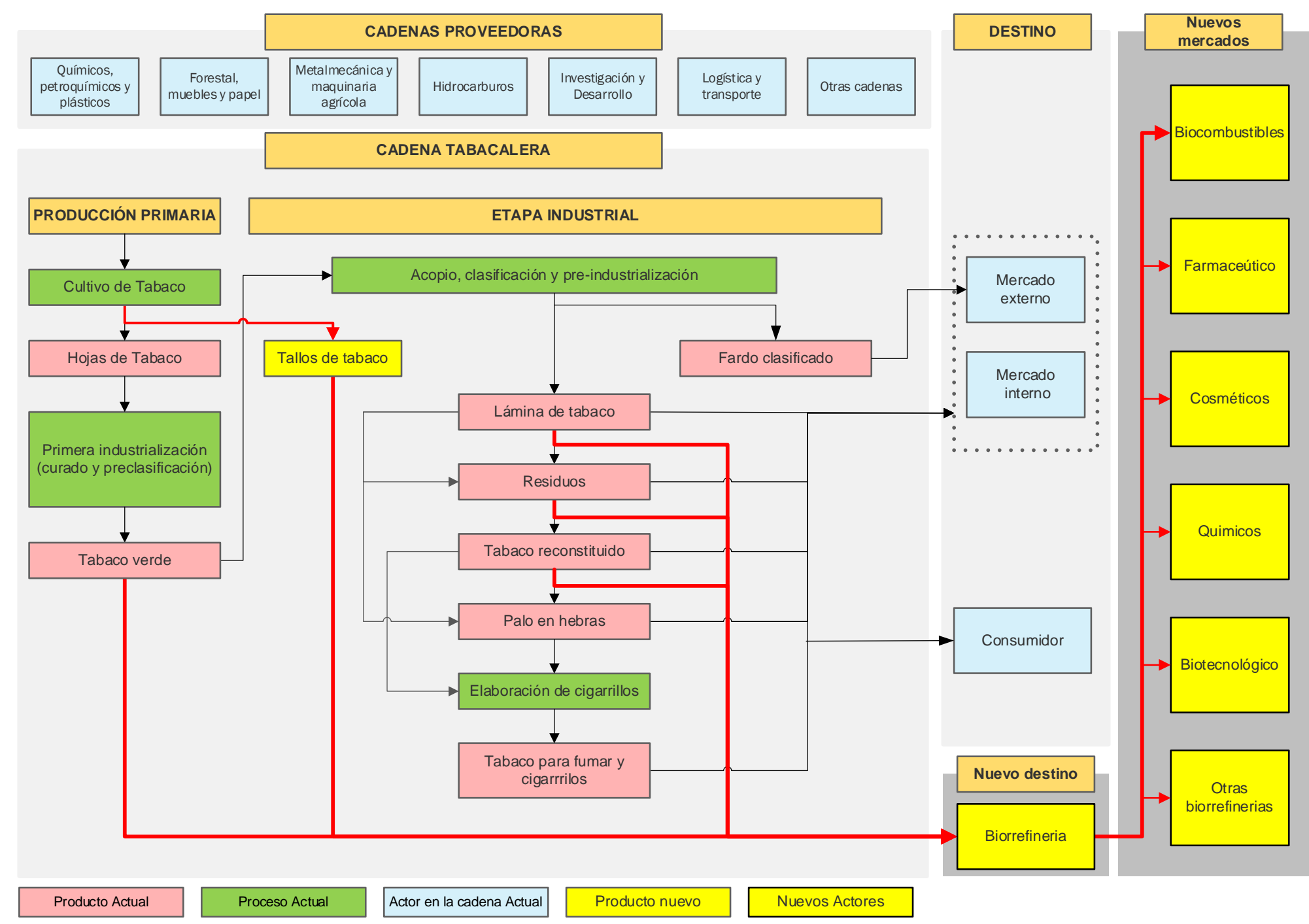

Figura 6. Cadena de valor del tabaco actual. Adaptado de [12] y ampliada (este trabajo) 


\section{Tabaco como materia prima de una biorrefinería}

Existen numerosos antecedentes en las publicaciones científicas sobre la utilización del tabaco como materia prima de plataformas o procesos de una biorrefinería. En general, la mayoría de estas publicaciones utiliza un proceso específico para la obtención de un solo producto. Son pocos los trabajos en los que el enfoque se direcciona a una utilización total de la biomasa. Algunas de las fortalezas identificadas para el uso del tabaco producido en las provincias del norte Argentino son: la composición química, alto rendimiento de biomasa en $\mathrm{kg} / \mathrm{ha}$, alto nivel de conocimiento en el cultivo agrícola, abundantes antecedentes de investigaciones en usos alternativos al actual, la economía de escala en la producción industrial y el acceso a subproductos $y$ residuos en volumen, y centralizado en centros de acopio, lo que favorece la homogeneidad y accesibilidad del producto.

1. Composición química: la cantidad de principios activos identificados en la planta de tabaco fue creciendo a lo largo de los años. Desde 1946, donde se identificaron menos de 10 tipos de componentes, como alcaloides, proteínas, nitratos, etc., hasta la actualidad donde hay identificados aproximadamente 5595 componentes [14]. En la Tabla 4 se presenta la composición química del tabaco en concentraciones promedio, clasificadas por tipos de componentes. Aproximadamente la mitad de los componentes de la planta son carbohidratos estructurales y el resto son compuestos extraíbles con alguna bioactividad.

2. Alto rendimiento de biomasa en $\mathrm{kg} / \mathrm{ha}$ : Estudios de rendimiento del cultivo de tabaco en Salta mencionan que el rendimiento de hoja seca de tabaco varía entre 2,4 y 4 t/ha [15], dependiendo del método de cultivo. Este valor no contempla la biomasa generada por los tallos que quedan en el terreno luego de la cosecha de las hojas. La cantidad de biomasa que queda en las fincas con los tallos alcanza las 3 t/ha [16].Como el tabaco no es un alimento, solo se podría comparar con otros cultivos industriales como materia prima para una biorrefinería como las plantaciones forestales, biomasas lignocelulósicas, plantas no comestibles, otros residuos agroindustriales o agroforestales. Bajo estas circunstancias, no existe en esta zona de Argentina otro cultivo con el mismo volumen de producción.

3. Alto nivel de conocimiento en el cultivo agrícola: El inicio del cultivo de tabaco en Argentina se remonta al año 1873 [17]. El conocimiento tecnológico del manejo 
del cultivo es avanzado, existe mano de obra especializada y recursos para mantener altos rendimientos y calidad en el producto obtenido en las fincas.

4. Abundantes antecedentes de investigaciones en usos alternativos al actual. En la Tabla 6 se presentan algunos antecedentes donde usan tabaco como materia prima para obtener distintos productos con alguna bioactividad o utilidad comercial. Estos productos se obtienen mediante procesos que pueden enmarcarse en el ámbito de una biorrefinería. Los aceites esenciales que se obtienen por arrastre de vapor tienen una composición diferente a los obtenidos con solventes orgánicos. Dependiendo del tipo de producto que se quiera obtener, se puede realizar la extracción con un solo método como extracción con solventes o arrastre por vapor, o se puede utilizar un método a continuación de otro [18]. El etanol se puede obtener de la fermentación del tallo que queda en las fincas [1921], de las hojas de FCV o de los residuos de las acopiadoras de tabaco. La conversión de los carbohidratos estructurales en azúcares fermentables se realiza mediante hidrólisis enzimática o con agua en estado subcrítico [22] o supercrítico (este trabajo). Los principios activos con más antecedentes son la nicotina y el solanesol, ambos con múltiples usos y aplicaciones en la industria que se detallarán más adelante. Por último, hay una serie de principios activos como escualeno, ácido clorogénico, rutina y vitamina $E$ que tienen una bioactividad amplia y conocida. Aunque la cantidad de estos principios activos puede ser relativamente baja, una biorrefinería de una escala lo suficientemente grande podría obtener una cantidad aprovechable de cada uno de estos principios activos.

5. Economía de escala en la producción agroindustrial. Entre las provincias de Salta y Jujuy se producen en promedio unos 70 millones de kilogramos de láminas de FCV, producir esta cantidad de tabaco para cigarrillos genera 37 millones de kilogramos de subproductos o residuos. Una economía de escala, básicamente, tiene menores costos unitarios de producción, por lo tanto, el valor económico de los residuos o subproductos son también bajos. Si bien la provincia de Jujuy produce el $56 \%$ del volumen total, la distancia entre los dos centros de acopio más importantes (Cooperativa de Productores Tabacaleros de Jujuy y Cooperativa de Productores Tabacaleros de Salta) es de solo $110 \mathrm{~km}$. Estas consideraciones resultan en un fácil acceso a la materia prima para una biorrefinería en un volumen importante y centralizado en estos centros de acopio. Además, como estos subproductos se obtienen de un proceso de clasificación de las láminas, van 
saliendo de la línea de producción separados por tamaño y tipo, obteniéndose scrap, fibras y palos homogéneos.

6. Favorece la seguridad alimentaria. En el año 2012 la FAO publicó un documento donde analiza el impacto negativo que puede tener la creciente demanda de bioenergía sobre la seguridad alimentaria [23]. Básicamente se busca que no se reemplacen cultivos de alimentos por cultivos para biomasa utilizable en bioenergía. Considerando que el cultivo del tabaco lleva casi 150 años en esta zona del norte de Argentina y que los productores tabacaleros no suelen diversificar sus plantaciones, se podría decir que un proyecto de biorrefinería, utilizando tabaco como materia prima no afectaría la seguridad alimentaria.

\subsection{Scrap y palos: subproductos de la industrialización primaria de tabaco Virginia}

Luego de la cosecha del tabaco Virginia, se realiza un proceso de curado que provoca una seria de cambios físicos y químicos para obtener tabaco para fumar. Este proceso se lleva a cabo durante 7 días aproximadamente en estufas llamadas BulkCuring. El tabaco ya curado se denomina Flue-Cured Virginia (FCV) y sale de las fincas preclasificado en fardos de $50 \mathrm{~kg}$ aproximadamente.

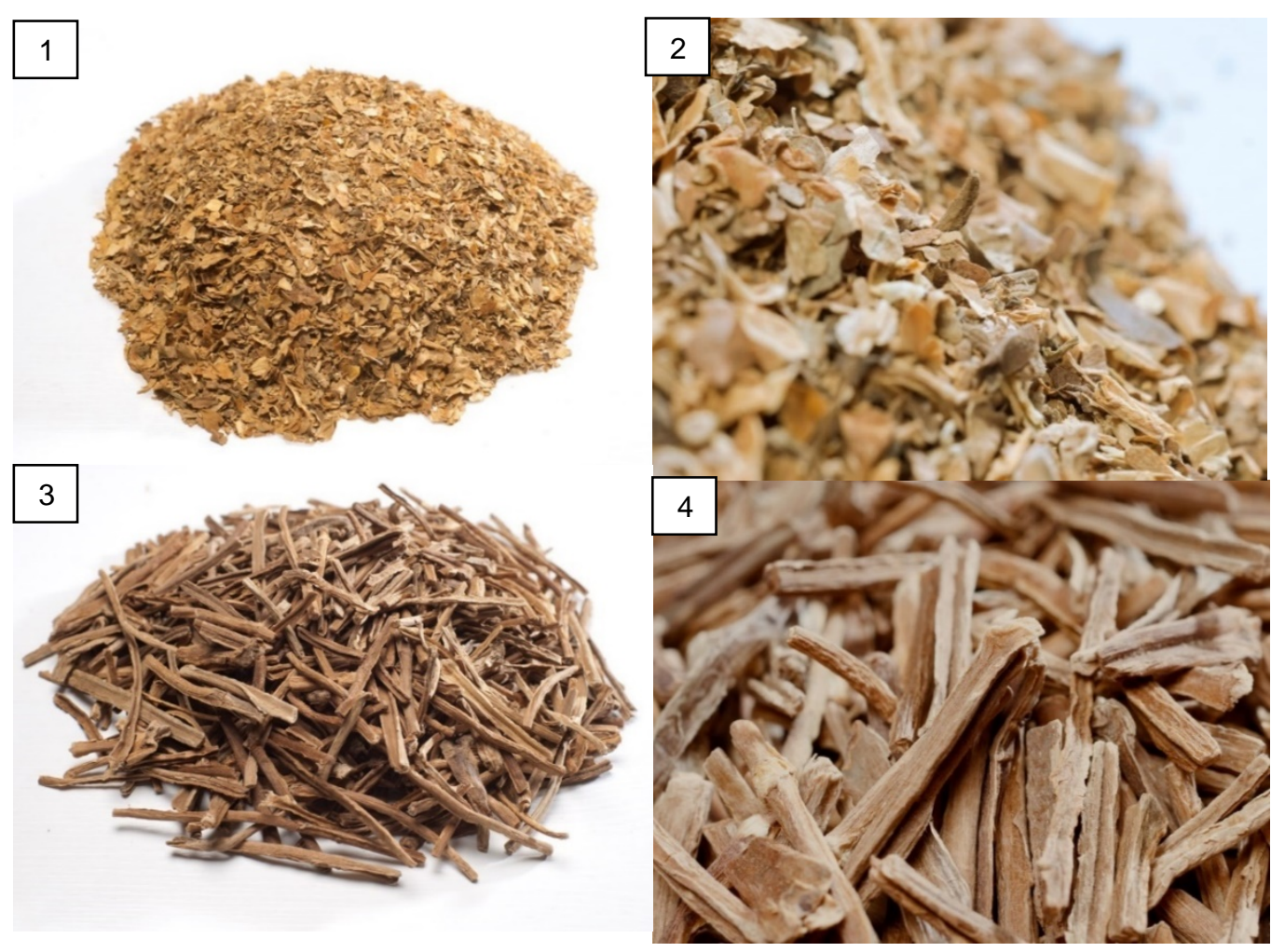

Figura 8. Scrap (1 y 2) y Fibras (3 y 4) de Flue-Cured Virginia. Imágenes tomadas de www.worldtobacco.it 
Tabla 4. Composición química de la planta de tabaco, en concentraciones promedio [14].

\begin{tabular}{|c|c|c|c|}
\hline \multicolumn{2}{|c|}{ Clasificación del Componente } & & Conc. Promedio (\%) \\
\hline \multirow{5}{*}{ 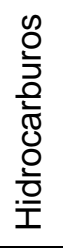 } & Alcanos & & 0,32 \\
\hline & Alquenos y alquinos & & 0,09 \\
\hline & Acíclicos & & 0,22 \\
\hline & Monocíclicos aromáticos & & 0,08 \\
\hline & Policíclicos aromáticos & & 0,0001 \\
\hline \multirow{22}{*}{$\begin{array}{l}\text { o } \\
\frac{0}{\sigma} \\
\frac{\pi}{\bar{d}} \\
\text { d. } \\
\bar{x}\end{array}$} & & Subtotal & 0,71 \\
\hline & Alcoholes & & 1,7 \\
\hline & Fitoesteroles y derivados & & 0,2 \\
\hline & Aldehídos & & 1,4 \\
\hline & Cetonas & & 1,8 \\
\hline & Ácidos carboxílicos & & 9,8 \\
\hline & Lípidos (ceras) y resinas & & 9,0 \\
\hline & Aminoácidos & & 2,0 \\
\hline & Esteres & & 0,9 \\
\hline & Lactonas & & 0,001 \\
\hline & Anhidridos & & 0,0001 \\
\hline & Carbohidratos & & 40,2 \\
\hline & Celulosa: 13,3 \% & & \\
\hline & Pectinas: 11,4 \% & & \\
\hline & Azúcares: $14,1 \%$ & & \\
\hline & Almidón: 1,4% & & \\
\hline & Fenoles & & 8,3 \\
\hline & Lignina: 2,25 \% & & \\
\hline & Otros fenólicos: $6,05 \%$ & & \\
\hline & Quinonas & & 0,001 \\
\hline & Esteres & & 0,4 \\
\hline & & Subtotal & 75,7 \\
\hline \multirow{8}{*}{ 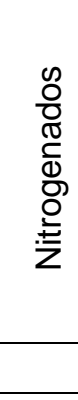 } & Nitrilos & & 0,0001 \\
\hline & Proteínas, enzimas y aminas & & 6,4 \\
\hline & Amidas & & 0,06 \\
\hline & Imidas & & 0,02 \\
\hline & N-Nitrosaminas & & 0,002 \\
\hline & Otros nitrogenados & & 4,5 \\
\hline & Alcaloides & & 2,0 \\
\hline & & Subtotal & 12,98 \\
\hline \multirow{5}{*}{ 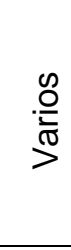 } & Sulfurosos & & 0,7 \\
\hline & Halogenados, y gases fijos & & 1,5 \\
\hline & Metales, no metales y iones & & 7,2 \\
\hline & Residuos de pesticidas & & 0,000001 \\
\hline & Todos los otros componentes & & 1,2 \\
\hline & & Subtotal & 10,61 \\
\hline & & TOTAL & 100,00 \\
\hline
\end{tabular}


Los productores entregan los fardos de FCV en las acopiadores donde comienza la industrialización primaria para separar las láminas de las venas y tallos de las hojas. Este proceso se denomina despalillado. Antes de ingresar a este proceso, se acondiciona el tabaco aumentando su humedad hasta el $20 \%$ y su temperatura a $50{ }^{\circ} \mathrm{C}$ para que las venas se doblen sin quebrarse y se separen de la lámina. El despalillado se lleva a cabo en equipos con cilindros y peines que van separando la lámina de las venas llamados trilladores. Esto se realiza en varias etapas donde la distancia entre peines va disminuyendo a medida que avanza el material. Luego del despalillado se realiza la separación de las láminas del material producido por los trilladores (palos, scrap y polvos) mediante un lecho fluidizado con aire. En esta etapa se obtienen las fracciones de palos y scrap separadas y clasificadas por tamaño [24].

Por cada kilo de tabaco que sale de las fincas de los productores se obtienen aproximadamente 650 gramos de lámina y 350 gramos de subproductos o residuos como scrap, fibra y palos. Tomando los datos del punto 4, para la campaña 2016/2017, se obtuvieron aproximadamente 17 millones de kilogramos de residuos o subproductos de tabaco, solo en la provincia de Salta.

La composición química del scrap y de los palos es ligeramente diferente, el scrap tiene más celulosa que los palos y los palos tienen más lignina que el scrap. En la Tabla 5 se presentan la caracterización realizada con el scrap y los palos del tabaco para este trabajo producido en la provincia de Salta. La separación del scrap y del palo es una ventaja para utilizar un proceso en una biorrefinería según lo que se busque obtener. Por ejemplo, si se quiere obtener azúcares fermentables es conveniente usar scrap y si se busca obtener algún componente de los extraíbles como xilo-oligosacáridos convendría utilizar los palos.

Tabla 5. Composición química del scrap y palos de Flue-Cured Virginia (\%)

\begin{tabular}{ccccccccc}
\hline Materia prima & Extraíbles & Humedad & Proteínas & Celulosa & Hemicelulosa & Lignina & Cenizas & Total \\
\hline Scrap & 57,31 & 10,47 & 11,23 & 9,79 & 2,47 & 6,00 & 2,58 & 99,86 \\
Palos & 59,08 & 8,59 & 9,04 & 5,17 & 3,96 & 10,15 & 3,62 & 99,62 \\
\hline
\end{tabular}


Tabla 6. Algunos antecedentes de productos que se pueden obtener usando tabaco como materia prima en una biorrefinería

\begin{tabular}{|c|c|c|c|}
\hline Producto & Materia Prima & Procesos & Ref \\
\hline Aceites esenciales & Scrap & Extracción con solventes orgánicos y arrastre por vapor & [25] \\
\hline Aceites esenciales & Hojas de FCV & Extracción con membrana de polietileno de baja densidad & [26] \\
\hline Azucares fermentables & Hojas de FCV & Hidrólisis con agua subcrítica & [27] \\
\hline Azucares fermentables & Hojas de FCV & Hidrolisis enzimática & [28] \\
\hline Azucares fermentables y Fenoles & $\begin{array}{l}\text { Hojas y residuos de } \\
\text { FCV }\end{array}$ & Hidrólisis con agua subcrítica & [29] \\
\hline Biocombustibles: biogás, biodiesel y etanol & Hojas & Varios & [30] \\
\hline Biocombustibles y Escualeno & Hojas & Estudio de factibilidad económica & [31] \\
\hline Biogás & Scrap, palos y polvo & Digestión anaeróbica & [32] \\
\hline Briquetas & Palos y venas & Molido y chipeado & [33] \\
\hline Escualeno & Hojas & Ingenieria genética. Aumento del contenido de escualeno & [34] \\
\hline Etanol & Hojas y Tallo & Modificación genética, Hidrólisis enzimática y Fermentación & [35] \\
\hline Etanol & Tallo & Hidrólisis enzimática y Fermentación & [36] \\
\hline Etanol & Tallo & Hidrólisis enzimática y Fermentación & [37] \\
\hline Etanol & Tallo & Oxidación húmeda, hidrolisis enzimática y Fermentación & [38] \\
\hline Flavonoides: Rutina, quercetina y apigenina & $\begin{array}{l}\text { Hojas y residuos de } \\
\text { FCV }\end{array}$ & Extracción con solventes orgánicos & [39] \\
\hline Nicotina & Hojas & Extracción sólido-líquido con solventes orgánicos & [40] \\
\hline Nicotina & Hojas & $\begin{array}{l}\text { Arrastre por vapor, extracción con solventes, asistida con ultrasonidos y } \\
\text { microondas }\end{array}$ & [41] \\
\hline Nicotina & Hojas de FCV & Extracción con $\mathrm{CO}_{2} \mathrm{SC}$ & [42] \\
\hline Nicotina & Hojas de tabaco & Extracción con $\mathrm{CO}_{2} \mathrm{SC}$ & [43] \\
\hline Nicotina & Residuos de tabaco & Extracción con $\mathrm{CO}_{2} \mathrm{SC}$ & [44] \\
\hline Nicotina, Solanesol y proteínas & Hojas verdes & Maceración y extracción con solventes & [45] \\
\hline
\end{tabular}


Pectina

Acido clorogénico y Rutina

Acido clorogénico, Rutina, Acido cafeico, escopoletina, y escopolina

Polisacáridos

Precursor de Coq10

Precursor de Coq10

Proteínas

Proteínas

Proteínas

Pulpa de celulosa

Pulpa para papel

Pulpa para papel

Solanesol

Solanesol

Solanesol

Solanesol

Solanesol

Solanesol

Solanesol

Solanesol

Solanesol

Solanesol y nicotina

Vitamina E

Xilo-oligosacáridos
Hojas - venas

Hojas de FCV

Hojas de FCV

Residuos de tabaco

Residuos de tabaco

Residuos de tabaco

FCV

FCV

FCV

Tallos de FCV

Residuos de tabaco

Residuos de tabaco

Hojas de FCV

Hojas de FCV

Residuos de tabaco

Hojas de FVC

Hojas de FVC

Hojas de FCV

Hojas de FCV

Hojas de FCV

Hojas de FCV

Residuos de tabaco

Hojas de FCV

Tallos
Extracción sólido-líquido

[46]

Extracción con etanol

Extracción en fase solida

Extracción con etanol

Biomasa hidrolizada

Síntesis química para obtener CoQ10 desde Solanesol

$[49$

$[50]$

[51]

Extracción con agua y metanol en 2 etapas

$[52]$

Extracción acuosa en varias etapas

Extracción con Solventes orgánicos y extracción acuosa

Hidrólisis ácida

Extracción con agua caliente

Explosión con vapor

Extracción con $\mathrm{CO}_{2} \mathrm{SC}$

Extracción con Solventes orgánicos

Extracción con solventes orgánicos y purificación

Extracción con Solventes orgánicos

Extracción con solventes orgánicos: percolación, soxhlet y columna burbujeante

Extracción con Solventes orgánicos, asistido con microondas

Extracción con Solventes orgánicos

Extracción con solventes, asistida con ultrasonidos y microondas

Extracción en fase solida

Extracción en columna cromatográfica

Extracción con solventes orgánicos

Hidrólisis ácida y enzimática
[54]

[55]

[56] 


\subsection{Solanesol}

El solanesol en un alcohol terpenoide de cadena abierta, compuesto de nueve unidades isoprenoides. Su fórmula molecular simplificada es $\mathrm{C}_{45} \mathrm{H}_{74} \mathrm{O}$, y su peso molecular es $631,086 \mathrm{gr} / \mathrm{mol}$. En su forma normal es un sólido blanquecino que al disolverse se torna un poco amarillento. Es ligeramente soluble en hexano y muy soluble en etanol a temperatura ambiente [70].

Este compuesto fue aislado e identificado desde el tabaco por Rowland [59] en 1956. Al hacer una extracción de FCV con metanol y éter, y posteriormente una separación por cromatografía líquida obtuvo varias fracciones distintas. Llamando solanesol a la fracción más abundante de los componentes extraíbles con solventes orgánicos.

Si bien el solanesol está presente en otras plantas de la familia de las solanáceas como las hojas de papa $(0,04-0,4 \%)$, de berenjena $(0,2-0,4 \%)$, de pimiento $(0,9-0,35 \%)$ y del tomate (0,1-0,35\%); la concentración es mayor en la planta de tabaco y en mayor proporción en las hojas de la misma alcanzando valores de hasta el $4 \%$ del peso de la hoja de FCV en base seca $[71,72]$.

Por otra parte, el contenido de solanesol varía por múltiples factores. El primero es el genético, las plantas de tabaco burley y tabaco negro contienen un mayor contenido de solanesol que las hojas de FCV. Otro factor importante son los laborales culturales durante el cultivo, Burton [73] estudió la influencia de la posición de las hojas (superiores, medianas y bajeras), la diferencia de una temporada a la siguiente, el estrés hídrico, la senescencia foliar ${ }^{1}$, el proceso de curado, el desflorado y la influencia del nitrógeno en la fertilización. Burton concluye que, seleccionando el genotipo adecuado, sometiendo a un estrés hídrico el cultivo y cosechando luego del topping ${ }^{2}$ se puede incrementar el contenido de solanesol considerablemente.

Como se mencionó anteriormente, el solanesol es un alcohol y cuando un alcohol reacciona con un ácido graso ocurre una reacción de esterificación, obteniendo como resultado un éster más una molécula de agua. La nomenclatura para los esteres tiene dos partes, la primera proviene del ácido que lo forma y la segunda del alcohol que

\footnotetext{
${ }^{1}$ La senescencia es un proceso de las plantas en el cual se preparan para un periodo de reposo.

2 Topping: es el proceso de cortar la inflorescencia de la planta de tabaco antes que se desarrolle, para favorecer el tamaño, grosor y contenido de nicotina de la hoja de tabaco
} 
proviene, Por ejemplo, el Ester que se forma del solanesol y el ácido acético se denomina acetato de solanesilo.

El solanesol se encuentra en el tabaco en forma libre y esterificado como esteres de solanesilo. En el tabaco burley, el porcentaje de solanesol libre se incrementa luego del curado [74], esto representaría una ventaja de usar el tabaco curado en vez de usar el tabaco verde para la extracción de solanesol. Si bien en algunas publicaciones se menciona que el solanesol esterificado alcanza valores de hasta el $68 \%$ y en otras que prácticamente el total de solanesol se encuentra libre [73], no representaría ninguna dificultad realizar una saponificación para transformar los esteres de solanesilo en solanesol. Ishida [76] identificó y cuantificó 11 ésteres de solanesilo en 4 variedades de tabaco (virginia, burley, oriental y tabaco oscuro) de 5 países de origen distintos (EE.UU., Brasil, Grecia, Turquía y Filipinas), los valores de solanesol libre obtenidos van desde el 1,86 \% (tabaco Virginia de EE.UU.) hasta el 7,71\% (tabaco oscuro de Filipinas) y los valores de los esteres de solanesilo van desde 11,99\% al 65,95 \% para el tabaco burley de Brasil y el tabaco oscuro de Filipinas. En la tabla 8 se presentan los valores obtenidos por Ishida.

\subsubsection{Bioactividad del solanesol}

La bioactividad del solanesol y de sus ésteres incluye propiedades antibacteriales, antivirales, antifúngicas, anticancerígenas, antinflamatorias y antiulcerosas entre otras [77]. Qin [78] formuló micelas con solanesol para que actúe como fotoprotector de la molécula de coenzima Q10 obteniendo un 88\% de CoQ10 sin degradar luego de 25 horas de exposición a la luz solar. Bai [79] estudió que el solanesol podría eliminar los radicales libres generados por la luz solar e inhibir los efectos sobre la tirosinasa. Huang [80] evalúo la capacidad anti radical libre de un extracto de tabaco obtenido con $\mathrm{CO}_{2}$ supercrítico versus un extracto obtenido por calentamiento a reflujo, concluyendo que la actividad anti radicales libres es mayor cuanto mayor sea la concentración de solanesol (alrededor del 3\%).

En el campo de la medicina, Yao [80] comprobó los efectos hepatoprotectores y estimulantes del crecimiento de las células del hígado del solanesol. La actividad antibacterial contra microorganismos patógenos gram-negativos y gram-positivos [81]; el efecto antiinflamatorio de un gel con solanesol in vivo versus un gel con diclofenaco [82] y la formulación con solanesol de un portador de fármacos contra el cáncer que evita los efectos secundarios de otros portadores y genera un efecto sinérgico [83] son algunas de las tantas bioactividades prometedoras de este compuesto. 


\subsubsection{Usos del solanesol}

El uso más difundido del solanesol es como precursor en la síntesis química de Coenzima Q10 y los análogos de las vitaminas $\mathrm{K}[71,84,85]$ y en la biosíntesis de Coenzima Q10 agregando solanesol en el caldo de cultivo de distintos microrganismos como Rhodobacter sphaeroides [86], Rhodospirillum rubrum [87] y Sphingomonas sp. [88]. Taylor menciona que la creciente demanda de CoQ10 debido a los beneficios que presenta como suplemento vitamínico y prevención de enfermedades, aumentará la demanda de solanesol [89]. 
Tabla 7. Esteres de solanesol [76]

\begin{tabular}{cl}
\hline Formula molecular reducida & \multicolumn{1}{c}{ Ester } \\
\hline Sol-OH & Solanesol \\
Sol-C2 & Acetato de solanesilo \\
Sol-C18:3 & a-Lineonalato de solanesilo \\
Sol-C18:2 & Lineonalato de solanesilo \\
Sol-C14 & Miristeato de solanesilo \\
Sol-C15 & Pentadecanoato de solanesilo \\
Sol-C18:1 & Oleato de solanesilo \\
Sol-C16 & Palmitato de solanesilo \\
Sol-C17 & Margrato de solanesilo \\
Sol-C18 & Estearato de solanesilo \\
Sol-C20 & Araquidonato de solanesilo \\
Sol-C22 & Behenato de solanesilo
\end{tabular}

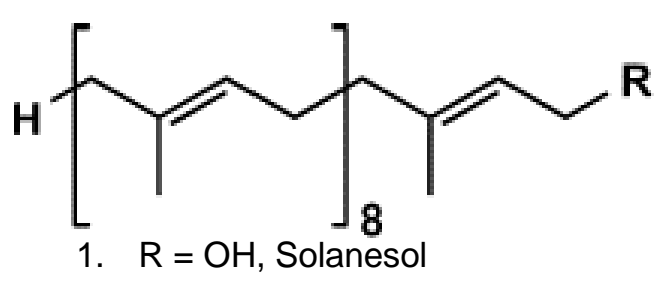

2. $\mathrm{R}=\mathrm{O}_{2} \mathrm{CR}$, Ester de Solanesol

Figura 8. Estructura del solanesol y sus esteres

Tabla 8. Contenido de los distintos esteres de solanesol en distintas muestras de tabaco [76]

\begin{tabular}{|c|c|c|c|c|c|c|c|c|c|c|c|c|c|c|c|}
\hline & & & Ester total & Sol-C2 & Sol-C18:3 & Sol-C18:2 & Sol-C14 & Sol-C15 & Sol-C18:1 & Sol-C16 & Sol-C17 & Sol-C18 & Sol-C20 & Sol-C22 & Sol-OH \\
\hline FCV & (EEUU) & $\begin{array}{c}(\mu \mathrm{g} / \mathrm{mL}) \\
(\%)\end{array}$ & $\begin{array}{c}2669,99 \\
15,53\end{array}$ & 638 & 466,52 & 398,86 & 144,16 & 22,9 & 155,29 & 580,78 & 28,5 & 111,43 & 66,89 & 56,67 & 17195,41 \\
\hline FCV & (BRA) & $\begin{array}{c}(\mu \mathrm{g} / \mathrm{mL}) \\
(\%)\end{array}$ & $\begin{array}{c}2546,01 \\
22,16\end{array}$ & 475,41 & 633,21 & 465,04 & 71,73 & 21,75 & 176,98 & 532,5 & 21,33 & 89,75 & 33,00 & 25,31 & 11488,77 \\
\hline BLY & (BRA) & $\begin{array}{c}(\mu \mathrm{g} / \mathrm{mL}) \\
(\%)\end{array}$ & $\begin{array}{c}1538,5 \\
11,99\end{array}$ & 354,78 & 227,74 & 252,35 & 91,39 & 41,70 & 98,88 & 324,23 & 20,72 & 61,87 & 32,29 & 32,55 & 12835,98 \\
\hline BLY & (EEUU) & $\begin{array}{c}(\mu \mathrm{g} / \mathrm{mL}) \\
(\%)\end{array}$ & $\begin{array}{c}2378,41 \\
14,65\end{array}$ & 455,61 & 376,43 & 443,71 & 130,42 & 72,64 & 203,23 & 472,12 & 35,75 & 93,11 & 45,15 & 50,23 & 16230,84 \\
\hline ORI & (TUR) & $\begin{array}{c}(\mu \mathrm{g} / \mathrm{mL}) \\
(\%)\end{array}$ & $\begin{array}{c}2546,71 \\
34,69\end{array}$ & 107,00 & 1107,55 & 299,19 & 57,75 & 12,31 & 171,49 & 579,15 & 16,27 & 118,54 & 45,03 & 32,43 & 7342,18 \\
\hline DAC & (FIL) & $\begin{array}{c}(\mu \mathrm{g} / \mathrm{mL}) \\
(\%)\end{array}$ & $\begin{array}{c}2686,12 \\
65,95\end{array}$ & 75,64 & 554,94 & 334,19 & 94,62 & 48,19 & 406,18 & 813,66 & 32,41 & 186,15 & 70,93 & 69,19 & 4073,2 \\
\hline DAC & (BRA) & $\begin{array}{c}(\mu \mathrm{g} / \mathrm{mL}) \\
(\%)\end{array}$ & $\begin{array}{c}1763,66 \\
25,09\end{array}$ & 110,26 & 420,54 & 304,65 & 93,50 & 53,62 & 146,13 & 426,41 & 25,22 & 95,12 & 45,26 & 42,95 & 7030,01 \\
\hline
\end{tabular}

FCV: Flue Cured Virginia, BLY: Tabaco Burley, ORI: Tabaco Oriental, DAC: Tabaco negro secado por aire. EEUU: Estados Unidos, BRA: Brasil, GRC: Grecia, TUR: Turquía, FIL: Filipinas. 


\subsection{Nicotina}

La nicotina tiene una historia más antigua que la del solanesol y la información disponible es abundante [90]. Básicamente, la nicotina es un compuesto orgánico nitrogenado alcalino (alcaloide). Es un líquido transparente a amarillo pálido, que en contacto con la luz y el aire se vuelve marrón. Su fórmula molecular es C10H14N2, y su peso molecular es de $162,263 \mathrm{~g} / \mathrm{mol}$. Es miscible en agua y muy soluble en etanol, cloroformo, éter, keroseno y aceites.

A bajas dosis es estimulante del sistema nervioso central, y a dosis más alta es un compuesto tóxico por inhalación, ingestión y por absorción cutánea. Esto plantea dos escenarios opuestos, el primer escenario negativo por su toxicidad y el segundo positivo por su aplicación en medicamentos para paliar los síntomas del Alzheimer y para tratamientos para dejar de fumar.

La farmacopea europea establece los parámetros para considerar a la nicotina como componente puro cuando él área de cada una de las impurezas no supere el 0,3 \% del pico del área obtenido por HPLC de la solución de referencia [91]. Define también como impurezas a los derivados de la nicotina anatabina, $\beta$-nicotirina, cotinina, miosmina, óxido $N^{\prime}$ de nicotina, nornicotina y anabisina (ver Figura 9) . La nicotina, en presencia de luz y aire se vuelve oscura y más viscosa, esto se debe a la oxidación provocada por el efecto de los radicales libres [92]. La miosmina, y el óxido N’ de nicotina fueron identificados como los principales productos de degradación debido a la exposición solar y al aire de una solución acuosa de nicotina [93].

Por una parte, para analizar la nicotina como una sustancia tóxica hay que tener en cuenta las dosis a las cuales se considera este efecto negativo. Por ejemplo, la dosis letal media en ratas (LD50) es de $24 \mathrm{mg} / \mathrm{kg}$ por vía oral; en humanos, se estimó la dosis letal entre 50 y $60 \mathrm{mg}$ para una persona de $70 \mathrm{~kg}$ absorbiendo el $100 \%$ de $30-40 \mathrm{mg} / \mathrm{m} 3$ durante 30 minutos a razón $50 \mathrm{l} / \mathrm{min}$ por inhalación [94]. Consecuente con este dato, la concentración máxima permitida en ambientes es de $0,5 \mathrm{mg} / \mathrm{m} 3$ según la ley de higiene y seguridad en el trabajo de Argentina [95]. Sin embargo, en un trabajo publicado en 2014 [96], el autor cuestiona que los valores vigentes de las normativas sobre la nicotina no son actuales y que, si bien debe manejarse con cuidado por ser un producto tóxico, es necesario aclarar que hace falta ingerir más de $0,5 \mathrm{gr}$ de nicotina para tener un efecto letal. 


\subsubsection{Usos de la Nicotina}

La nicotina como compuesto puro, se utiliza como ingrediente de las soluciones de los cigarrillos electrónicos, en productos farmacéuticos, y como pesticida apto para cultivos orgánicos. La F.D.A clasifica a los productos derivados del tabaco para fumar, que no son cigarrillos, como vaporizadores, cigarrillos y sistemas electrónicos para suministrar nicotina. Para estos productos, se estima que para el año 2030 las ventas en el mundo alcanzaran un valor de US $\$ 51.000$ millones [97].

Por otro lado, está el uso de la nicotina como producto farmacéutico. Existen en el mercado una variedad importante de formulaciones que tienen como principal componente la nicotina. $\mathrm{Y}$ tienen como finalidad los tratamientos para dejar de fumar como, por ejemplo, Nicotrol $₫$ inhalador de laboratorios Pfizer, Nicorette $₫$ chicles, parches, inhalador y spray bucal de Johnson \& Johnson y Habitrol ${ }^{\circledR}$ parches de laboratorios Dr. Reddys.<smiles>CN1CCCC1c1cccnc1</smiles>

Nicotina $\left(\mathrm{C}_{10} \mathrm{H}_{14} \mathrm{~N}_{2}\right)$<smiles>C1=CCC(c2cccnc2)NC1</smiles>

Anatabina $\left(\mathrm{C}_{10} \mathrm{H}_{12} \mathrm{~N}_{2}\right)$<smiles>CN1C(=O)CCC1c1cccnc1</smiles>

Cotinina $\left(\mathrm{C}_{10} \mathrm{H}_{12} \mathrm{~N}_{2} \mathrm{O}\right)$<smiles>[O-][n+]1ccccc1</smiles>

Oxido N-nicotina $\left(\mathrm{C}_{10} \mathrm{H}_{14} \mathrm{~N}_{2} \mathrm{O}\right)$<smiles>c1cncc(C2=NCCC2)c1</smiles>

Miosmina $\left(\mathrm{C}_{9} \mathrm{H}_{10} \mathrm{~N}_{2}\right)$<smiles>c1cncc([C@@H]2CCCN2)c1</smiles>

Nornicotina $\left(\mathrm{C}_{9} \mathrm{H}_{12} \mathrm{~N}_{2}\right)$<smiles>c1cncc(C2CCCCN2)c1</smiles>

Anabisina $\left(\mathrm{C}_{10} \mathrm{H}_{14} \mathrm{~N}_{2}\right)$

Figura 9. Molécula de nicotina y sus productos de degradación 


\subsection{Otros componentes de interés}

De los análisis por GC-MS realizados en este trabajo se pudieron identificar otros componentes de la fase orgánica obtenida de la extracción líquido-líquido. Los componentes detectados son escualeno, vitamina E, rutina y campesterol. En el Anexo de información complementaria de este trabajo se presentan los cromatogramas del aceite de tabaco obtenido. Estos componentes también son de interés comercial debido a su actividad biológica como antioxidantes, vitaminas, antimicrobianos, etc.

El escualeno es un terpenoide con aplicaciones en la industria cosmética, de alimentos y farmacéutica [98]. Tradicionalmente se obtiene del hígado de los tiburones, por lo que encontrar o desarrollar una fuente sustentable de este compuesto es objeto de varias investigaciones. Rosales et al [99] mencionan al tabaco como una fuente vegetal para la obtención de este principio activo en porcentajes desde el 2 al 20\%. Existen antecedentes de extracción de escualeno con $\mathrm{CO}_{2} \mathrm{SC}$ desde otras matrices como semillas de amaranto (0,3\%) [100], aceite de oliva desodorizado (28\%) [101] y aceite de salvado de arroz (2,9\%) [102].

La vitamina $E$ ( $\alpha$-tocoferol) es un antioxidante que protege a las células de los radicales libres. Tiene funciones en el sistema inmunológico y en la formación de glóbulos rojos. Fue aislado del tabaco Virginia en 1958 por Roland [68] obteniendo un $0,02 \%$ de este componente en base seca (un porcentaje similar al del solanesol). Ohgaki et al [103] determinó la solubilidad de la vitamina E en el $\mathrm{CO}_{2} \mathrm{SC}$ y Brunner [104] separó este componente de una mezcla compleja con $\mathrm{CO}_{2} \mathrm{SC}$. Estos 2 trabajos son una pequeña parte de la información disponible sobre la afinidad de este principio activo y el $\mathrm{CO}_{2} \mathrm{SC}$.

Por último, la rutina es un flavonoide con una variada actividad en la salud humana como antialérgico, antinflamatorio, anti proliferativo y anticancerígeno [105]. Se encuentra en el tabaco junto al ácido clorogénico entre un 1-2\% [107] cada uno, en base seca. Estos componentes podrían aislarse del extracto supercrítico de tabaco con las técnicas adecuadas, o darle un efecto sinérgico a este extracto en un potencial uso farmacéutico.

\section{Conclusiones}

Del estudio sobre el tabaco producido en la región del noroeste argentino, se puede extraer los siguientes puntos que sirven para fortalecer y validar la propuesta de este trabajo de usar los subproductos como materia prima en una biorrefinería: 
- El tabaco tiene una gran variedad de principios activos que pueden extraerse, separarse y purificarse del tabaco. Como son: solanesol, nicotina, acido clorogénico, rutina, entre otros compuestos minoritarios.

- El tallo y los palos son biomasas lignocelulósicas similares a la biomasa forestal (porcentajes de celulosas, hemicelulosa y lignina) que pueden emplearse en una biorrefinería de segunda generación.

- Los subproductos del despalillado se concentran en un solo lugar, separados y clasificados por tamaño. Facilitando su posterior uso en la biorrefinería, centralizando la producción de biomas y evitando costos de logística y transporte.

- Impacto económico y social que tiene este cultivo en esta región con la cantidad de mano de obra directa e indirecta que emplea y la cantidad de recursos que aporta al estado. El tabaco, aporta un 1\% del PBI nacional, porcentaje levemente superior al aporte del impuesto a los combustibles. 


\section{Bibliografia}

[1] R. Birner, «Bioeconomy Concepts», en Bioeconomy, I. Lewandowski, Ed. Cham: Springer International Publishing, 2018, pp. 17-38.

[2] German Bioeconomy Council, «Comunicado Cumbre Global de Bioeconomía 2018». 2018, [En línea]. Disponible en: gbs2018.com.

[3] «Helping consumers choose sustainable products and services», European Commission. https://ec.europa.eu/commission/publications/helping-consumerschoose-sustainable-products-and-services_en (accedido nov. 20, 2019).

[4] SamDB, «Home», BiosocietyVision. https://biosocietyvision.eu/ (accedido nov. 20, 2019).

[5] Climate and Environment Division y FAO, «Towards sustainable bioeconomy guidelines». 2019, [En línea]. Disponible en: www.fao.org/energy/bioeconomy.

[6] F. Cherubini et al., «Toward a common classification approach for biorefinery systems», Biofuels, Bioprod. Bioref., vol. 3, n. ${ }^{\circ}$ 5, pp. 534-546, sep. 2009, doi: 10.1002/bbb.172.

[7] O. de las Naciones Unidas para la Alimentación y la Agricultura, Análisis espacial del balance energético derivado de biomasa en Argentina. Metodología Wisdom. Food \& Agriculture Org., 2009.

[8] O. de las Naciones Unidas para la Alimentación y la Agricultura, Análisis espacial del balance energético derivado de biomasa. Metodología Wisdom. Provincia de Salta: Colección Documentos Técnicos N². Food \& Agriculture Org., 2016.

[9] E. D. Keoke y K. M. Porterfield, Encyclopedia of American Indian Contributions to the World: 15,000 Years of Inventions and Innovations. Infobase Publishing, 2009.

[10] J. Mackay, M. Eriksen, M. P. Eriksen, y W. H. Organization, The Tobacco Atlas. World Health Organization, 2002.

[11] J. E. Brooks, Tobacco / 1507- 1615. 1937.

[12] C. von Linné y L. Salvius, en Species plantarum, vol. 1, Holmiae : Impensis Laurentii Salvii, 1753, p. 18.

[13] T. C. Tso, «Tobacco», en Ullmann's Encyclopedia of Industrial Chemistry, WileyVCH Verlag GmbH \& Co. KGaA, Ed. Weinheim, Germany: Wiley-VCH Verlag GmbH \& Co. KGaA, 2000, p. a27_123.

[14] O. Wilhelm Thomé, Flora von Deutschland Österreich und der Schweiz. 1885.

[15] 2019 FAO, «FAOSTAT», Datos obtenidos de FAOSTAT, 2017. http://www.fao.org/faostat/en/\#data/QC (accedido jun. 10, 2019).

[16] «OMS | Partes en el Convenio Marco de la OMS para el Control del Tabaco», WHO. http://www.who.int/fctc/signatories_parties/es/ (accedido oct. 22, 2019). 
[17] V. C. Li y S. Tang, «China's New Road for Tobacco Control: Tobacco Crop Substitution», Am J Public Health, vol. 108, n. ${ }^{\circ}$ 10, pp. 1316-1317, oct. 2018.

[18] Ministerio de Agricultura de la Nación Argentina, «Mercado interno», 2018. https://www.agroindustria.gob.ar/sitio/areas/tabaco/produccion_mercados/interno/i ndex.php (accedido dic. 08, 2018).

[19] Ministerio de Agricultura de la Nacion Argentina, «Tabaco: Area plantada, cosechada, produccion y rendimiento_2007-2017».

https://www.agroindustria.gob.ar/sitio/areas/tabaco/produccion_mercados/interno/i ndex.php (accedido nov. 19, 2019).

[20] D. E. OConnor, «Informes de Cadena de Valor: Tabaco», Secretaría de Política Económica y Planificación del Desarrollo. Ministerio de Hacienda y Finanzas Públicas Presidencia de la Nación, 32, dic. 2016.

[21] Ministerio de Agricultura, Ganadería y Pesca de la Nación, Impacto regional del convenio marco para el control del tabaco, 1era ed. Buenos Aires, 2011.

[22] Instituto de Tecnología Agropecuaria, «Ciencia y tecnología de los cultivos industriales - Tabaco», INTA, vol. 4.

[23] F. G. Barla y S. Kumar, «Tobacco biomass as a source of advanced biofuels», Biofuels, vol. 0, n. ${ }^{\circ}$ 0, pp. 1-12, oct. 2016, doi: 10.1080/17597269.2016.1242684.

[24] M. A. R. Faraldo, Historia del cultivo del tabaco en Salta. Ministerio de Agricultura, Ganadería y Pesca de la Nación, 2012.

[25] X. Zhang, H. Gao, L. Zhang, D. Liu, y X. Ye, «Extraction of essential oil from discarded tobacco leaves by solvent extraction and steam distillation, and identification of its chemical composition», Industrial Crops and Products, vol. 39, pp. 162-169, sep. 2012, doi: 10.1016/j.indcrop.2012.02.029.

[26] R. Schneider, L. Anacker, M. Szarblewski, L. Silva, M. Moraes, y V. Corbellini, «Bioethanol Production from Residual Tobacco Stalks», Current Journal of Applied Science and Technology, vol. 24, n. ${ }^{\circ}$ 6, pp. 1-9, dic. 2017, doi: 10.9734/CJAST/2017/37948.

[27] C. Martín et al., «Preparation of hydrolysates from tobacco stalks and ethanolic fermentation by Saccharomyces cerevisiae», World Journal of Microbiology and Biotechnology, vol. 18, n. ${ }^{\circ}$ 9, pp. 857-862, dic. 2002.

[28] C. Martin, T. Fernandez, A. Garcia, E. Carrillo, y A. B. Thomsen, «Wet Oxidation Pretreatment of Tobacco Stalks and Orange Waste for Bioethanol Production. Preliminary results», Cellulose Chemistry and Technology, vol. 42, n. ${ }^{\circ} 7-8, \mathrm{pp}$. 429-434, 2009. 
[29] S. Kumar, J. L. G. Moscoso, I. Bobe, y P. Majeranowski, «Green process to hydrolyze carbohydrates from tobacco biomass using subcritical water», US20140331993A1, nov. 13, 2014.

[30] Climate, Energy and Tenure Division y FAO, Impactos de la bioenergía sobre la seguridad alimentaria Guía para la evaluación respuesta a nivel nacional y de proyecto. 2012.

[31] A. Rodgman y T. A. Perfetti, The Chemical Components of Tobacco and Tobacco Smoke, Second Edition. CRC Press, 2016.

[32] E. Corradini, H. Zilocchi, R. Cuesta, R. Segesso, M. L. Jiménez, y J. Musco, «Caracterización del sector productor tabacalero en la República Argentina», 3, jun. 2005.

[33] M. Yokoi y M. Shimoda, «Extraction of Volatile Flavor Compounds From Tobacco Leaf Through a Low-Density Polyethylene Membrane», J Chromatogr Sci, vol. 55, n. ${ }^{\circ} 3$, pp. 373-377, mar. 2017, doi: 10.1093/chromsci/bmw178.

[34] R. M. Graciano, V. P. de Freitas, y M. Abel, «Simultaneous saccharification and fermentation of tobacco samples», Analecta Technica Szegedinensia, vol. 8, n. ${ }^{\circ}$, pp. 80-89.

[35] S. Jokić, T. Gagić, Ž. Knez, M. Banožić, y M. Škerget, «Separation of active compounds from tobacco waste using subcritical water extraction», The Journal of Supercritical Fluids, vol. 153, p. 104593, nov. 2019.

[36] A. Maisashvili, H. L. Bryant, y J. W. Richardson, «Economic feasibility of tobacco leaves for biofuel production and high value squalene», International Food and Agribusiness Management Review, vol. 19, n. ${ }^{\circ}$ 4, pp. 145-162, nov. 2016.

[37] K. K. Meher, A. M. Panchwagh, S. Rangrass, y K. G. Gollakota, «Biomethanation of tobacco waste», Environmental Pollution, vol. 90, n. ${ }^{\circ}$ 2, pp. 199-202, ene. 1995, doi: 10.1016/0269-7491(94)00107-O.

[38] M. Pesevski, B. Iliev, D. Zivkovic, V. Jakimovska-Popovska, M. Srbinoska, y B. Filiposki, «Possibilities for utilization of tobacco stems for production of energetic briquettes», J Agric Sci BGD, vol. 55, n. ${ }^{\circ}$ 1, pp. 45-54, 2010, doi: 10.2298/JAS1001045P.

[39] Z. Jiang et al., «Agronomic and chemical performance of field-grown tobacco engineered for triterpene and methylated triterpene metabolism», Plant Biotechnology Journal, vol. 16, n. ${ }^{\circ}$ 6, pp. 1110-1124, 2018, doi: 10.1111/pbi.12855. [40] I. Farran, A. F.-S. Millan, M. Ancin, L. Larraya, y J. Veramendi, «Increased bioethanol production from commercial tobacco cultivars overexpressing 
thioredoxin f grown under field conditions», Mol Breeding, vol. 34, n. ${ }^{\circ} 2$, pp. 457469, ago. 2014, doi: 10.1007/s11032-014-0047-x.

[41] F. Fathiazad, A. Delazar, R. Amiri, y S. D. Sarker, «Extraction of Flavonoids and Quantification of Rutin from waste Tobacco Leaves», Iranian Journal of Pharmaceutical Research, vol. 0, n. ${ }^{\circ}$ 0, pp. 222-227, nov. 2010.

[42] A. F. Mulyadi, Susinggih Wijana, y A. S. Wahyudi, «Optimization of Nicotine Extraction In Tobacco Leaf (Nicotiana tabacum L.) :(Study : Comparison of Ether and Petroleum Ether)», 2013, doi: 10.13140/RG.2.1.2290.7926.

[43] F. W. Jones, B. O. Bateup, D. R. Dixon, y S. R. Gray, «Solubility of wool wax in supercritical carbon dioxide», The Journal of Supercritical Fluids, vol. 10, n. ${ }^{\circ} 2$, pp. 105-111, jun. 1997, doi: 10.1016/S0896-8446(97)00008-9.

[44] P. Hubert y O. G. Vitzthum, «Fluid Extraction of Hops, Spices, and Tobacco with Supercritical Gases», Angewandte Chemie International Edition in English, vol. 17, n. ${ }^{\circ} 10$, pp. 710-715, oct. 1978, doi: 10.1002/anie.197807101.

[45] M. Fischer y T. M. Jefferies, «Optimization of Nicotine Extraction from Tobacco Using Supercritical Fluid Technology with Dynamic Extraction Modeling», J. Agric. Food Chem., vol. 44, n. ${ }^{\circ}$ 5, pp. 1258-1264, ene. 1996, doi: 10.1021/jf950502+.

[46] J. Rincón, A. D. Lucas, M. A. García, A. García, A. Alvarez, y A. Carnicer, «Preliminary Study on the Supercritical Carbon Dioxide Extraction of Nicotine from Tobacco Wastes», Separation Science and Technology, vol. 33, n. ${ }^{\circ} 3$, pp. 411423, ene. 1998, doi: 10.1080/01496399808544776.

[47] K. Mahendra, C. V. Narasimha Rao, Y. L. N. Murthy, y K. Bala Murali Krishna, «Development of high value phytochemicals from green tobacco», International Journal of Chemical Sciences and Research, vol. 2011, n. ${ }^{\circ}$ (01), pp. 23-28, 2011.

[48] S. Eda y K. Katō, «Pectin Isolated from the Midrib of Leaves of Nicotiana tabacum», Agricultural and Biological Chemistry, vol. 44, n. ${ }^{\circ} 12$, pp. 2793-2801, dic. 1980, doi: 10.1080/00021369.1980.10864410.

[49] H. Wang, M. Zhao, B. Yang, Y. Jiang, y G. Rao, «ldentification of polyphenols in tobacco leaf and their antioxidant and antimicrobial activities», Food Chemistry, vol. 107, n. ${ }^{\circ} 4$, pp. 1399-1406, abr. 2008, doi: 10.1016/j.foodchem.2007.09.068.

[50] Z. Li et al., «Study on the Determination of Polyphenols in Tobacco by HPLC Coupled with ESI-MS After Solid-Phase Extraction», J Chromatogr Sci, vol. 41, n. ${ }^{\circ}$ 1, pp. 36-40, ene. 2003, doi: 10.1093/chromsci/41.1.36.

[51] Y. Jing et al., «Optimization of the extraction of polysaccharides from tobacco waste and their biological activities», International Journal of Biological 
Macromolecules, vol. 91, pp. 188-197, oct. 2016, doi:

10.1016/j.jibiomac.2016.05.069.

[52] Y. Tian, P. Machado, H. Fu, T.-S. Hahm, C.-I. Wei, y Y. Lo, «Photosynthetic Bioconversion of Coenzyme Q(10) Using Agrowaste Generated from Tobacco Biorefinery for Nonsmoking Applications: A Review», Journal of Food and Drug Analysis, vol. 20, pp. 173-178, 2012.

[53] S. R. Atla, B. Raja, y B. R. Dontamsetti, «A new method of synthesis of coenzyme Q10 from isolated solanesol from tobacco waste», International Journal of Pharmacy and Pharmaceutical Sciences, vol. 6, n. ${ }^{\circ}$ 8, pp. 499-502, sep. 2014.

[54] Z. Teng y Q. Wang, «Extraction, identification and characterization of the waterinsoluble proteins from tobacco biomass», Journal of the Science of Food and Agriculture, vol. 92, n. ${ }^{\circ}$ 7, pp. 1368-1374, 2012, doi: 10.1002/jsfa.4708.

[55] P. Fantozzi y A. Sensidoni, «Protein extraction from tobacco leaves: technological, nutritional and agronomical aspects», Plant Food Hum Nutr, vol. 32, n. ${ }^{\circ} 3-4$, pp. 351-368, sep. 1983, doi: 10.1007/BF01091194.

[56] H. Fu, P. A. Machado, T. S. Hahm, R. J. Kratochvil, C. I. Wei, y Y. M. Lo, «Recovery of nicotine-free proteins from tobacco leaves using phosphate buffer system under controlled conditions», Bioresource Technology, vol. 101, n. ${ }^{\circ}$ 6, pp. 2034-2042, mar. 2010, doi: 10.1016/j.biortech.2009.10.045.

[57] S. C. Agrupis y E. Maekawa, «Industrial Utilization of Tobacco Stalks (1) Preliminary Evaluation for Biomass Resources», Holzforschung, vol. 53, n. ${ }^{\circ}$, pp. 29-32, 2005, doi: 10.1515/HF.1999.005.

[58] J. Zeng et al., «Study on Tobacco Stem and Tobacco Dust Making Reconstituted Tobacco Paper-Base», AMR, vol. 550-553, pp. 3316-3322, jul. 2012, doi: 10.4028/www.scientific.net/AMR.550-553.3316.

[59] S. Agrupis, E. Maekawa, y K. Suzuki, «Industrial utilization of tobacco stalks II: preparation and characterization of tobacco pulp by steam explosion pulping», Journal of Wood Science, vol. 46, n. ${ }^{\circ}$ 3, p. 222, jun. 2000, doi: 10.1007/BF00776453.

[60] A. Ruiz-Rodriguez, M.-R. Bronze, y M. N. da Ponte, «Supercritical fluid extraction of tobacco leaves: A preliminary study on the extraction of solanesol», The Journal of Supercritical Fluids, vol. 45, n. ${ }^{\circ} 2$, pp. 171-176, jun. 2008, doi: 10.1016/j.supflu.2007.10.011.

[61] R. Rowland, P. Latimer, y J. Giles, «Flue-cured tobacco. I. Isolation of solanesol, an unsaturated alcohol», Journal of the American Chemical Society, vol. $78, \mathrm{n} .{ }^{\circ} 18$, pp. 4680-4683, 1956. 
[62] S. Atlas, B. Raja, y B. R. Dontamsetti, «A new method of extraction, isolation and determination of solanesol from tobacco waste (Nicotiana tobacum L.) by nonaqueous RP-HPLC», International Journal of Pharmacy and Pharmaceutical Sciences, vol. 6, pp. 543-546, ene. 2014.

[63] D. Tang et al., «Extraction and purification of solanesol from tobacco(I). Extraction and silica gel column chromatography separation of solanesol», Separation and Purification Technology, vol. 56, n. ${ }^{\circ}$ 3, pp. 291-295, sep. 2007, doi: 10.1016/j.seppur.2007.01.040.

[64] C. Zhao, Y. Zu, y C. Li, «Extraction of solanesol from tobacco (Nicotiana tobaccum L.) leaves by bubble column», Chemical Engineering and Processing: Process Intensification, vol. 48, n. ${ }^{\circ}$, pp. 203-208, ene. 2009, doi: 10.1016/j.cep.2008.03.005.

[65] H.-Y. Zhou y C.-Z. Liu, «Microwave-assisted extraction of solanesol from tobacco leaves», Journal of Chromatography A, vol. 1129, n. ${ }^{0}$ 1, pp. 135-139, sep. 2006, doi: 10.1016/j.chroma.2006.07.083.

[66] Q. Du, W. Daijie, y Y. Ito, «Preparation of Solanesol from a Tobacco Leaf Extract Using High Speed Countercurrent Chromatography», Journal of Liquid Chromatography \& Related Technologies, vol. 29, n. ${ }^{\circ} 17$, pp. 2587-2592, oct. 2006, doi: 10.1080/10826070600915197.

[67] P. A. Machado et al., «Recovery of solanesol from tobacco as a value-added byproduct for alternative applications», Bioresource Technology, vol. 101, n. ${ }^{\circ} 3$, pp. 1091-1096, feb. 2010, doi: 10.1016/j.biortech.2009.09.009.

[68] D.-S. Tang, H.-L. Liang, L. Zhang, y H.-L. Chen, «Solid Phase Extraction of Solanesol», Chroma, vol. 66, n. ${ }^{\circ} 1-2$, pp. 129-131, jul. 2007, doi: 10.1365/s10337007-0251-5.

[69] R.-S. Hu et al., «Simultaneous extraction of nicotine and solanesol from waste tobacco materials by the column chromatographic extraction method and their separation and purification», Separation and Purification Technology, vol. 146, pp. 1-7, may 2015, doi: 10.1016/j.seppur.2015.03.016.

[70] L. Rowland, «Isolation of alpha-tocopherol and solonachromene from flue-cured tobacco», 1958. Accedido: mar. 16, 2019. [En línea]. Disponible en: http://www.rjrtdocs.com/rjr/public/fileData/1646131.

[71] O. Akpinar, K. Erdogan, U. Bakir, y L. Yilmaz, «Comparison of acid and enzymatic hydrolysis of tobacco stalk xylan for preparation of xylooligosaccharides», LWT Food Science and Technology, vol. 43, n. ${ }^{0}$ 1, pp. 119-125, ene. 2010, doi: 10.1016/j.Iwt.2009.06.025. 
[72] J.-C. Liu, D.-Q. Li, R.-Q. Zhou, y F. Hao, «Solubilities of solanesol in acetonitrile, ethanol and n-hexane from 285 to $310 \mathrm{~K} »$, Korean J. Chem. Eng., vol. 24, n. ${ }^{\circ}$, pp. 113-115, ene. 2007, doi: 10.1007/s11814-007-5019-y.

[73] N. Yan, Y. Liu, D. Gong, Y. Du, H. Zhang, y Z. Zhang, «Solanesol: a review of its resources, derivatives, bioactivities, medicinal applications, and biosynthesis», Phytochem Rev, pp. 1-15, ene. 2015, doi: 10.1007/s11101-015-9393-5.

[74] C. Zhao, Y. Zu, C. Li, y C. Tian, «Distribution of solanesol in Nicotiana tabacum», J. of For. Res., vol. 18, n. ${ }^{\circ}$ 1, pp. 69-72, mar. 2007, doi: 10.1007/s11676-007-00130.

[75] H. R. Burton, G. Childs, J. L. Sims, y Walton, L., «Factors Influencing the Concentration of Solanesol in Burley Tobacco». University of Kentucky, 1989, [En línea]. Disponible en: http://tobaccodocuments.org/ctr/60036320A-6320A.html.

[76] Leffingwell, L.C., «Chapter 8. Leaf Chemistry. Basic chemical constituents of tobacco leaf and differences among tobacco types», en Tobacco: Production, chemistry and technology, Oxford ; Malden, MA, USA: Blackwell Science, 1999, p. 247.

[77] N. Ishida, «A novel method for analyzing solanesyl esters in tobacco leaves using atmospheric pressure chemical ionization/mass spectrometer», Journal of Chromatography A, vol. 1217, n. ${ }^{\circ} 37$, pp. 5794-5801, sep. 2010, doi: 10.1016/j.chroma.2010.07.037.

[78] B. Qin et al., «PEGylated Solanesol for Oral Delivery of Coenzyme Q10», J. Agric. Food Chem., vol. 65, n. ${ }^{0} 16$, pp. 3360-3367, abr. 2017, doi: 10.1021/acs.jafc. 7 b00165.

[79] Q. Bai et al., «[Antioxidant function of solanesol and its inhibitory effect on tyrosinase]», Sheng Wu Yi Xue Gong Cheng Xue Za Zhi, vol. 31, n. ${ }^{\circ} 4$, pp. 833836, 841, ago. 2014.

[80] W. Huang, Z. Li, H. Niu, J. Wang, y Y. Qin, «Bioactivity of solanesol extracted from tobacco leaves with carbon dioxide-ethanol fluids», Biochemical Engineering Journal, vol. 42, n. ${ }^{\circ}$ 1, pp. 92-96, oct. 2008, doi: 10.1016/j.bej.2008.06.002.

[81] X. Yao, Q. Bai, D. Yan, G. Li, C. Lü, y H. Xu, «Solanesol protects human hepatic L02 cells from ethanol-induced oxidative injury via upregulation of HO-1 and Hsp70», Toxicology in Vitro, vol. 29, n. ${ }^{\circ} 3$, pp. 600-608, abr. 2015, doi: 10.1016/j.tiv.2015.01.009.

[82] B. H. Chen, J. Zhang, y Y. U. He-Xiu, «In Vitro Study on the Antibacterial Activities of a Medicinal Intermediate,Solanesol», Qilu Pharmaceutical Affairs, 2007. 
[83] S. Pingali, V. Pujari, y M. Bhagavanraju, «Formulation and evaluation of antiinflammatory herbal gel containing isolated solanesol», Annals of Phytomedicine: An International Journal, vol. VI, pp. 127-131, jun. 2017, doi: 10.21276/ap.2017.6.1.19.

[84] B. Qin et al., «mPEGylated solanesol micelles as redox-responsive nanocarriers with synergistic anticancer effect», Acta Biomaterialia, vol. 64, pp. 211-222, dic. 2017, doi: 10.1016/j.actbio.2017.09.040.

[85] K. Hamamura et al., «Synthesis of [3'-14C] coenzyme Q10», Journal of Labelled Compounds and Radiopharmaceuticals, vol. 45, n. ${ }^{\circ} 10$, pp. 823-829, 2002, doi: 10.1002/jlcr.588.

[86] Y. Naruta, «Regio- and stereoselective synthesis of coenzymes Qn ( $n=2-10)$, vitamin K, and related polyprenylquinones», J. Org. Chem., vol. 45, n. ${ }^{\circ} 21$, pp. 4097-4104, oct. 1980, doi: 10.1021/jo01309a006.

[87] H.-S. Wu y J.-J. Tsai, «Separation and purification of coenzyme Q10 from Rhodobacter sphaeroides», Journal of the Taiwan Institute of Chemical Engineers, vol. 44, n. ${ }^{\circ}$ 6, pp. 872-878, nov. 2013, doi: 10.1016/j.jtice.2013.03.013.

[88] Y. Tian et al., «Tobacco biomass hydrolysate enhances coenzyme Q10 production using photosynthetic Rhodospirillum rubrum», Bioresource Technology, vol. 101, n. ${ }^{\circ} 20$, pp. 7877-7881, oct. 2010, doi: 10.1016/j.biortech.2010.05.020.

[89] L. Qiu et al., «Coenzyme Q10 production by immobilized Sphingomonas sp. ZUTE03 via a conversion-extraction coupled process in a three-phase fluidized bed reactor», Enzyme and Microbial Technology, vol. 50, n. ${ }^{\circ}$ 2, pp. 137-142, feb. 2012, doi: 10.1016/j.enzmictec.2011.11.006.

[90] M. A. Taylor y P. D. Fraser, «Solanesol: Added value from Solanaceous waste», Phytochemistry, vol. 72, n. ${ }^{\circ} 11-12$, pp. 1323-1327, ago. 2011, doi: 10.1016/j.phytochem.2011.03.015.

[91] Pubchem, «nicotine | C10H14N2 - PubChem», 2016. https://pubchem.ncbi.nlm.nih.gov/compound/nicotine (accedido dic. 29, 2016).

[92] European pharmacopoeia: published in accordance with the Convention on the elaboration of a European pharmacopoeia (European treaty series n. 50). Strasbourg: Council of Europe, 2013.

[93] P. A. Crooks, «IV. Chemical properties of nicotine and related compounds», en Analytical Determination of Nicotine and Related Compounds and their Metabolites, Elsevier, 1999, pp. 69-147.

[94] T. J. Smyth, V. N. Ramachandran, A. McGuigan, J. Hopps, y W. F. Smyth, «Characterisation of nicotine and related compounds using electrospray ionisation 
with ion trap mass spectrometry and with quadrupole time-of-flight mass spectrometry and their detection by liquid chromatography/electrospray ionisation mass spectrometry», Rapid Commun. Mass Spectrom., vol. 21, n. ${ }^{\circ} 4$, pp. 557-566, feb. 2007, doi: 10.1002/rcm.2871.

[95] «NIOSH», nov. 16, 2017. https://www.cdc.gov/niosh/idlh/54115.html (accedido ago. 12, 2018).

[96] «Ley 19587.» Boletin oficial de la Republica Argentina, abr. 28, 1972.

[97] B. Mayer, «How much nicotine kills a human? Tracing back the generally accepted lethal dose to dubious self-experiments in the nineteenth century», Arch Toxicol, vol. 88, n. ${ }^{\circ} 1$, pp. 5-7, 2014, doi: 10.1007/s00204-013-1127-0.

[98] WHO, «Electronic nicotine delivery systems», Conference of the Parties to the WHO Framework Convention on Tobacco Control, vol. Sixth session, 2014.

[99] M. A. Lozano-Grande, S. Gorinstein, E. Espitia-Rangel, G. Dávila-Ortiz, y A. L. Martínez-Ayala, «Plant Sources, Extraction Methods, and Uses of Squalene», International Journal of Agronomy, 2018, doi: 10.1155/2018/1829160.

[100] T. Rosales-Garcia, C. Jimenez-Martinez, y G. Davila-Ortiz, «Squalene Extraction: Biological Sources and Extraction Methods», International Journal of Environment, Agriculture and Biotechnology, vol. 2, n. ${ }^{\circ} 4$, pp. 1662-1670, 2017, doi: 10.22161/ijeab/2.4.26.

[101] H.-P. He, H. Corke, y J.-G. Cai, «Supercritical Carbon Dioxide Extraction of Oil and Squalene from Amaranthus Grain», J. Agric. Food Chem., vol. 51, n. ${ }^{\circ}$ 27, pp. 7921-7925, dic. 2003, doi: 10.1021/jf030488y.

[102] L. Vázquez, C. F. Torres, T. Fornari, F. J. Señoráns, y G. Reglero, «Recovery of squalene from vegetable oil sources using countercurrent supercritical carbon dioxide extraction», The Journal of Supercritical Fluids, vol. 40, n. ${ }^{0} 1$, pp. 59-66.

[103] H.-J. Kim, S.-B. Lee, K.-A. Park, y I.-K. Hong, «Characterization of extraction and separation of rice bran oil rich in EFA using SFE process», Separation and Purification Technology, vol. 15, n. ${ }^{\circ}$, pp. 1-8, ene. 1999, doi: 10.1016/S13835866(98)00048-3.

[104] Ohgaki K., Tsukahara I., Semba K., y Katayama T., «A fundamental sutdy of supercritical fluid extraction - Solubilities of alpha-tocopherol, palmitic acid and tripalmitin in compressed carbon dioxide at $25^{\circ} \mathrm{C}$ and $40^{\circ} \mathrm{C} »$, vol. $13, n .{ }^{\circ} 3$, pp. 298-303, 1987, doi: 10.1252/kakoronbunshu.13.298.

[105] G. Brunner, Th. Malchow, K. Stürken, y Th. Gottschau, «Separation of tocopherols from deodorizer condensates by countercurrent extraction with carbon dioxide», The Journal of Supercritical Fluids, vol. 4, n. ${ }^{\circ}$ 1, pp. 72-80, mar. 1991. 
[106] Pubchem, «Rutin». https://pubchem.ncbi.nlm.nih.gov/compound/5280805 (accedido mar. 16, 2019).

[107] C. Gong, A. Wang, y S. Wang, «Changes of Polyphenols in Tobacco Leaves During the Flue-Curing Process and Correlation Analysis on Some Chemical Components», Agricultural Sciences in China, vol. 5, n. ${ }^{\circ}$ 12, pp. 928-932, dic. 2006. 
Capítulo II.

Separación de la fracción extraíble del scrap de tabaco Virginia con $\mathrm{CO}_{2}$ Supercrítico 


\section{Introducción}

En el año 2018 se produjeron 8,3 millones de toneladas de tabaco en todo el mundo. China produjo el 53,8\% de esta cantidad, seguida de Brasil $(9,1 \%)$, India (9\%), EE.UU. (2,9\%), Indonesia (2,2\%), Zimbabwe (1,6\%), Zambia (1,4\%) y Argentina (1,3\%) [1]. En Argentina el 63\% de la producción en 2017 correspondió a la variedad Virginia con unos 73 millones de kilogramos producidos en su mayoría en las provincias de Salta y Jujuy. En estas provincias, 82.000 personas dependían de la industria tabacalera en 2010 [2].

Las hojas de tabaco se clasifican según su posición en el tallo como hojas superiores, medias e inferiores. Las hojas superiores se consideran generalmente como la mejor fracción y su calidad se asocia a un alto contenido de azúcar y nicotina y un bajo contenido de otros compuestos de nitrógeno [3]. Los tallos de las plantas no son utilizados por la industria del tabaco y suelen emplearse en las explotaciones agrícolas para el acondicionamiento del suelo [4] y el procesamiento de las hojas produce scrap, palos y fibras como un residuo.

El tabaco tiene varias ventajas como materia prima para una biorrefinería. Los cultivos de tabaco muestran altos rendimientos de biomasa y las plantas de tabaco tienen un bajo contenido de lignina en comparación con la típica biomasa forestal. Además, la industria tabacalera produce una gran cantidad de subproductos que representa alrededor del $30-35 \%$ de la cantidad total de biomasa introducida en el proceso (es decir, excluyendo los tallos de las plantas). Esta fracción contiene una amplia gama de compuestos de valor añadido como azúcares libres fácilmente extraíbles [5], escualeno [6], proteínas de grado alimentario [7] y compuestos bioactivos como solanesol [8] y nicotina [9].

El solanesol $\left(\mathrm{C}_{45} \mathrm{H}_{74} \mathrm{O}, \mathrm{PM}: 631,086 \mathrm{~g} / \mathrm{mol}\right)$ es un alcohol terpénico no cíclico, constituido por nueve unidades isoprenoides. El solanesol está presente en las hojas de las Solanáceas como la papa (en concentraciones que van del 0,04\% al 0,4\%), la berenjena $(0,2-0,4 \%)$, el pimiento $(0,35-0,9 \%)$ y el tomate $(0,1-0,35 \%)$, pero las hojas de tabaco muestran los mayores contenidos de solanesol que, en el caso del tabaco de Virginia, es del 5,7\%-6,4\% (base seca) en las hojas y 0,6\%-1,9\% en los tallos [10, 11]. El solanesol y los ésteres derivados son principios activos con propiedades antibacterianas, antivirales, antifúngicas, antiinflamatorias y antiulcerosas, entre otras [10]. El uso principal del solanesol en la industria química y farmacéutica es como precursor en la síntesis química de la Coenzima Q10 y los análogos de la vitamina K $[12,13,14]$, y en la síntesis biológica de la Coenzima Q10 utilizando Rhodobacter 
sphaeroides [15], Rhodospirillum rubrum [16] o Sphingomonas spp. [17]. Debido a estas aplicaciones, Taylor y otros [18] prevén un aumento del valor comercial del solanesol.

Por otra parte, la nicotina $\left(\mathrm{C}_{10} \mathrm{H}_{14} \mathrm{~N}_{2}\right.$, PM: $\left.162,263 \mathrm{~g} / \mathrm{mol}\right)$ es un alcaloide conocido por su presencia en el tabaco y, más recientemente, en los cigarrillos electrónicos, y por el efecto negativo de estos productos en la salud. Por otro lado, tiene aplicaciones farmacéuticas como estimulante, principio activo en productos para el tratamiento de los trastornos por el uso del tabaco y también en productos farmacéuticos para el tratamiento de las enfermedades de Alzheimer [26] y Parkinson [27]. Debido a estas aplicaciones la nicotina tiene un considerable valor comercial.

Por lo general, el solanesol se extrae utilizando disolventes orgánicos como el etanol, el hexano, el metanol y el éter [19]. Sin embargo, estos métodos tienen inconvenientes bien conocidos relacionados con el uso de disolventes tóxicos que deben ser eliminados del producto final lo que aumenta los costos. Por el contrario, la extracción de $\mathrm{CO}_{2}$ supercrítico presenta ventajas obvias ya que el $\mathrm{CO}_{2}$ es un disolvente no tóxico que puede ser fácilmente eliminado del producto final por despresurización y, como se indica en la Tabla 1, varios estudios previos han demostrado la viabilidad de la extracción de $\mathrm{CO}_{2}$ del solanesol de las plantas de tabaco produciendo extractos hasta con un $20-30 \%$ de contenido de solanesol. Por ejemplo, Ruiz Rodríguez et al.[20] estudiaron la extracción supercrítica con $\mathrm{CO}_{2}$ del solanesol desde el tabaco, considerando también la extracción simultánea de nicotina. Obtuvieron una proporción máxima de $18,91 \mathrm{~g}$ de solanesol/g de nicotina operando a $8 \mathrm{MPa}$ y $25^{\circ} \mathrm{C}$ (densidad de $\mathrm{CO}_{2}: 778 \mathrm{~kg} / \mathrm{m}^{3}$ ). Con respecto al contenido total de solanesol, las mejores condiciones fueron $25 \mathrm{MPa}$ y $50{ }^{\circ} \mathrm{C}$ obteniendo $0,294 \mathrm{~g}$ de solanesol $/ \mathrm{g}$ de extracto $(6 \mathrm{~g}$ de solanesol/g de nicotina).

Wang et al. [21] pretrataron las hojas de tabaco utilizando una mezcla de etanol y hexano (4:6) lo que permitió aumentar el contenido de solanesol desde 0,1 g de solanesol/g de extracto a $0,44 \mathrm{~g}$ de solanesol/g de extracto durante la extracción supercrítica. Además, analizaron el efecto del tamaño de las partículas considerando tamaños de 175, 225 y $550 \mu \mathrm{m}$, y observaron como al aumentar el tamaño de las partículas se empeoraba la transferencia de materia y el rendimiento de la extracción. Por otra parte, este pretratamiento dificulta la aplicación industrial y el escalado debido al uso de una mezcla de disolventes orgánicos a una temperatura cercana a su punto de ebullición $\left(40-60^{\circ} \mathrm{C}\right)$.

Rincón et al. [22] estudiaron la extracción supercrítica de nicotina de los residuos del tabaco (scrap y polvo) con tamaños de partículas que oscilan entre 200 y $1000 \mu \mathrm{m}$. Las mejores condiciones fueron a $30 \mathrm{MPa}$ y $60{ }^{\circ} \mathrm{C}$ (densidad del $\mathrm{CO}_{2}: 830 \mathrm{~kg} / \mathrm{m}^{3}$ ), 
alcanzando una recuperación de nicotina entre el $24 \%$ y el $43 \%$ del contenido original de nicotina en el tabaco.

El objetivo de este trabajo es recuperar la fracción de alto valor añadido de solanesol del scrap de tabaco mediante la extracción supercrítica de $\mathrm{CO}_{2}$. Para ello, se realiza una segunda extracción (líquido-líquido) del extracto en condiciones ambientales para obtener el producto final. Se analiza la influencia de las variables de operación del proceso y se desarrolla un modelo matemático para ayudar a la optimización del proceso. El propósito final es contribuir a la valorización de los subproductos de la industria del tabaco Virginia.

\section{Materiales y Métodos}

\subsection{Materia prima e insumos}

Para los experimentos de extracción con $\mathrm{CO}_{2}$ se usó scrap de tabaco, un subproducto del proceso de despalillado de la hoja de tabaco de Virginia. El scrap está constituido por trozos de hoja de tabaco de menos de $25 \mathrm{~mm}$. Este material fue suministrado por la Cooperativa de Productores Tabacaleros de la Provincia de Salta (CO.PRO.TAB.).

El scrap fue molido en un molino de cuchillos Retsch SM100 que tiene un tamiz integrado para obtener un tamaño de partícula promedio de $500 \mu \mathrm{m}$. Los estándares de solanesol (> 90\% HPLC) y nicotina (99\% GC) fueron proporcionados por Sigma-Aldrich Mientras que el $\mathrm{CO}_{2}$ líquido fue proporcionado por Carburos Metálicos. Se utilizaron los siguientes disolventes de grado analítico: $\mathrm{n}$-Hexano (95\%), éter de petróleo $\left(60-80{ }^{\circ} \mathrm{C}\right)$ y etanol absoluto.

\subsection{Extracción con $\mathrm{CO}_{2}$ supercrítico}

La extracción supercrítica se llevó a cabo en una planta piloto con recirculación de $\mathrm{CO}_{2}$ cuyo esquema se puede ver en la Figura 1. La planta piloto tiene un extractor de 5 L, una válvula reguladora de contrapresión GO (BP-66), una bomba de diafragma Dosapro (MB 140 SL-10) -que permite operar hasta una presión de 40 MPa y un caudal máximo de hasta 15 kg.h-1-, y un separador donde se recoge el extracto. El flujo másico de $\mathrm{CO}_{2}$ se midió con un medidor de flujo tipo Coriolis de REHONIK (RHM-03). 
Tabla 1: Algunos trabajos previos sobre extracción con $\mathrm{CO}_{2}$ supercrítico de tabaco

\begin{tabular}{|c|c|c|c|c|c|c|c|c|c|c|}
\hline Materia Prima & Cantidad & $\begin{array}{l}\text { Tamaño } \\
\text { de } \\
\text { partícula } \\
\quad(\mu \mathrm{m})\end{array}$ & $\begin{array}{l}\text { Densidad } \\
\mathrm{CO}_{2} \\
(\mathrm{~kg} / \mathrm{m} 3)\end{array}$ & $\mathrm{P}, \mathrm{T}$. & $\begin{array}{c}\text { Caudal } \\
\mathrm{CO}_{2}\end{array}$ & $\begin{array}{c}\text { Solanesol } \\
\text { (mg/mg } \\
\text { extracto) }\end{array}$ & $\begin{array}{l}\text { Nicotina } \\
\text { (mg/mg } \\
\text { extracto) }\end{array}$ & $\begin{array}{c}\text { Extracto } \\
\text { (g/kg } \\
\text { Materia. } \\
\text { Prima) }\end{array}$ & Escala & Ref. \\
\hline Hojas & $14 \mathrm{~cm}^{3}$ & 425 & $605-880$ & $\begin{array}{l}\text { 8- } 25 \mathrm{MPa} \\
25-60^{\circ} \mathrm{C}\end{array}$ & $3,5 \mathrm{~g} / \mathrm{min}$ & $\begin{array}{c}0,104- \\
0,294\end{array}$ & $\begin{array}{c}0,012- \\
0,049\end{array}$ & s.d. & Lab. & [20] \\
\hline Scrap & $7 \mathrm{~g}$ & $\begin{array}{l}150-200 \\
200-300 \\
300-800\end{array}$ & $222-910$ & $\begin{array}{c}10-30 \\
\mathrm{MPa} \\
40-80^{\circ} \mathrm{C}\end{array}$ & 1-2 LPM & $\begin{array}{c}0,045- \\
0,125\end{array}$ & - & $7-48,8$ & Lab. & [21] \\
\hline $\begin{array}{l}\text { Scrap + polvo } \\
\text { (Residuos de } \\
\text { las hojas) }\end{array}$ & $100 \mathrm{~g}$ & $200-1000$ & $500-900$ & $\begin{array}{c}15-30 \\
\mathrm{MPa} \\
40-70^{\circ} \mathrm{C}\end{array}$ & 0,1-1 LPM & - & 0,0039 & s.d. & Lab. & [22] \\
\hline Scrap & $600 \mathrm{~g}$ & 500 & $781-940$ & $\begin{array}{c}15-37 \\
\mathrm{MPa} \\
40-58{ }^{\circ} \mathrm{C}\end{array}$ & $\begin{array}{c}120-310 \\
\mathrm{~g} / \mathrm{min}\end{array}$ & $\begin{array}{c}0,205- \\
0,230\end{array}$ & $\begin{array}{c}0,029- \\
0,044\end{array}$ & $34,5-99,4$ & Piloto & $\begin{array}{c}\text { Este } \\
\text { trabajo }\end{array}$ \\
\hline
\end{tabular}


La secuencia del proceso es la siguiente: El material vegetal se carga en una cesta con un diámetro interno de $100 \mathrm{~mm}$ y $486 \mathrm{~mm}$ de largo dentro del extractor. El extractor se cierra con una tapa cónica mediante un sistema hidráulico que proporciona suficiente presión para evitar las fugas de $\mathrm{CO}_{2}$. Una vez que el extractor está sellado, el sistema se presuriza con $\mathrm{CO}_{2}$ líquido que proviene de una batería de botellas de $\mathrm{CO}_{2}$. Una vez que el sistema se ha llenado con $\mathrm{CO}_{2}$ líquido, el extractor se presuriza con el $\mathrm{CO}_{2}$ bombeado y al mismo tiempo se calienta a la temperatura de extracción. Este calentamiento se realiza con un calentador eléctrico que calienta la tubería desde la bomba hasta el extractor, y un calentador eléctrico que calienta el cuerpo del extractor. Cuando se alcanza el valor de presión deseado se abre la válvula reguladora provocando una caída de la presión del disolvente, transformándolo en fase gaseosa. Así, cuando entra en el separador, el extracto precipita debido a la baja densidad del $\mathrm{CO}_{2}$ gaseoso. El separador tiene una válvula esférica en la parte inferior que permite la recuperación del extracto a medida que se realiza la extracción y, de esta manera, se puede ir obtenido los datos para la determinación las curvas de extracción. El $\mathrm{CO}_{2}$ gaseoso sale del separador a una presión de unos $5 \mathrm{MPa}$ y entra en un condensador que permite licuarlo -bajando su temperatura- permitiendo que el sistema funcione en un circuito cerrado.

En pruebas preliminares se observó que después de 3 horas de extracción se recuperó el 95\% del extracto y para extraer el 5\% restante fue necesario emplear 3 horas adicionales. Por esta razón, el tiempo de extracción de las pruebas se fijó en 3 horas. Los experimentos se realizaron con $300 \mathrm{~g}$ y $600 \mathrm{~g}$ de materia prima con una densidad de lecho normal $(200 \mathrm{~kg} / \mathrm{m} 3)$ y con una alta densidad de lecho $(280 \mathrm{~kg} / \mathrm{m} 3)$ que se logró mediante la compactación manual.

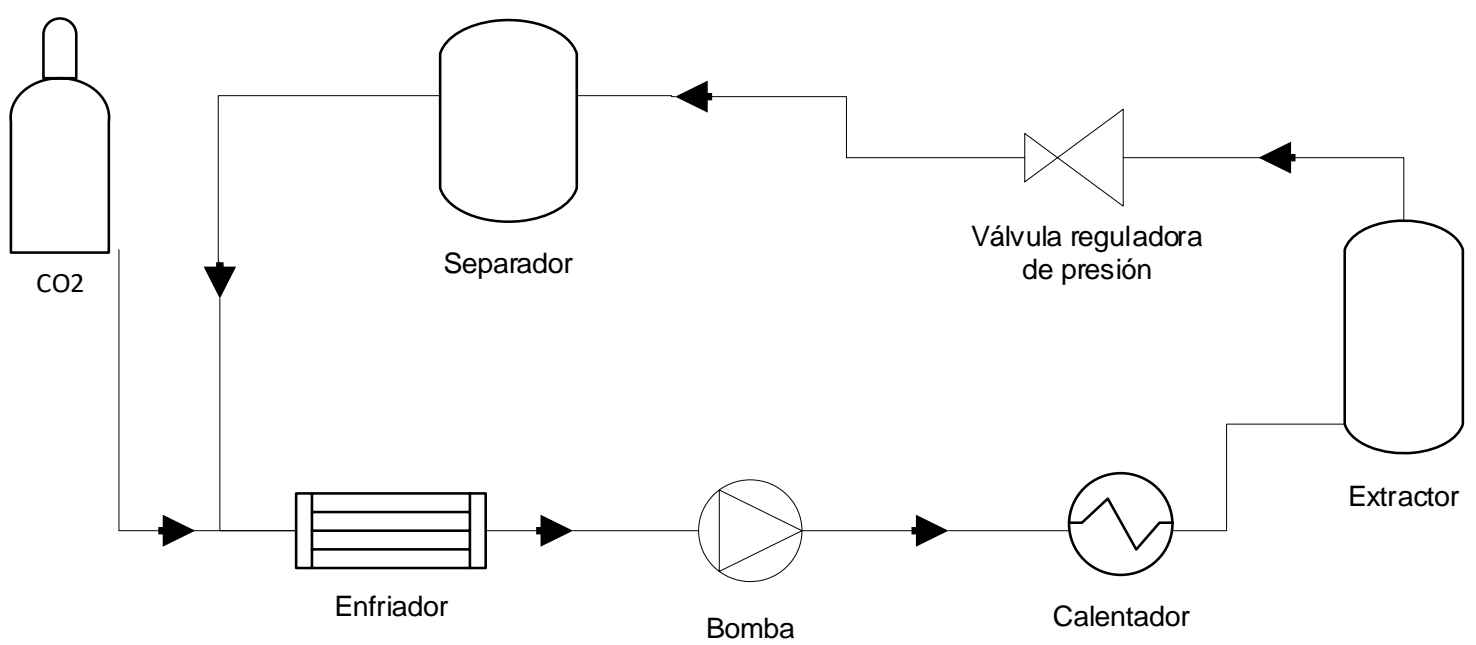

Figura 1. Esquema de la planta piloto de extracción 


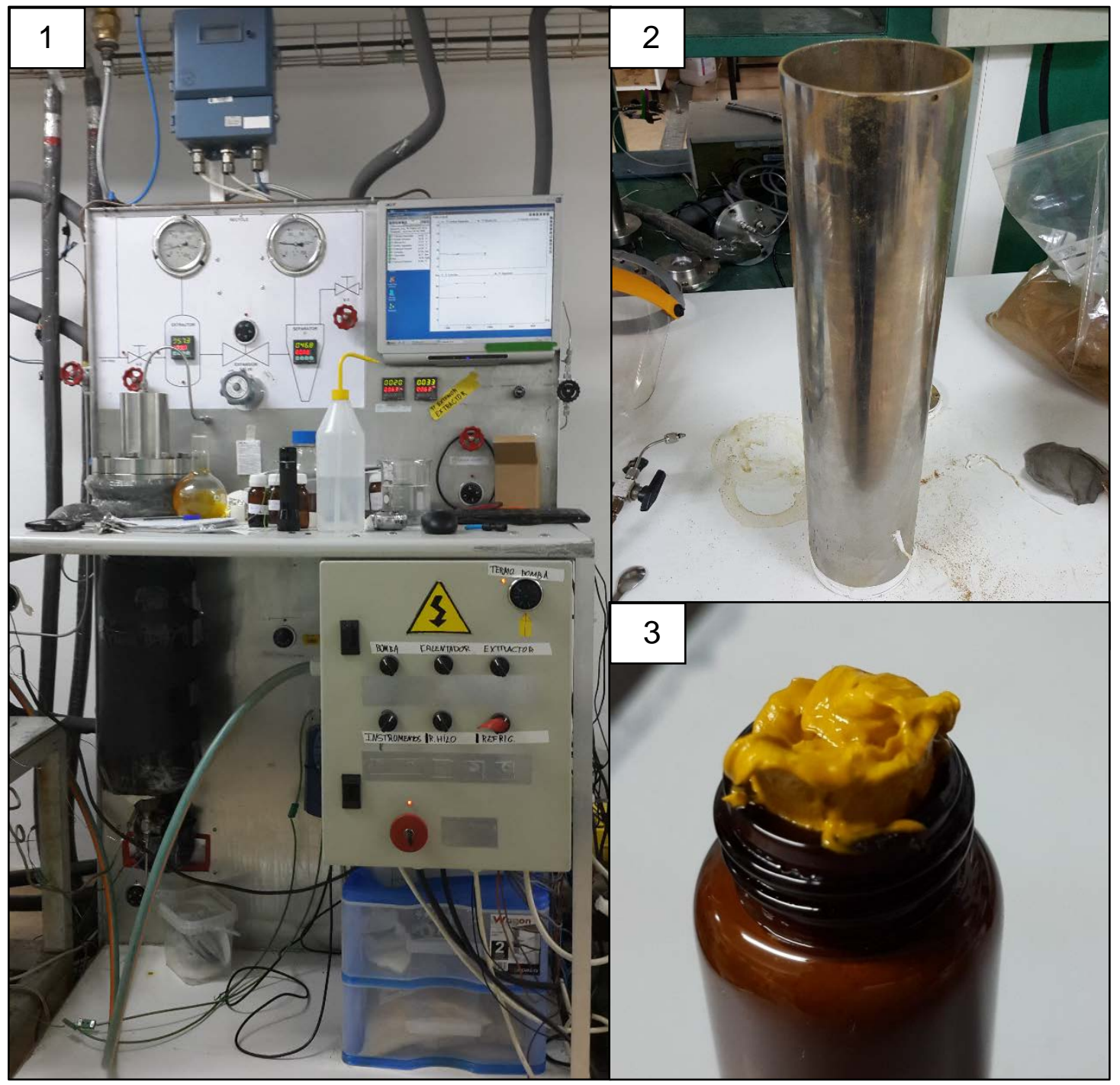

Figura 2.(1) Imagen de la planta piloto de $\mathrm{CO}_{2} \mathrm{SC}$ de la UVa.

(2) Imagen de la cesta.(3) Extracto de tabaco.

\subsection{Extracción líquido-líquido y fraccionamiento}

La extracción líquido-líquido se llevó a cabo sobre la base del método propuesto por $\mathrm{Hu}$ et al. [23]. En este trabajo, el extracto obtenido con $\mathrm{CO}_{2}$ supercrítico se somete a una extracción líquido-líquido con éter de petróleo y etanol para separar el solanesol de la nicotina. Este procedimiento difiere del de Hu que realiza una extracción sólidolíquido del residuo de tabaco con diferentes proporciones de éter de petróleo y etanol y luego eluye la solución en una columna cromatográfica.

La extracción líquido-líquido consistió en disolver $10 \mathrm{~g}$ del extracto en $300 \mathrm{~mL}$ de etanol (ajustado a pH 2 con $\mathrm{HCl}$ ) a $32{ }^{\circ} \mathrm{C}$ durante 3 horas con un agitador magnético. Luego se añadieron $200 \mathrm{~mL}$ de éter de petróleo y se continuó agitando durante 3 horas más. Esta mezcla se colocó en un embudo de decantación. El extracto se mantuvo homogéneo hasta que se añadió el 1 \% v/v de agua e inmediatamente se separó en dos fases. 
La fase etanol-agua se lavó 3 veces con $50 \mathrm{~mL}$ de éter mediante una agitación suave en un embudo de separación y finalmente todo el etanol se evaporó a $60{ }^{\circ} \mathrm{C}$ en un evaporador rotativo. Al residuo del rotavapor se le añadió agua con pH 10 para eliminar la nicotina. Se eliminó el agua y el residuo restante se disolvió con éter de petróleo y esta solución se añadió a la fase de éter de la primera parte de la extracción líquido-líquido.

El procedimiento utilizado en este trabajo busca separar la nicotina del solanesol en el extracto. Hu et al. [23] demostraron que en el primer paso de la separación líquidolíquido prácticamente toda la nicotina (98\%) se transfiere a la fase etanol-agua cuando se acidifica $(\mathrm{pH}=2)$ y prácticamente todo el solanesol (96\%) se extrae en la fase orgánica cuando el pH de la fase acuosa está en el mismo valor.

\subsection{Caracterización del extracto}

La humedad residual de la materia prima se determinó midiendo la reducción de peso de $5 \mathrm{~g}$ de muestra después de $3 \mathrm{~h}$ de secado a 99,5 ${ }^{\circ} \mathrm{C}$. La concentración de nicotina en las muestras obtenidas por extracción de fluido supercrítico se midió mediante cromatografía de gases con un detector de ionización de llama (GC / FID 7890A / G1888A Agilent) utilizando una columna HP-5 (longitud: 30 m, diámetro interior: $32 \mathrm{~mm}$, espesor de película: $25 \mathrm{~mm}$ ) y helio como gas portador a un caudal de 20 $\mathrm{mL} / \mathrm{min}$. La temperatura del inyector fue de $300^{\circ} \mathrm{C}$. Se utilizó una rampa de temperatura en el horno de la siguiente manera: $50^{\circ} \mathrm{C}$ a $130^{\circ} \mathrm{C}$ a $5^{\circ} \mathrm{C} / \mathrm{min}, 130{ }^{\circ} \mathrm{C}$ a $250{ }^{\circ} \mathrm{C}$ a 20 ${ }^{\circ} \mathrm{C} / \mathrm{min}$, temperatura constante a $250^{\circ} \mathrm{C}$ durante $20 \mathrm{~min}$, y $250^{\circ} \mathrm{C}$ a $300^{\circ} \mathrm{C}$ a $10^{\circ} \mathrm{C} / \mathrm{min}$.

Los análisis cualitativos y cuantitativos de solanesol y nicotina se realizaron en un HPLC/DAD Alliance 2695 Waters con detector de UV y una columna Symmetry C18 (Waters, tamaño de las partículas: $5 \mathrm{~mm}$, Diámetro interno de la columna: 4,6 mm, longitud de la columna: $150 \mathrm{~mm}$ ).

La concentración de solanesol, tanto en las muestras obtenidas por extracción supercrítica como en las obtenidas por extracción con disolvente, se determinó utilizando una fase móvil compuesta por una mezcla de acetonitrilo:2-propanol (60:40 $\mathrm{v} / \mathrm{v}$ ) a $1 \mathrm{~mL} / \mathrm{min}$, y un detector de UV ajustado a una longitud de onda de $210 \mathrm{~nm}$.

La concentración de nicotina obtenida en la extracción líquido-líquido se analizó utilizando una fase móvil de una solución acuosa de metanol: 2-propanol de trietilamina al 0,2\% (4:6,v/v) a un flujo de 0,8 $\mathrm{mL} / \mathrm{min}$ y se detectó a $254 \mathrm{~nm}$. Todas las muestras se filtraron a través de un filtro de membrana de 0,45 $\mathrm{m}$ antes de la inyección. 


\subsection{Modelado fenomenológico de la extracción supercrítica}

El modelo matemático desarrollado por Cabeza et al. [24] se utilizó para modelar las curvas de extracción obtenidas durante los experimentos. Este modelo se basa en la descripción del proceso de extracción presentada por García et al. [25] que considera tres etapas de separación. La primera etapa de extracción está controlada por el transporte externo, la segunda etapa está controlada tanto por el transporte externo como por la difusión interna, y la tercera etapa está controlada por la difusión interna. Basándose en esta descripción, Cabeza at al. [24] definieron un coeficiente de transferencia de masa global presentado en la ecuación 1 . En esta ecuación, $k_{S C F} \cdot a_{S C F}$ caracteriza la transferencia de masa durante la etapa de transferencia de masa externa, que es el mecanismo de control hasta el tiempo $t_{C}, \mathrm{y} k_{S}$. $a_{S}$ es el coeficiente de transferencia de masa interna, que es la etapa de control durante los últimos pasos de la extracción a partir del tiempo $t_{C_{2}}$. En el rango intermedio entre el tiempo $t_{C_{1}}$ y $t_{C_{2}}$ ambos mecanismos son significativos y el factor $F$ representa si esta etapa intermedia es controladora del proceso de extracción global: con $\mathrm{F}=0$, esta etapa no es significativa, mientras que con $\mathrm{F}=1$ esta etapa intermedia, en la que los pasos de difusión interna y externa son mecanismos de control durante la extracción, es la etapa predominante.

$$
K . a=\frac{k_{S C F} \cdot a_{S C F} \cdot\left(\frac{F}{1+e^{-\left(t-t_{c_{1}}\right)}}\right)}{1+e^{\left(t-t_{C_{2}}\right)}}+\frac{k_{S} \cdot a_{S}}{1+e^{\left(t-t_{C_{2}}\right)}}
$$

El coeficiente de transferencia de masa se correlacionó con la curva de extracción experimental mediante la minimización de la Desviación Media Absoluta (DMA) entre los resultados experimentales y los calculados, definida en la ecuación 2. Además, se calculó el coeficiente de correlación $\mathrm{R}^{2}$ tal como se define en la ecuación 3 , para caracterizar mejor la concordancia entre los experimentos y los cálculos.

$$
\begin{aligned}
& \text { A.A.D. }=\sum_{i=1}^{n} \frac{1}{n} \frac{\left|x_{i E X P}-x_{i S I M}\right|}{x_{i E X P}} \cdot 100 \\
& R^{2}=\frac{\sum(x-\bar{x})(y-\bar{y})}{\sum(x-\bar{x})^{2} \sum(y-\bar{y})^{2}}
\end{aligned}
$$

\section{Resultados y discusión}

\subsection{Extracción con $\mathrm{CO}_{2}$ supercrítico}

En la Tabla 2 se presentan los experimentos de extracción realizados junto con los principales resultados obtenidos en relación con el rendimiento total de la extracción 
y la concentración de solanesol y nicotina en el extracto. Como parámetros clave del proceso, se consideraron tres densidades de $\mathrm{CO}_{2}: 781 \mathrm{~kg} / \mathrm{m} 3,882$ kg/m3 y 940 kg/m3. $\mathrm{La}$ cantidad de materia prima utilizada en el experimento fue de $300 \mathrm{~g}$ o $600 \mathrm{~g}$. Además, también se analizó la influencia de la compactación del lecho: en algunos experimentos el lecho se compactó mediante presión manual, mientras que en otros se consideró un lecho con su porosidad espontánea sin compactación. En ambos casos el volumen final de la cama se midió posteriormente. Los experimentos 1 y 2 se realizaron por duplicado para comprobar la reproducibilidad; la tabla 3 presenta la desviación media absoluta de estos experimentos.

Como se presenta en el cuadro 2, los rendimientos de extracción aumentan en todos los casos cuando se compacta el lecho. Una posible razón de este resultado puede ser una modificación de la relación de disolventes $\left(\mathrm{kg} \mathrm{CO}_{2} / \mathrm{h} / \mathrm{kg}\right.$ de materia prima) cuando se compacta el lecho porque, como ha señalado Brunner [28], a altas relaciones de disolventes el tiempo de residencia dentro del extractor disminuye, con lo que se reduce el rendimiento de la extracción. De hecho, analizando los resultados en los experimentos en los que el lecho no fue compactado (exp. 4, 7 y 8 ) se puede observar que el rendimiento disminuye a medida que aumenta la relación de disolventes. De manera similar, en los experimentos en los que el lecho fue compactado (exp. 2, 5, 6 y 9) el rendimiento disminuyó al aumentar la proporción de disolvente. Sin embargo, si se comparan los resultados obtenidos en las mismas condiciones de funcionamiento con y sin compactación (exp. 1 y 3, exp. 2 y 4 , exp. 5 y 7, exp. 6 y 8) se observa en todos los casos la tendencia opuesta, lo que indica que este parámetro no justifica el resultado observado.

Una posible explicación alternativa de los menores rendimientos observados en los experimentos sin compactación del lecho podría ser que la agregación suelta del lecho en los experimentos sin compactación facilita que el lecho se rompa durante el experimento y promueve la generación de espacios vacíos en los recipientes que actúan como canales preferenciales.

Además, los rendimientos disminuyen drásticamente cuando la cantidad de materia prima utilizada se reduce a $300 \mathrm{~g}$. Con esta cantidad menor, un espacio importante del recipiente extractor queda vacío y se puede promover aún más la generación de vías de acceso directo. Por otro lado, se observa que el rendimiento de la extracción aumenta cuando se incrementa la presión o la temperatura. En particular, la temperatura aparece como un parámetro significativo que determina el rendimiento de extracción mientras que la densidad, que combina la influencia de la temperatura y la presión, no tiene una influencia clara como parámetro independiente porque el experimento 9 , con una densidad de $940 \mathrm{~kg} / \mathrm{m}^{3}$, produjo rendimientos más bajos que el 
experimento 1, realizado con una densidad menor de $882 \mathrm{~kg} / \mathrm{m}^{3}$, pero una temperatura mayor de $58{ }^{\circ} \mathrm{C}$. Esta observación puede explicarse mejor considerando los resultados presentados en la figura 2, en la que se comparan las curvas de extracción obtenidas a diferentes densidades de $\mathrm{CO}_{2}$. Los datos de los experimentos 1 y 2 de la figura 2 corresponden al promedio de los experimentos $1 \mathrm{a}$ con $1 \mathrm{~b}$ y $2 \mathrm{a}$ con $2 \mathrm{~b}$. Como se presenta en esta figura, las curvas de extracción obtenidas en los experimentos 1 y 9 son muy similares con pendientes iguales en la etapa lineal inicial de la curva de extracción que indican una solubilidad equivalente con esta combinación de valores de presión y temperatura, mientras que en el experimento 2 se observa una pendiente inicial más baja correspondiente a una solubilidad menor. La pendiente de la curva en la primera etapa no es perfectamente lineal, pero permanece constante dentro de ciertos límites.

Con respecto a la extracción de solanesol, los mejores resultados se obtuvieron con el experimento 4, que arrojó 33,33 g de solanesol/kg de materia prima operando a $15 \mathrm{MPa}$ y $40{ }^{\circ} \mathrm{C}$. En comparación con los resultados de la literatura, se obtuvo una relación de 12,29 $\mathrm{g}$ de solanesol/g de nicotina en el experimento $6\left(781 \mathrm{~kg} / \mathrm{m} 3,40{ }^{\circ} \mathrm{C}\right.$, $15 \mathrm{MPa}$ ), que es muy similar al valor de 12,20 obtenido por Ruiz-Rodríguez y otros [20] en un experimento de extracción realizado en condiciones similares $\left(781 \mathrm{~kg} / \mathrm{m} 3,40{ }^{\circ} \mathrm{C}\right.$, $15 \mathrm{MPa}$ ). Con respecto a la extracción de nicotina, los mejores resultados se obtuvieron con las condiciones del experimento $5\left(37 \mathrm{MPa}, 58^{\circ} \mathrm{C}\right)$. Por último, si el objetivo es la maximización de la selectividad de la extracción expresada como la relación entre la cantidad de solanesol extraído y la cantidad de nicotina extraída, los mejores resultados se obtienen en el experimento $2\left(15 \mathrm{MPa}, 40^{\circ} \mathrm{C}\right)$ con una relación de aproximadamente 17.

Estos resultados sugieren que una posible estrategia para obtener la mayor cantidad posible de solanesol y nicotina en una sola extracción podría consistir en realizar una extracción en dos etapas, con una primera etapa realizada a 15 MPa y 40 ${ }^{\circ} \mathrm{C}$ y una segunda etapa realizada a $37 \mathrm{MPa}$ y $58{ }^{\circ} \mathrm{C}$. Con este método se obtendrían dos fracciones de extracto, una primera con una elevada relación solanesol/nicotina y una segunda con una menor cantidad de solanesol y una elevada recuperación de nicotina. Posteriormente estos extractos se fraccionan como se describe en el apartado 2.3. 
Tabla 2. Experimentos de extracción supercrítica y rendimientos

\begin{tabular}{|c|c|c|c|c|c|c|c|c|c|c|c|c|}
\hline Exp. & $\begin{array}{l}\text { MP } \\
(\mathrm{g})\end{array}$ & $\begin{array}{c}\text { Densidad } \\
\mathrm{CO}_{2} \\
\left(\mathrm{~kg} / \mathrm{m}^{3}\right) \\
\end{array}$ & $\begin{array}{c}\text { Presión } \\
(\mathrm{MPa})\end{array}$ & $\begin{array}{l}\text { Temp. } \\
\left({ }^{\circ} \mathrm{C}\right)\end{array}$ & $\begin{array}{c}\text { Compactación } \\
\text { Lecho }\end{array}$ & $\begin{array}{c}\text { Caudal } \\
\mathrm{CO}_{2}(\mathrm{~kg} / \mathrm{h})\end{array}$ & $\begin{array}{c}\mathrm{CO}_{2} \\
\text { utilizado } \\
(\mathrm{kg})\end{array}$ & $\begin{array}{c}\text { Caudal } \\
\mathrm{CO}_{2} / \mathrm{kg} \\
\mathrm{MP} \\
\end{array}$ & $\begin{array}{l}\text { Extracto } \\
\text { (g/kg MP) }\end{array}$ & $\begin{array}{l}\text { Solanesol } \\
\text { (g/kg MP) }\end{array}$ & $\begin{array}{l}\text { Nicotina } \\
\text { (g/kg MP) }\end{array}$ & $\begin{array}{c}\text { Solanesol/ } \\
\text { Nicotina }\end{array}$ \\
\hline $1^{a}$ & 600 & 882 & 37 & 58 & Alta & 10,26 & 30,77 & 17,10 & 99,37 & 26,33 & 1,88 & 14,00 \\
\hline $2^{\mathrm{a}}$ & 600 & 781 & 15 & 40 & Alta & 16,38 & 49,13 & 27,73 & 64,17 & 17,05 & 0,96 & 17,76 \\
\hline $2^{b}$ & 600 & 781 & 15 & 40 & Alta & 14,33 & 43,00 & 23,88 & 53,60 & 16,13 & 0,97 & 16,63 \\
\hline 3 & 600 & 882 & 37 & 58 & Normal & 6,83 & 20,50 & 11,38 & 82,30 & 26,74 & s.d. & s.d. \\
\hline 5 & 300 & 882 & 37 & 58 & Alta & 11,67 & 35,00 & 38,90 & 60,02 & 17,52 & 2,10 & 8,34 \\
\hline 6 & 300 & 781 & 15 & 40 & Alta & 16,50 & 49,50 & 55,00 & 46,98 & 16,72 & 1,36 & 12,29 \\
\hline 7 & 300 & 882 & 37 & 58 & Normal & 7,83 & 23,50 & 26,10 & 43,50 & 11,44 & 1,52 & 7,52 \\
\hline 8 & 300 & 781 & 15 & 40 & Normal & 18,6 & 45,80 & 62,00 & 34,53 & 4,69 & 0,79 & 5,94 \\
\hline 9 & 600 & 940 & 37 & 40 & Alta & 8,57 & 25,70 & 14,28 & 72,51 & 20,08 & 1,23 & 16,32 \\
\hline
\end{tabular}

MP: Materia Prima, s.d.: sin datos., en los exp 3 y 4 la nicotina no pudo ser medida

Tabla 3. Desviación Media Absoluta (D.M.A.) de los experimentos 1 y 2 realizados por duplicado

\begin{tabular}{cccc}
\hline Experimento & $1^{\mathrm{a}}$ & $1^{\mathrm{b}}$ & $2^{\mathrm{a}}$ \\
\hline D.M. A. & $2,49 \%$ & $4,39 \%$ & $1,81 \%$ \\
\hline
\end{tabular}




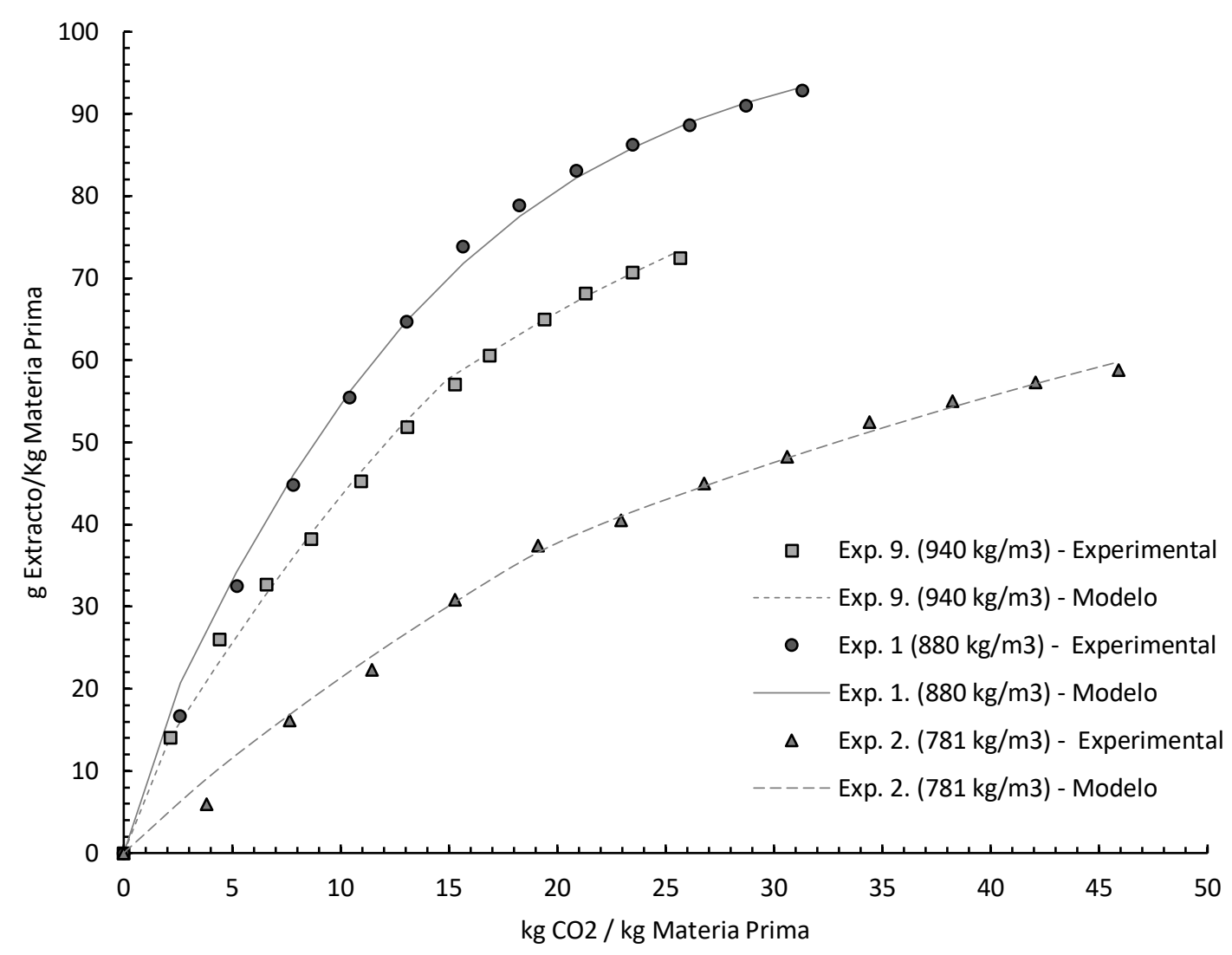

Figura 2. Curvas de extracción con diferentes densidades de $\mathrm{CO}_{2}$

\subsection{Modelado fenomenológico}

El modelo fenomenológico de la extracción de fluidos supercríticos desarrollado por Cabeza et al. [25] ha sido utilizado para modelar las curvas de extracción obtenidas. En la figura 2 se comparan las curvas de extracción experimental con los resultados del modelo. Como se presenta en esta figura, se obtiene una buena correlación entre los resultados experimentales y los del modelo. Esta observación se confirma con las mediciones de la Desviación Media Absoluta (D.M.A.) entre el rendimiento simulado $\left(X_{i S I M}\right)$ y el rendimiento experimental $\left(X_{i E X P}\right)$ del modelo que figura en el cuadro 4 , que muestran altos coeficientes de determinación (más de 0,99) y una D.M.A. pequeña (menos de 4,70\%).

Además de las curvas de extracción, el modelo permite calcular los perfiles de composición a lo largo de las fases sólida y fluida en función del tiempo. En la figura 3 se presentan resultados representativos de los experimentos 1 y 2 .

En lo que respecta a los perfiles de composición en la fase de fluido (Figura $3 \mathrm{~A}$ y B), comparando los resultados de los experimentos 1 y 2 se puede observar que mientras que en las condiciones experimentales 1 los perfiles de concentración disminuyen significativamente a lo largo del tiempo (en correspondencia con la reducción de la cantidad de soluto restante en el sólido), en las condiciones 
experimentales 2 se observa un perfil de composición más plano con el tiempo que permanece casi al valor de concentración máxima durante los primeros 50 minutos de extracción, lo que sugiere que en estas condiciones la concentración de solutos en $\mathrm{CO}_{2}$ está cerca de los valores de saturación.

Además, la correlación del modelo con las curvas de extracción experimental proporciona una estimación de las propiedades clave durante la extracción y, en particular, de la solubilidad y los coeficientes de transferencia de masa [24]. En principio, se espera que la solubilidad dependa de la densidad de los fluidos -que aumenta a mayores densidades de fluido- así como de la temperatura debido al efecto de la temperatura en la presión de sublimación. Las solubilidades experimentales se reportan en la Tabla 5. Estas solubilidades se calcularon como la relación entre la cantidad de extracto recuperado en el separador después de 15 min de extracción y la masa de $\mathrm{CO}_{2}$. Por otro lado, la Tabla 6 también da las solubilidades estimadas con el modelo matemático, que como las solubilidades experimentales se calcularon como la relación entre la cantidad de extracto predicho por el modelo después de 15 min de extracción y la masa de $\mathrm{CO}_{2}$. Se puede observar que las solubilidades experimental y estimada muestran un buen acuerdo. Además, como se presenta en la figura 2, se obtuvieron resultados similares en cuanto a la solubilidad en los experimentos 1 y 9 mientras que los resultados del experimento 2 indicaron un valor menor de solubilidad en estas condiciones. La tabla 6 también informa del coeficiente de partición $h$ definido como la relación entre la concentración del extracto en el sólido $C_{S}$ y la concentración en el fluido $C_{L}$ en el tiempo t (15 min), mientras que $V_{S}$ y $V_{L}$ son los volúmenes de las fases sólida y fluida, respectivamente, en este momento.

Por otro lado, la tabla 7 presenta los coeficientes de transferencia de masa estimados. Los experimentos de mayor rendimiento en la primera etapa de extracción, que son controlados por la solubilidad, muestran un tiempo $t_{C_{1}}$ más corto, como es el caso de los experimentos 1 y 3 . Los experimentos que produjeron un rendimiento menor, como el experimento 7 , muestran un valor $h$ menor y un coeficiente de transferencia de masa interna mayor que los experimentos con un rendimiento mayor.

Tabla 4. Comparación de los resultados del modelo versus resultados experimentales

\begin{tabular}{cccc}
\hline Experimento & 1 & 2 & 9 \\
\hline$D \cdot M \cdot A$. & $2,98 \%$ & $4,61 \%$ & $2,28 \%$ \\
$\mathrm{R}^{2}$ & 0,998 & 0,997 & 0,997 \\
\hline
\end{tabular}



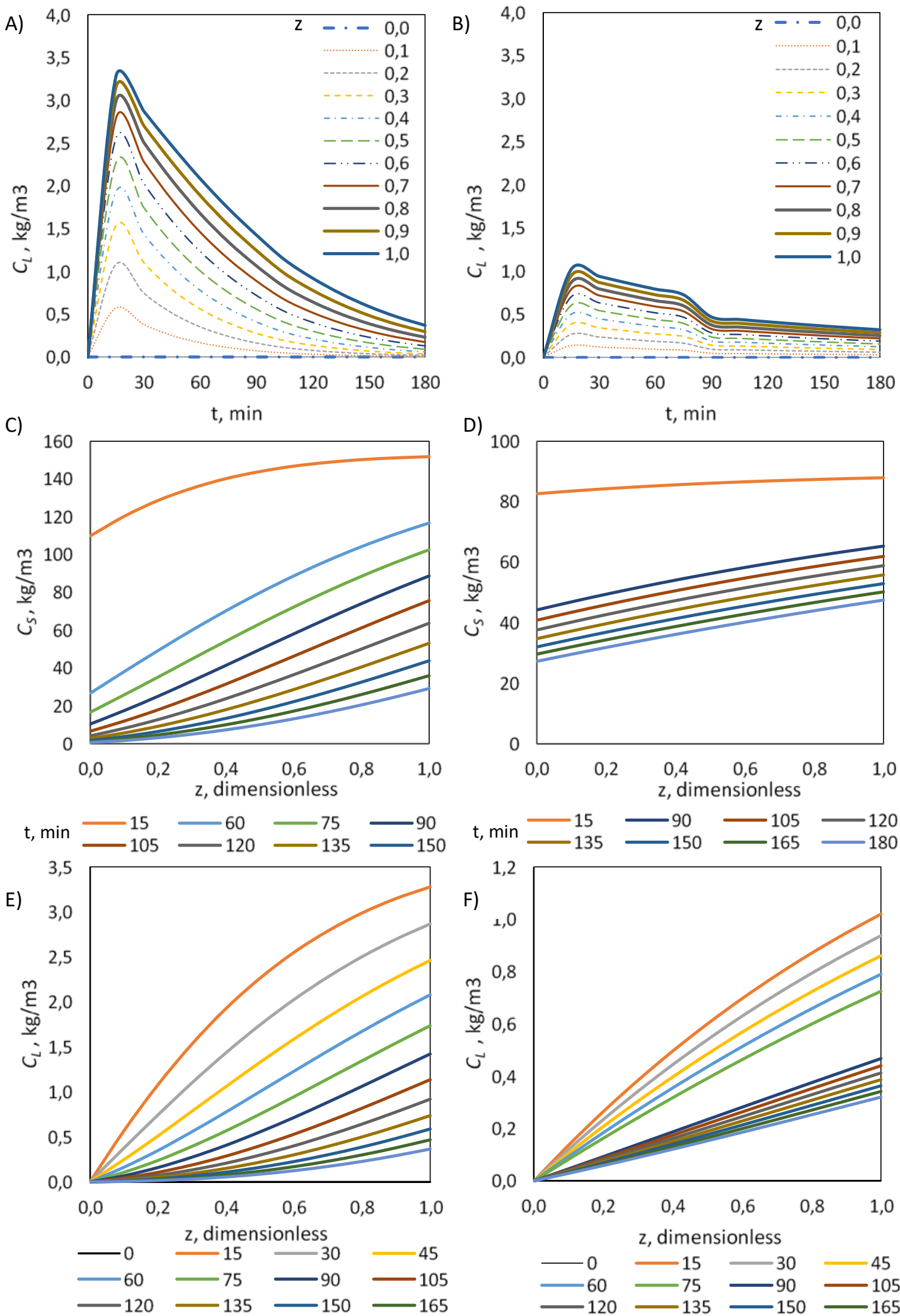

Figura 3. A) Concentración del extracto en función del tiempo en la fase supercrítica a lo largo del extractor para el experimento $1, z=0$ corresponde al fondo y $z=1$ en la parte superior del extractor. B) Ídem a A para el experimento 2. C) Concentración del extracto en la fase sólida en función de $z$, a lo largo del tiempo, para el experimento 1. D) Idem a C, para el experimento 2. E) Concentración del extracto en la fase supercrítica en función de $z$, a lo largo del tiempo, para el experimento 1. F) Idem a E, para el experimento 2. 
Tabla 5. Solubilidades experimentales estimadas

\begin{tabular}{cccccccc}
\hline Exp, & $\begin{array}{c}\text { Densidad } \\
\mathrm{CO}_{2} \\
(\mathrm{~kg} / \mathrm{m} 3)\end{array}$ & $\begin{array}{c}\mathrm{P} \\
(\mathrm{MPa})\end{array}$ & $\begin{array}{c}\mathrm{T} \\
\left({ }^{\circ} \mathrm{C}\right)\end{array}$ & $\begin{array}{c}\mathrm{t} \\
(\mathrm{min})\end{array}$ & $\begin{array}{c}\text { Extracto } \\
(\mathrm{kg})\end{array}$ & $\begin{array}{c}\mathrm{CO}_{2} \\
(\mathrm{~kg})\end{array}$ & $\left.\begin{array}{c}\mathrm{S}_{\text {experimental }} \\
(\mathrm{kg} \text { Ext/kg CO}\end{array}\right)$
\end{tabular}

Tabla 6. Solubilidades del extracto calculadas con los resultados del modelo

\begin{tabular}{cccccccccc}
\hline Exp. & $\begin{array}{c}\mathrm{T} \\
(\mathrm{min})\end{array}$ & $\begin{array}{c}\mathrm{Q} \mathrm{CO}_{2} \\
(\mathrm{~g} / \mathrm{min})\end{array}$ & $\begin{array}{c}\mathrm{CO}_{2} \\
(\mathrm{~kg})\end{array}$ & $\begin{array}{c}h \\
(\mathrm{adim})\end{array}$ & $\begin{array}{c}\mathrm{C}_{\mathrm{s}} \\
\left(\mathrm{kg} / \mathrm{m}^{3}\right)\end{array}$ & $\begin{array}{c}V_{\mathrm{S}} \\
\left(\mathrm{m}^{3}\right)\end{array}$ & $\begin{array}{c}\mathrm{C}_{L} \\
\left(\mathrm{~kg} / \mathrm{m}^{3}\right)\end{array}$ & $\begin{array}{c}V_{L} \\
\left(\mathrm{~m}^{3}\right)\end{array}$ & $\begin{array}{c}S_{\text {modelo }} \\
(\mathrm{kg} \mathrm{Ext} / \mathrm{kg} \\
\left.\mathrm{CO}_{2}\right)\end{array}$ \\
\hline 1 & 15 & 174 & 2,61 & 0,0240 & 151,77 & 0,00034 & 3,6425 & 0,00228 & 0,0032 \\
2 & 15 & 255 & 3,83 & 0,0205 & 87,96 & 0,00064 & 1,8032 & 0,00213 & 0,0010 \\
9 & 15 & 142 & 2,13 & 0,0260 & 108,81 & 0,00050 & 2,8291 & 0,00212 & 0,0028 \\
\hline
\end{tabular}

Tabla 7. Coeficientes de transferencia de masa estimados

\begin{tabular}{cccccccccccc}
\hline Exp. & $\begin{array}{c}\text { M.P. } \\
(\mathrm{kg})\end{array}$ & $\begin{array}{c}\text { Densidad } \\
\mathrm{CO}_{2} \\
\left(\mathrm{~kg} / \mathrm{m}^{3}\right)\end{array}$ & $\begin{array}{c}\mathrm{P} . \\
(\mathrm{MPa})\end{array}$ & $\begin{array}{c}\mathrm{T} . \\
\left({ }^{\circ} \mathrm{C}\right)\end{array}$ & $\begin{array}{c}k_{S C F}, a_{S C F} \\
\left(\mathrm{~min}^{-1}\right)\end{array}$ & $\begin{array}{c}k_{S}, a_{S} \\
\left(\mathrm{~min}^{-1}\right)\end{array}$ & $\begin{array}{c}t_{C_{1}} \\
(\mathrm{~min})\end{array}$ & $\begin{array}{c}t_{C_{2}} \\
(\mathrm{~min})\end{array}$ & $\begin{array}{c}F \\
(\operatorname{adim})\end{array}$ & $R^{2}$ & $\begin{array}{c}D . M . A . \\
(\%)\end{array}$ \\
\hline $1^{\mathrm{a}}$ & 0,6 & 882 & 37 & 58 & 0,170 & 0,160 & 60 & 90 & 1,00 & $9,98 \mathrm{E}-01$ & 2,98 \\
$2^{\mathrm{a}}$ & 0,6 & 781 & 15 & 40 & 0,099 & 0,060 & 50 & 80 & 1,00 & $9,97 \mathrm{E}-01$ & 4,61 \\
3 & 0,6 & 882 & 37 & 58 & 0,110 & 0,048 & 35 & 55 & 1,00 & $9,95 \mathrm{E}-01$ & 2,28 \\
4 & 0,6 & 781 & 15 & 40 & 0,298 & 0,055 & 20 & 100 & 1,00 & $9,98 \mathrm{E}-01$ & 2,75 \\
5 & 0,3 & 882 & 37 & 58 & 0,076 & 0,020 & 50 & 80 & 1,00 & $9,99 \mathrm{E}-01$ & 2,23 \\
6 & 0,3 & 781 & 15 & 40 & 0,129 & 0,045 & 30 & 90 & 1,00 & $9,98 \mathrm{E}-01$ & 2,82 \\
7 & 0,3 & 882 & 37 & 58 & 0,300 & 0,045 & 60 & 90 & 0,50 & $9,97 \mathrm{E}-01$ & 3,50 \\
8 & 0,3 & 781 & 15 & 40 & 0,079 & 0,032 & 15 & 55 & 1,00 & $9,95 \mathrm{E}-01$ & 3,89 \\
9 & 0,6 & 940 & 37 & 40 & 0,160 & 0,070 & 50 & 105 & 1,00 & $9,97 \mathrm{E}-01$ & 2,28 \\
\hline
\end{tabular}

\subsection{Fraccionamiento mediante extracción líquido-líquido}

Como se mencionó en el punto 2.3, el objetivo de los experimentos de extracción líquido-líquido era la separación de la nicotina y el solanesol obtenidos en los extractos. Como primer resultado, cabe mencionar que se observó la formación de una interfaz gelatinosa entre la fase orgánica y la acuosa en la que podía estar presente y perderse una cierta cantidad de extractos ya que esta fracción no podía ser recuperada y analizada.

En los análisis de HPLC de la fase de éter de petróleo no se detecta nicotina, por lo tanto, se puede concluir que la nicotina se elimina completamente de esta fase hasta una concentración inferior al límite de detección. Por otra parte, el solanesol se distribuye entre las dos fases: en la primera etapa de la separación, el 55 \% del solanesol permanece en la fase de etanol-agua y el $36 \%$ en la fase de éter de petróleo. Este 
resultado es coherente con los datos presentados por Liu et al. , [29], que demostraron que el solanesol es muy soluble en etanol, pero tiene una baja solubilidad en el éter.

Como se ha descrito anteriormente, tras la evaporación al vacío, la mezcla de nicotina y solanesol obtenida -luego de la eliminación del disolvente de la fase etanolagua- se extrajo con agua a pH 10 para extraer la nicotina, y el solanesol restante -tras la extracción de la nicotina- se combinó con el extracto éter. Luego de este proceso, se obtuvieron dos fracciones: la fracción éter, que contenía el 91\% de la cantidad inicial de solanesol en el extracto de $\mathrm{CO}_{2}$ y cuyo contenido de nicotina estaba por debajo del límite de detección, y la fase etanol-agua que contenía el 75\% de la cantidad inicial de nicotina.

\section{Conclusiones}

Se ha investigado la extracción supercrítica con $\mathrm{CO}_{2}$ del solanesol y la nicotina de los residuos del tabaco. La presión es un parámetro clave del proceso que determina el rendimiento y la selectividad de la extracción, porque el mayor rendimiento de extracción de solanesol (33,33 g de solanesol/kg de materia prima) se obtuvo a una presión de trabajo de $15 \mathrm{MPa}$, mientras que el mayor rendimiento de extracción de nicotina (2,10 g de nicotina/kg de materia prima) se obtuvo a una presión de funcionamiento más alta de $37 \mathrm{MPa}$. Además, estos resultados sugieren que una posible estrategia de operación para maximizar la cantidad de solanesol y nicotina en una sola extracción, puede llevarse a cabo en dos etapas. El primer paso a $15 \mathrm{MPa}$ y $40{ }^{\circ} \mathrm{C}$ y el segundo a $37 \mathrm{MPa}$ y $58^{\circ} \mathrm{C}$. Esta estrategia sería válida para la configuración del equipo utilizado en este trabajo, de un extractor y un separador, es decir, para otras configuraciones como un extractor seguido de dos separadores en línea, la estrategia sería diferente. Los resultados de la modelización indican que los mejores resultados se obtienen en condiciones en las que la extracción está limitada por la solubilidad. Tras un proceso de fraccionamiento líquido-líquido, se obtuvieron dos fracciones de productos: una fracción de éter que contiene el 91\% del solanesol extraído y una fracción alcohólica que contiene el $75 \%$ de la nicotina. Estos resultados demuestran la viabilidad de utilizar las fracciones de residuos de tabaco, como el scrap, como fuentes de compuestos valiosos y como medio de valorización de estas fracciones residuales. 


\section{Bibliografía}

[1] 2019 FAO, FAOSTAT. (2017). http://www.fao.org/faostat/en/\#data/QC (accedido en Marzo 2020).

[2] Ministerio de Agricultura de la Nación Argentina, Mercado interno, (2018). https://www.agroindustria.gob.ar/sitio/areas/tabaco/produccion_mercados/interno/i ndex.php (accedido en Marzo 2020).

[3] J.C. Leffingwell, Nitrogen components of leaf and their relationship to smoking quality and aroma, Recent Adv. Tob. Sci. 2 (1976) 1-31.

[4] C. Ministerio de Hacienda y Finanzas públicas de la nación Argentina, Tabaco, 1. 32 (2016). https://www.economia.gob.ar/peconomica/docs/SSPE_Cadenas\%20de\%20valor_ Tabaco.pdf (accedido en Marzo 2020

[5] T. Pang, C. Bai, Y. Xu, P.D.G. Xu, Z. Yuan, Y. Su, L. Peng, Determination of Sugars in Tobacco Leaf by HPLC with Evaporative Light Scattering Detection, J. Liq. Chromatogr. Relat. Technol. 29 (2006) 1281-1289.

[6] T. Rosales-Garcia, C. Jimenez-Martinez, G. Davila-Ortiz, Squalene Extraction: Biological Sources and Extraction Methods, Int. J. Environ. Agric. Biotechnol. 2 (2017) 1662-1670.

[7] P. Fantozzi, A. Sensidoni, Protein extraction from tobacco leaves: technological, nutritional and agronomical aspects, Plant Foods Hum. Nutr. 32 (1983) 351-368.

[8] W. Huang, Z. Li, H. Niu, J. Wang, Y. Qin, Bioactivity of solanesol extracted from tobacco leaves with carbon dioxide-ethanol fluids, Biochem. Eng. J. 42 (2008) 9296.

[9] M. Fischer, T.M. Jefferies, Optimization of Nicotine Extraction from Tobacco Using Supercritical Fluid Technology with Dynamic Extraction Modeling, J. Agric. Food Chem. 44 (1996) 1258-1264.

[10] N. Yan, Y. Liu, D. Gong, Y. Du, H. Zhang, Z. Zhang, Solanesol: a review of its resources, derivatives, bioactivities, medicinal applications, and biosynthesis, Phytochem. Rev. (2015) 1-15.

[11] C. Zhao, Y. Zu, C. Li, C. Tian, Distribution of solanesol in Nicotiana tabacum, J. For. Res. 18 (2007) 69-72.

[12] S.R. Atla, B. Raja, B.R. Dontamsetti, A new method of synthesis of coenzyme Q10 from isolated solanesol from tobacco waste, Int. J. Pharm. Pharm. Sci. 6 (2014) 499-502. 
[13] K. Hamamura, I. Yamatsu, N. Minami, Y. Yamagishi, Y. Inai, S. Kijima, T. Nakamura, Synthesis of [3'-14C] coenzyme Q10, J. Label. Compd. Radiopharm. 45 (2002) 823829.

[14] Y. Naruta, Regio- and stereoselective synthesis of coenzymes Qn ( $n=2-10)$, vitamin K, and related polyprenylquinones, J. Org. Chem. 45 (1980) 4097-4104.

[15] H.-S. Wu, J.-J. Tsai, Separation and purification of coenzyme Q10 from Rhodobacter sphaeroides, J. Taiwan Inst. Chem. Eng. 44 (2013) 872-878.

[16] Y. Tian, T. Yue, Y. Yuan, P.K. Soma, P.D. Williams, P.A. Machado, H. Fu, R.J. Kratochvil, C. Wei, Y.M. Lo, Tobacco biomass hydrolysate enhances coenzyme Q10 production using photosynthetic Rhodospirillum rubrum, Bioresour. Technol. 101 (2010) 7877-7881.

[17] L. Qiu, H. Ding, W. Wang, Z. Kong, X. Li, Y. Shi, W. Zhong, Coenzyme Q10 production by immobilized Sphingomonas sp. ZUTE03 via a conversion-extraction coupled process in a three-phase fluidized bed reactor, Enzyme Microb. Technol. 50 (2012) 137-142.

[18] M.A. Taylor, P.D. Fraser, Solanesol: Added value from Solanaceous waste, Phytochemistry. 72 (2011) 1323-1327. doi:10.1016/j.phytochem.2011.03.015.

[19] P.A. Machado, H. Fu, R.J. Kratochvil, Y. Yuan, T.-S. Hahm, C.M. Sabliov, C. Wei, Y.M. Lo, Recovery of solanesol from tobacco as a value-added byproduct for alternative applications, Bioresour. Technol. 101 (2010) 1091-1096.

[20] A. Ruiz-Rodriguez, M.-R. Bronze, M.N. da Ponte, Supercritical fluid extraction of tobacco leaves: A preliminary study on the extraction of solanesol, J. Supercrit. Fluids. 45 (2008) 171-176.

[21] Y. Wang, W. Gu, Study on supercritical fluid extraction of solanesol from industrial tobacco waste, J. Supercrit. Fluids. 138 (2018) 228-237.

[22] J. Rincón, A.D. Lucas, M.A. García, A. García, A. Alvarez, A. Carnicer, Preliminary Study on the Supercritical Carbon Dioxide Extraction of Nicotine from Tobacco Wastes, Sep. Sci. Technol. 33 (1998) 411-423.

[23] R.-S. Hu, J. Wang, H. Li, H. Ni, Y.-F. Chen, Y.-W. Zhang, S.-P. Xiang, H.-H. Li, Simultaneous extraction of nicotine and solanesol from waste tobacco materials by the column chromatographic extraction method and their separation and purification, Sep. Purif. Technol. 146 (2015) 1-7.

[24] A. Cabeza, F. Sobrón, J. García-Serna, M.J. Cocero, Simulation of the supercritical $\mathrm{CO}_{2}$ extraction from natural matrices in packed bed columns: User-friendly simulator tool using Excel, J. Supercrit. Fluids. 116 (2016) 198-208. 
[25] G García-Serna, M.J. Cocero Mathematical model of supercritical extraction applied to oil seed extraction by $\mathrm{CO}_{2}+$ saturated alcohol - I. desorption model. Journal of Supercritical Fluids, 20(3), (2001) 229-243.

[26] P. A. Newhouse, A. Potter, M. Kelton, y J. Corwin, «Nicotinic treatment of Alzheimer's disease», Biological Psychiatry, vol. 49, n.o 3, pp. 268-278, feb. 2001.

[27] M. C. Kelton, H. J. Kahn, C. L. Conrath, y P. A. Newhouse, «The effects of nicotine on Parkinson's disease», Brain Cogn, vol. 43, n.o 1-3, pp. 274-282, ago. 2000.

[28] G. Brunner, «Gas Extraction». Springer, 1994.

[29] J.-C. Liu, D.-Q. Li, R.-Q. Zhou, y F. Hao, «Solubilities of solanesol in acetonitrile, ethanol and n-hexane from 285 to $310 \mathrm{~K} »$, Korean J. Chem. Eng., vol. 24, n.o 1, pp. 113-115, ene. 2007. 


\section{Información Complementaria}




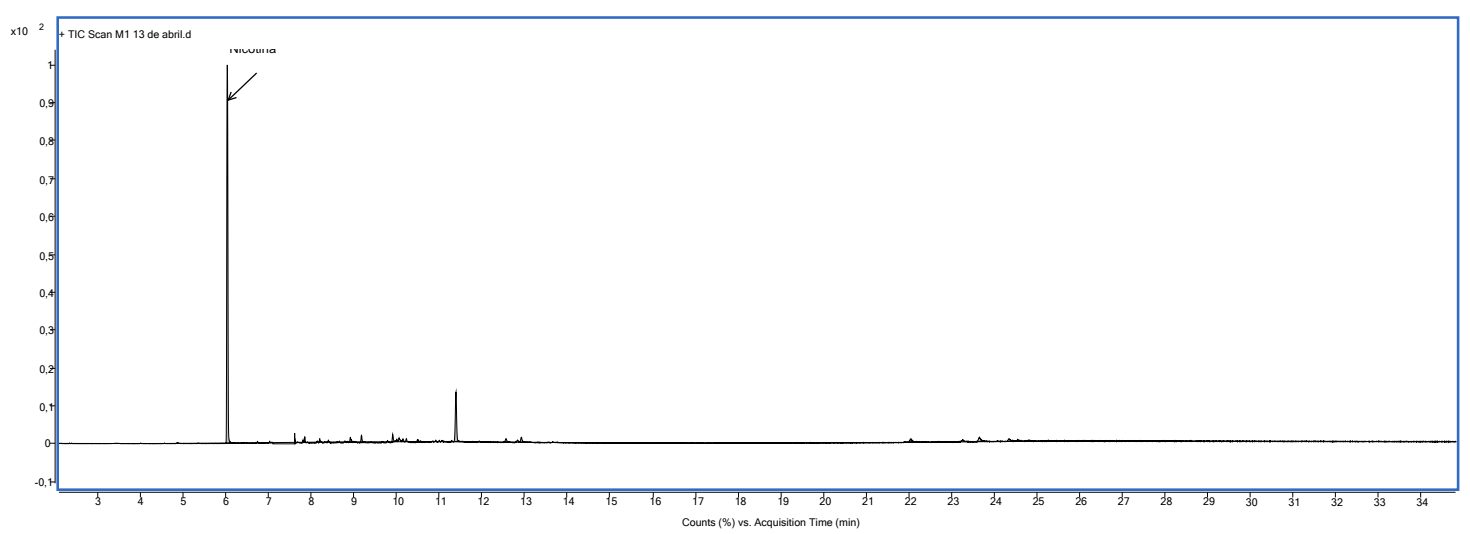

Figura 1. Cromatograma de la fase Agua-EtOH (muestra 1) de la separación líquido-líquido. El pico de nicotina corresponde al $75 \%$ de la nicotina presente en la muestra original

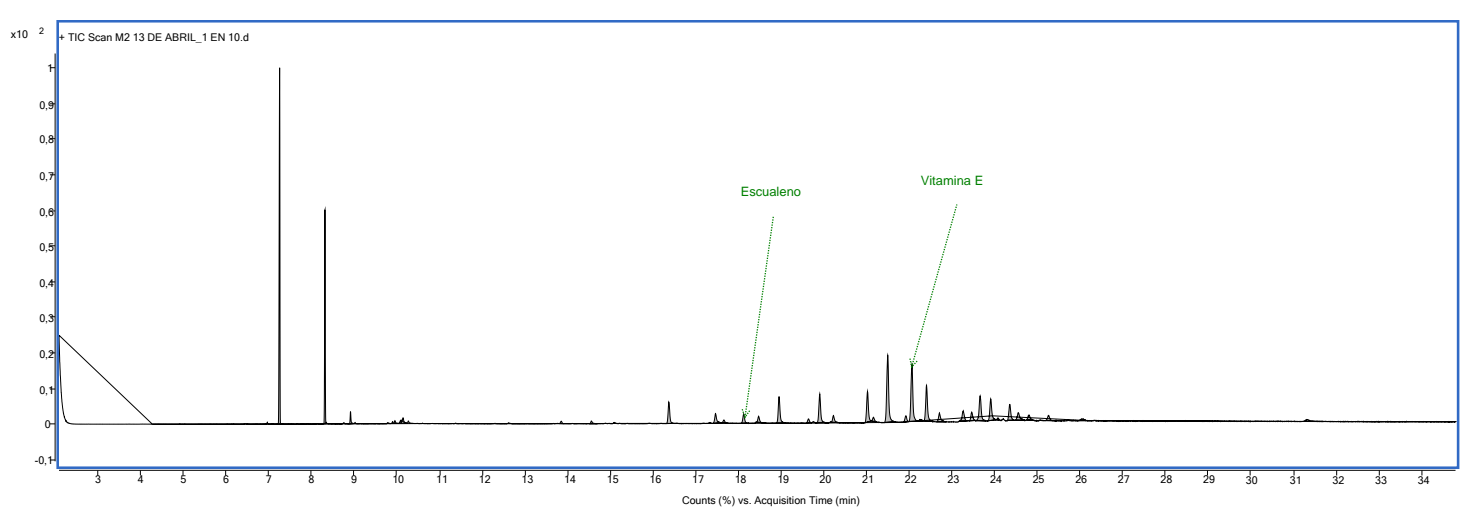

Figura 2. Cromatograma de la fase con éter (muestra 2) de la separación líquido-líquido. Sin presencia de nicotina. Se detectó Escualeno y Vitamina E en la misma muestra

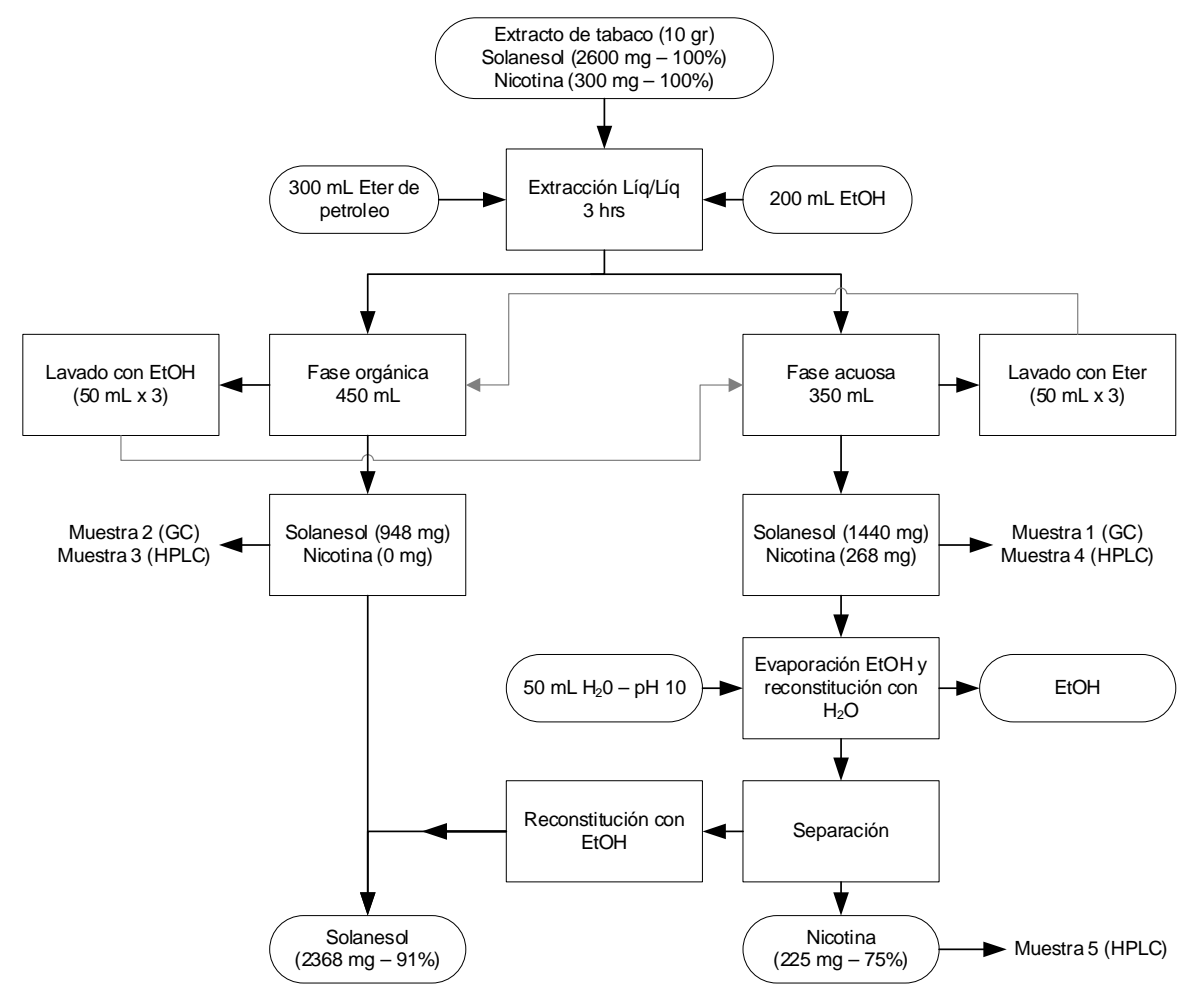

Figura 3. Balance de masa de la separación líquido-líquido 


\section{Capítulo III.}

Hidrólisis ultrarrápida en Agua Supercrítica

(ASC) de la fracción lignocelulósica del

scrap de tabaco Virginia 


\section{Introducción}

\subsection{Integración del proceso de hidrólisis a una biorrefinería de scrap}

En el Capítulo I se presentaron las consideraciones por las cuales se presenta al tabaco y sus subproductos (scrap, palos y tallos) como una materia prima idónea para una biorrefinería. Se destaca la disponibilidad centralizada de gran cantidad de biomasa en las provincias del noroeste argentino y la composición química de esta biomasa. La composición química del tabaco se podría agrupar en 2 categorías para direccionar su posterior uso. La primera categoría estaría conformada por principios activos de alto valor para extracción, y la segunda por carbohidratos estructurales para hidrólisis.

En el Capítulo II, se desarrolló la extracción con $\mathrm{CO}_{2} \mathrm{SC}$ de dos de los principios activos más importantes como solanesol y nicotina. Se obtuvieron altos rendimientos y mediante una sencilla operación de separación se pudieron obtener fracciones del extracto enriquecidos en cada uno de los dos principios activos mayoritarios.

En este capítulo se encara, mediante un proceso eficiente y amigable con el medio ambiente, la valorización de los subproductos del tabaco mediante la hidrólisis de los carbohidratos estructurales para la obtención de azúcares fermentables.

La primera ventaja para el uso del scrap y los palos del tabaco Virginia es la composición química. El scrap y los palos tienen entre el 50 y el $60 \%$ w/w de su composición formada por componentes fácilmente extraíbles en agua y el resto, son los carbohidratos estructurales (celulosa, hemicelulosa y lignina). Los componentes fácilmente extraíbles son azúcares reductores, proteínas y pectina. Los azúcares reductores son uno de los factores más importantes para determinar la calidad del tabaco virginia curado para usarlo para la fabricación de cigarrillos. Por esta razón existen métodos analíticos estándar para su determinación [1-2] y numerosas publicaciones que buscan mejorar la extracción de estos azúcares [3]-[6]. En líneas generales, del total de extraíbles, más de la mitad es sacarosa, seguido por glucosa y fructosa.

Con respecto a la celulosa, hemicelulosa y lignina, la distribución porcentual de estos cambia considerablemente entre el scrap, y los palos y el tallo. El scrap tiene más celulosa, poca hemicelulosa y menos lignina y, los palos junto con los tallos tienen porcentajes similares de celulosa y hemicelulosa y mucha más lignina. Debido a que la composición del tallo y los palos es similar a las materias primas forestales, se han evaluado usos para los tallos como pulpa para cartón [7], fabricación de briquetas [8] y obtención de xilo-oligosacáridos [9], entre otros. 
Los estudios realizados con procesos convencionales de hidrolisis optimizan la etapa de obtención de los azúcares fermentables para la posterior producción de etanol mediante fermentación con levaduras [10]. El microorganismo más utilizado en la producción industrial de etanol es la levadura Saccharomyces cerevisiae debido a su rápido crecimiento, y tolerancia al alcohol [11]. En su estado natural, esta levadura metaboliza glucosa, galactosa y sacarosa (C-6) y no asimila xilosa y arabinosa (C-5) entre otros nutrientes [12] Los principales productos obtenidos por la hidrólisis de biomasas lignocelulósicas son una combinación de hexosas (C-6) y pentosas (C-5) y en el caso de las biomasas ricas en sacarosa y/o almidón el principal producto obtenido son hexosas. Teniendo en cuenta esta última consideración, un segundo enfoque puede encontrarse en la literatura, y consiste en el desarrollo de cepas de Saccharomyces genéticamente modificadas para poder fermentar hexosas y pentosas [13].

Para este trabajo, se tuvo en cuenta, no solo la cantidad de azúcares disponibles para una posterior fermentación, sino también la obtención de otros productos para ser usados como plataformas intermedias y compuestos clave para la producción selectiva de compuestos para obtener otros productos con interés industrial.

Con este capítulo se completan los escenarios propuestos de una biorrefinería a base de scrap y palos de tabaco.

El objetivo de este trabajo es estudiar la viabilidad técnica de la utilización de la hidrólisis con agua supercrítica para comprender los productos que pueden obtenerse en una biorrefinería de residuos de tabaco. La biorrefinería considera la separación del compuesto activo utilizando tecnologías limpias, y la intensificación de los procesos, para obtener componentes activos valiosos por medio de $\mathrm{CO}_{2}$ supercrítico y una fracción lignocelulósica derivada de ese proceso, sin degradación. Esta última fracción se hidroliza para obtener una fracción líquida compuesta principalmente de azúcares C5 y C6, y en menor medida aldehídos y ácidos. Este concepto de biorrefinería basada en $\mathrm{CO}_{2} \mathrm{SC}$ y ASC permitirá valorizar los residuos en las zonas rurales donde se produce el tabaco.

\subsection{Hidrólisis de los carbohidratos estructurales}

Los carbohidratos estructurales son celulosa, hemicelulosa y lignina. La hidrólisis de los materiales lignocelulósicos depende principalmente de su estructura debido a que la celulosa tiene una estructura cristalina y resistente, la lignina que rodea a la celulosa actúa de barrera y esta estructura da lugar a un fuerte limitación a la transferencia de masa de los disolventes [14]. La hidrólisis de los carbohidratos estructurales del tabaco permite obtener diferentes compuestos como azúcares fermentables para la producción 
de etanol [15] hidrolizando la celulosa y los xiloligosacaridos hidrolizando la hemicelulosa [9].

La celulosa es un polisacárido constituido por moléculas de D-glucosa unidas por enlaces glucosídicos $\beta-1,4$. Este polisacárido se encuentra en la pared celular como unidades microscópicas llamadas micelas y las micelas se organizan en estructuras más grandes llamadas microfibrillas las cuales se empaquetan formando una estructura cristalina y ordenada. Esta estructura previene la penetración de moléculas como las de agua o de enzimas [16]. La cantidad de unidades del monómero que conforman la celulosa determinan el grado de polimerización. Dependiendo la parte de la planta de tabaco, el grado de polimerización de la celulosa en la lámina del tabaco es del orden de 1.100-1.600 y en las venas entre 1.600-1.800 [17].

La hemicelulosa está compuesta por cadenas cortas de polisacáridos de distintos monómeros. En su estado natural, posee una estructura amorfa y se compone de tres grupos de polisacáridos: xilanos, mananos y galactanos, cada uno de estos compuestos de monómeros como xilosa, manosa, galactosa, glucosa y arabinosa [14]. Su función es la de mantener unida la celulosa con la lignina. La composición de la hemicelulosa varía considerablemente en el tabaco según su variedad, labores culturales y medioambientales [17]. Por ejemplo, la hemicelulosa de los tallos de tabaco de Turquía descripta por Akpinar et al [9] está compuesta por un 93,5\% de xilosa, 6,54 \% de glucosa y 11,2 \% ácido urónico, en cambio, en tallos de tabaco Virginia de Japón, prácticamente el $100 \%$ de la hemicelulosa está compuesta por xilosa. Jacin et al [18] determinaron que la hemicelulosa de las venas de tabaco Virginia estaban compuestas por un $86 \%$ de xilosa, $9,2 \%$ de glucosa y $2,2 \%$ de arabinosa.

La lignina es un polímero de unidades fenilpropanoides unidas entre si por enlaces carbono-carbono. Mantiene unidas las fibras de celulosa brindándoles resistencia pero reduciendo la accesibilidad de las enzimas a los enlaces glicósidos para el caso de la hidrólisis enzimática, lo que hace necesario un pretratamiento de la biomasa [19]. El contenido de lignina en la biomasa forestal varía según la especie. En general las maderas blandas contienen un porcentaje de celulosa, hemicelulosa y lignina del $42 \%$, $21 \%$ y $32 \%$ respectivamente y en las maderas duras este contenido es del $46 \%, 24 \%$ y 26\%[7]. Agrupis et al [20] evaluaron la utilización de los tallos del tabaco FCV como materia prima para la producción de papel por su contenido de celulosa (40\%), hemicelulosa (30\%) y bajo contenido de lignina (18\%), obteniendo pulpa para papel con buena resistencia pero baja calidad en el brillo en comparación con el papel obtenido de maderas. 
La conversión de estos polímeros en sus monómeros se puede realizar por medio de procesos enzimáticos, ácidos o mediante agua sub o supercrítica. La hidrólisis enzimática tiene una mayor selectividad, un mayor rendimiento, menores costos de operación y menor consumo de energía que la hidrólisis ácida [21]. A su vez, la hidrólisis mediante agua cercana a su punto crítico se presenta como una buena alternativa frente a la hidrólisis enzimática principalmente por los tiempos extremadamente cortos de reacción (de milisegundos a segundos) contra los tiempos del proceso enzimático que son de varias horas hasta días [22].

\subsection{Hidrólisis enzimática versus hidrólisis con agua supercrítica}

Existen antecedentes del uso de tabaco o sus residuos sometidos a procesos de hidrólisis enzimática, algunos con hidrólisis con agua subcrítica, pero prácticamente ningún antecedente con hidrólisis con ASC. En la Tabla 1 se presenta una recopilación de los trabajos más relevantes publicados.

El material más utilizado es el tallo del tabaco, principalmente debido a la similaridad de su composición con la de los productos forestales. Sin embargo, los rendimientos de la conversión enzimática de los tallos son menor que los rendimientos obtenidos de las hojas. Martín et al [15] hidrolizaron enzimáticamente tallos de tabaco durante $96 \mathrm{~h}$ y sometiendo la materia prima a un pretratamiento con vapor de agua a $205^{\circ} \mathrm{C}$ obtuvieron un rendimiento de 18-20 g/L de glucosa, sin datos del contenido original de celulosa para calcular el porcentaje de conversión. Unos años mas tarde, el mismo autor publicó otro trabajo [23] donde hidroliza enzimáticamente tallos de tabaco, haciendo un pretratamiento con agua a $195^{\circ} \mathrm{C}$ y oxígeno a $1.2 \mathrm{MPa}$ durante $15 \mathrm{~min}$. Con ese pretratamiento aumenta el porcentaje de conversión de celulosa en glucosa desde el $2,5 \%$ al $56 \%$ en un período de 24 horas con el pretratamiento incluido. Farrán et al. [24] hidrolizaron muestras de hojas y tallos de tabaco con enzimas, el porcentaje de conversión de los carbohidratos estructurales de las hojas obtenido superó el $100 \%$, esto lo atribuyen a la presencia de azucares solubles en la materia prima y a una subestimación de la cantidad original de estos. El porcentaje de conversión de la celulosa en glucosa que obtuvieron fue del 51 \% luego de 72 h de hidrólisis enzimática.

En el año 2014 se publicó una patente [25] en la cual se utiliza agua en estado subcrítico $\left(180-305^{\circ} \mathrm{C}\right.$ y 1,2 - $\left.14 \mathrm{MPa}\right)$ para hidrolizar la fracción sólida que se obtiene de una extrusión de plantas de tabaco verdes. La fracción líquida contiene un 2\% de azucares libres de los cuales el $85 \%$ es glucosa. En una estrategia similar a la propuesta en este trabajo, la fracción liquida se mezcla con el producto de la hidrólisis en una 
posterior fermentación. Los porcentajes de conversión de celulosa en glucosa van desde el 10,5 hasta $41,1 \%$.

La principal diferencia entre los trabajos con hidrólisis enzimática y este trabajo es el tiempo necesario para la hidrólisis, que es del orden de días versus milisegundos que demora la hidrólisis con ASC. Con respecto a la patente, la concentración de azúcares libres en la fracción líquida es muy baja debido a que la materia prima utilizada es tabaco verde. Durante el curado del tabaco el almidón se transforma en azucares reductores. Por lo que sería conveniente, para un proceso de hidrólisis, utilizar tabaco curado y no tabaco verde.

\section{Materiales y Métodos}

\subsection{Materiales}

En los experimentos se utilizaron tres materias primas diferentes: scrap de tabaco sin tratar, palos y scrap que se sometió previamente a una extracción de $3 \mathrm{~h}$ con dióxido de carbono supercrítico, según el procedimiento descrito por Tita el al [26]. En los experimentos realizados en la planta de escala de laboratorio, estos materiales se molieron en un molino de bolas planetarias de laboratorio (Retsch PM110), obteniendo un tamaño de partículas inferior a $125 \mu \mathrm{m}$, mientras que, en los experimentos realizados en la planta piloto, los materiales se molieron con un molino de cuchillas (Retsch SM 100), obteniendo un tamaño de partículas de hasta $500 \mu$.

Los siguientes compuestos, utilizados como estándares en el análisis de cromatografía líquida (HPLC), fueron comprados a Sigma Aldrich (España): celobiosa (pureza $\geq 98 \%$ ), glucosa ( $\geq 99 \%$ ), xilosa ( $\geq 99 \%$ ), galactosa ( $\geq 99 \%$ ), manosa ( $\geq 99 \%$ ), arabinosa ( $\geq 99 \%$ ), gliceraldehído $(\geq 95 \%)$, glicolaldehído ( $\geq 99 \%$ ), piruvaldehído ( $\geq$ $99 \%$ ), ácido láctico ( $\geq 85 \%$ ), ácido fórmico ( $\geq 98 \%$ ), ácido acético ( $\geq 99 \%$ ), ácido acrílico ( $\geq 99 \%$ ), furfural ( $\geq 99 \%$ ) y 5-hidroximetil furfural ( $\geq 99 \%$ ). La fase móvil de los ensayos de HPLC se preparó utilizando agua ultra pura Mili-Q y ácido sulfúrico de grado HPLC (Sigma Aldrich, $\geq 96 \%$ ). En los ensayos de determinación de lignina y carbohidratos estructurales se utilizaron ácido sulfúrico ( $\geq 96 \%$ ) y carbonato de calcio ( $\geq 99 \%)$, también proporcionados por Sigma Aldrich. 
Tabla 1. Algunos antecedentes de hidrólisis de tabaco mediante enzimas y agua sub y supercrítica

\begin{tabular}{|c|c|c|c|c|c|c|c|c|c|}
\hline Hidrólisis & $\begin{array}{l}\text { Materia } \\
\text { prima }\end{array}$ & Pretratamiento & Condiciones & Temperatura & Presión & $\begin{array}{l}\text { Tiempo de } \\
\text { residencia/reacción }\end{array}$ & \%conversión & Rendimiento & Ref. \\
\hline Enzimática & $\mathrm{T}$ & $\begin{array}{l}\text { Vapor de agua a } \\
205^{\circ} \mathrm{C} \text { durante } \\
5 / 10 \text { min }\end{array}$ & Batch & $40^{\circ} \mathrm{C}$ & Atm & $96 \mathrm{~h}$ & $s / d$ & $\begin{array}{c}18-20 \mathrm{~g} / \mathrm{L} \\
\text { (glucosa + } \\
\text { manosa) }\end{array}$ & [15] \\
\hline Enzimática & $\mathrm{T}$ & $s / p$ & Batch & $50^{\circ} \mathrm{C}$ & Atm & $24 \mathrm{~h}$ & 2,5 & $s / d$ & [23] \\
\hline Enzimática & $\mathrm{T}$ & $\begin{array}{l}\text { Vapor de agua. } \\
195^{\circ} \mathrm{C} \text { durante } \\
5 / 10 \mathrm{~min}+\mathrm{O}_{2}\end{array}$ & Batch & $50^{\circ} \mathrm{C}$ & Atm & $24 \mathrm{~h}$ & 56,1 & $\mathrm{~s} / \mathrm{d}$ & ídem \\
\hline Enzimática & $\mathrm{H}$ & $\begin{array}{c}\text { 1hr en } 0,1 \mathrm{M} \\
\text { bufer citratro a } \\
110^{\circ} \mathrm{C}, 10 \% \\
(\mathrm{w} / \mathrm{w})\end{array}$ & Batch & $50^{\circ} \mathrm{C}$ & Atm & $72 \mathrm{~h}$ & $109-115$ & $\begin{array}{l}\text { 15,9 \% (w/w) } \\
\text { azúcar } \\
\text { fermentable }\end{array}$ & [24] \\
\hline Enzimática & $\mathrm{T}$ & $\begin{array}{c}30 \mathrm{~min} \text { en agua, } \\
170,190 \mathrm{y} \\
\left.210^{\circ} \mathrm{C}\right), 1 \% \text { de } \\
\mathrm{H}_{2} \mathrm{SO}_{4}\end{array}$ & Batch & $50^{\circ} \mathrm{C}$ & Atm & $72 \mathrm{~h}$ & $51,5-63$ & $\begin{array}{c}17,9 \%(\mathrm{w} / \mathrm{w}) \\
\text { fracción sólida } \\
2,59 \%(\mathrm{w} / \mathrm{w}) \\
\text { fracción líquida }\end{array}$ & ídem \\
\hline Enzimática & $\mathrm{T}$ & $1-3 \% \mathrm{H}_{2} \mathrm{SO}_{4}$ & Batch & $50^{\circ} \mathrm{C}$ & Atm & $74 \mathrm{~h}$ & $41,2-54,2$ & $9,8 \mathrm{~g} / \mathrm{L}$ & {$[27]$} \\
\hline \multirow[t]{4}{*}{$\begin{array}{c}\text { Agua } \\
\text { subcrítica }\end{array}$} & $\mathrm{P}$ & $\begin{array}{l}\text { Molido húmedo, } \\
\text { 5-15 \% w/w }\end{array}$ & Continuo & $200-305^{\circ} \mathrm{C}$ & $14 \mathrm{MPa}$ & $10-15$ seg & $32,35-41,14$ & $0,46-0,75 \mathrm{mg} / \mathrm{L}$ & [25] \\
\hline & $\mathrm{P}$ & $\begin{array}{l}\text { Molido húmedo, } \\
\text { 5-15 \% w/w }\end{array}$ & $\begin{array}{c}\text { Batch en } 2 \\
\text { etapas }\end{array}$ & $\begin{array}{l}\text { 1. } 180^{\circ} \mathrm{C} \\
\text { 2. } 280^{\circ} \mathrm{C}\end{array}$ & $\begin{array}{ll}\text { 1. } & s / d \\
\text { 2. } & s / d\end{array}$ & $\begin{array}{l}\text { 1. } 3 \text { min } \\
\text { 2. } 3 \mathrm{~min}\end{array}$ & $\begin{array}{l}\text { 1. } 22,27 \\
\text { 2. } 10,48\end{array}$ & $\begin{array}{c}1.4,25 \mathrm{~g} / \mathrm{L} \\
\text { azucares } \\
2.4,77 \mathrm{~g} / \mathrm{L} \\
\text { azucares }\end{array}$ & ídem \\
\hline & $\mathrm{T}$ & $\begin{array}{l}\text { Molido húmedo, } \\
\text { 5-15 \% w/w }\end{array}$ & $\begin{array}{l}\text { Batch en } 1 \\
\text { etapa }\end{array}$ & $180^{\circ} \mathrm{C}$ & $\mathrm{s} / \mathrm{d}$ & $14-17 \min$ & 12,8 & $2,7 \mathrm{~g} / \mathrm{L}$ & ídem \\
\hline & $\mathrm{T}$ & $\begin{array}{l}\text { Molido húmedo, } \\
\text { 5-15 \% w/w }\end{array}$ & $\begin{array}{c}\text { Batch en } 1 \\
\text { etapa }+ \\
\text { H2SO4 }\end{array}$ & $180^{\circ} \mathrm{C}$ & 1,2 MPa & $3-8 \min$ & $24,4-32,6$ & $5,15-6,92 \mathrm{~g} / \mathrm{L}$ & ídem \\
\hline
\end{tabular}

T: Tallos de tabaco, H: Hojas de tabaco, P: planta entera, S: Scrap de tabaco 


\subsection{Composición de las materias primas y análisis de los productos}

La materia prima se caracterizó siguiendo un protocolo NREL [28], [29]. Mediante este procedimiento, fue posible cuantificar los carbohidratos estructurales (celulosa, hemicelulosa, lignina soluble e insoluble) y los extractivos.

El método propuesto por NREL para la determinación de las proteínas, utiliza un factor de conversión de nitrógeno a proteína (NF). Este factor se basa en la cantidad de nitrógeno determinado por el método Kjeldahl y el perfil de aminoácidos de la muestra. Para calcular la cantidad de proteínas que aparecen en la Tabla 3, se utilizaron los perfiles de aminoácidos de tabaco publicados por Kung y Tso [30] y Moldoveanu et al. [31]. Y con estos perfiles, se calculó el NF con la ayuda de una hoja de cálculo publicada por NREL [32]. El valor obtenido del NF fue 4,3. Utilizar un NF=6,25 para el cálculo de las proteínas como en algunas publicaciones [33], [34], daría una sobrestimación de la cantidad de proteínas del $45 \%$ por encima del valor real. Haciendo que el balance de masa supere el 100\%. Esta particularidad fue estudiada por Tkachuk [35] en 1969 y más recientemente por Mariotti et al [36]

El contenido de carbono en el producto líquido se determinó mediante el análisis del carbono orgánico total (COT) con el equipo COT-VCSH de Shimadzu. La composición del producto líquido se determinó por análisis HPLC. La columna utilizada para la separación de los compuestos fue la Shodex $\mathrm{SH}-1011$ a $50{ }^{\circ} \mathrm{C}$, utilizando ácido sulfúrico $(0,01 \mathrm{~N})$ como fase móvil con un flujo de 0,8 $\mathrm{ml} / \mathrm{min}$. Se utilizó el detector IR Waters 2414 para identificar los azúcares y sus derivados, y un detector Waters UV-Vis para determinar la concentración de 5-hidroximetilfurfural (5-HMF) a una longitud de onda de $254 \mathrm{~nm}$.

La concentración de oligosacáridos solubles en las muestras líquidas se determinó mediante hidrólisis ácida a glucosa y determinación por HPLC siguiendo un procedimiento analítico de laboratorio del NREL [37], como se indica a continuación. A $10 \mathrm{~mL}$ de alícuotas de líquido filtrado, se añadieron $4 \mathrm{~mL}$ de $\mathrm{H} 2 \mathrm{SO} 4 \mathrm{al}$ 96\%. La muestra se mantuvo en un horno a $30{ }^{\circ} \mathrm{C}$ durante $60 \mathrm{~min}$. Luego se agregaron $86 \mathrm{~mL}$ de agua Milli-Q, y la muestra se incubó a $121{ }^{\circ} \mathrm{C}$ durante $60 \mathrm{~min}$. Se añadió carbonato de calcio a $20 \mathrm{~mL}$ de esta muestra para neutralizar el $\mathrm{pH}$, y finalmente el sobrenadante fue filtrado y analizado por HPLC.

\subsection{Proceso FASTSUGARS}

La hidrólisis con agua supercrítica se realizó utilizando el proceso FASTSUGARS desarrollado por el Grupo de Proceso de Alta Presión de la Universidad de Valladolid. 
El proceso FASTSUGARS puede ser dividido en 4 etapas: 1-Presurización, 2Calentamiento de la biomasa, 3-Reacción y 4-Despresurización [38]:

1. Presurización: Dos bombas de desplazamiento positivo (P-1 y P-2) son usadas para bombear continuamente agua y la suspensión de biomasa hasta la presión de trabajo (25 MPa) y a temperatura ambiente. El caudal del agua máximo de agua alcanza los $5 \mathrm{~kg} / \mathrm{h}$ y la suspensión de biomasa se bombea a un caudal de 1,5 kg/h.

2. Calentamiento de la biomasa: El agua se precalienta en el intercambiador de calor HE-1 con recuperación de calor del efluente de salida del reactor. Un segundo calentador eléctrico con una potencia ajustable de $10 \mathrm{~kW}$ permite calentar el agua hasta $400^{\circ} \mathrm{C}$. En estas condiciones de presión y temperatura (25 MPa y $400{ }^{\circ} \mathrm{C}$ ), el agua se encuentra en estado supercrítico. El proceso opera con tiempos de reacción inferiores a $1 \mathrm{~s}$, por lo que se calienta por contacto directo en una $\mathrm{T}$ de mezcla. La relación biomasa/SCW es de 1:3, detalles del calentamiento se aportan en Vaquerizo et al [39].

3. . El flujo de SCW a la entrada del reactor, ingresa a al punto de unión $M$ donde se hará la mezcla, a un caudal de $4,5 \mathrm{~kg} / \mathrm{h}$ y una temperatura de $500^{\circ} \mathrm{C}$, el flujo de biomasa (a temperatura ambiente) ingresa a la misma unión a un caudal de 1,5 $\mathrm{kg} / \mathrm{h}$, esto resulta en un calentamiento instantáneo de la mezcla biomasa/SCW a la temperatura de operación del reactor de $400{ }^{\circ} \mathrm{C}$. Para evitar pérdidas de calor, todos los elementos de la planta que operan a temperatura elevada están aislados con lana de roca.

4. Reacción: Una vez que se alcanzan la temperatura de operación, el tiempo de reacción de la biomasa controla la selectividad [40]. El tiempo de reacción se calculó con la relación del volumen del reactor y el caudal volumétrico en el reactor. El volumen $V$ del reactor en $\mathrm{m}^{3}$ se obtuvo usando el diámetro $D$, la longitud $L$. El caudal $F_{V}$ se calculó usando la densidad del medio de reacción en el reactor a temperatura ambiente, considerando que el fluido es agua pura. Debido a que el reactor está aislado térmicamente y que el enfriamiento es instantáneo, se puede considerar que la temperatura es constante a lo largo de todo el reactor. Por lo tanto, la densidad también se consideró constante a través del reactor y el tiempo de reacción se calculó usando la Ecuación 1:

$$
t_{R}=\frac{V}{F_{v}}=\frac{\pi D^{2}}{4} L \frac{\rho_{h}}{F_{v, 0} \rho_{0}}
$$


En la Ecuación 1, $\rho_{h}$ y $\rho_{0}$ representan la densidad en $\mathrm{kg} / \mathrm{m}^{3}$ a las condiciones de reacción y a condiciones ambiente respectivamente. $F_{v, 0}$ es el caudal medido en condiciones ambiente en $\mathrm{kg} / \mathrm{s}$. Usando la relación $\rho_{h} / \rho_{0}, F_{v, 0}$ se transforma en $F_{v}$.

5. Despresurización: Una brusca despresurización genera un rápido descenso de la temperatura debido al efecto Joule-Thomson, por lo tanto, se detiene la reacción de hidrólisis. Esto se logra a través de una válvula reguladora de presión para alta presión y temperatura V-1 (30VRMM4512 de Autoclave Engineers). El método de enfriamiento es un factor clave en el proceso FASTSUGARS, debido a que es el mecanismo usado para detener efectivamente la reacción, evitando una reacción descontrolada. Con este método, fue posible reducir repentinamente la presión desde $25 \mathrm{MPa}$ hasta la presión ambiente y la temperatura del producto desde $400^{\circ} \mathrm{C}$ hasta $150^{\circ} \mathrm{C}$. El sistema de enfriamiento fue capaz de enfriar el producto rápidamente, evitando la dilución, que hubiese ocurrido si se realizaba el enfriamiento por inyección de agua fría.

\subsection{Rendimiento.}

El rendimiento de los componentes principales (hexosas, pentosas, glicolaldehído y 5-HMF) se determinaron con la ecuación 2:

$$
\begin{gathered}
Y_{S}=\frac{C_{S}}{S_{i n}} \\
S_{i n=} C_{i n} \cdot S_{T}
\end{gathered}
$$

Donde: $Y_{S}$ es el rendimiento del componente $S, C_{S}$ es la concentración de $S$ en el producto en ppm y $S$ es la concentración de azúcares en la entrada del reactor en ppm, calculado usando la Ecuación 3. En la esta ecuación, $C_{\text {in }}$ es la concentración de los subproductos de tabaco a la entrada del reactor en ppm y $S_{T}$ es la fracción de celulosa y hemicelulosa en la materia prima, que representa la proporción de los subproductos de tabaco que pueden ser hidrolizadas en azucares

\subsection{Hidrólisis de agua supercrítica a escala de laboratorio}

Los experimentos a escala de laboratorio se llevaron a cabo utilizando la planta continúa representada en la Figura 1, que fue diseñada y construida por el grupo de investigación HPP de la Universidad de Valladolid y que se describe en detalle en el trabajo anterior [41]. Esta configuración permite operar a una presión de hasta $25 \mathrm{MPa}$ y una temperatura de hasta $400^{\circ} \mathrm{C}$, utilizando un flujo de alimentación máximo de $3 \mathrm{~kg} / \mathrm{h}$ de suspensión de biomasa y un flujo de agua de hasta $5 \mathrm{~kg} / \mathrm{h}$. 


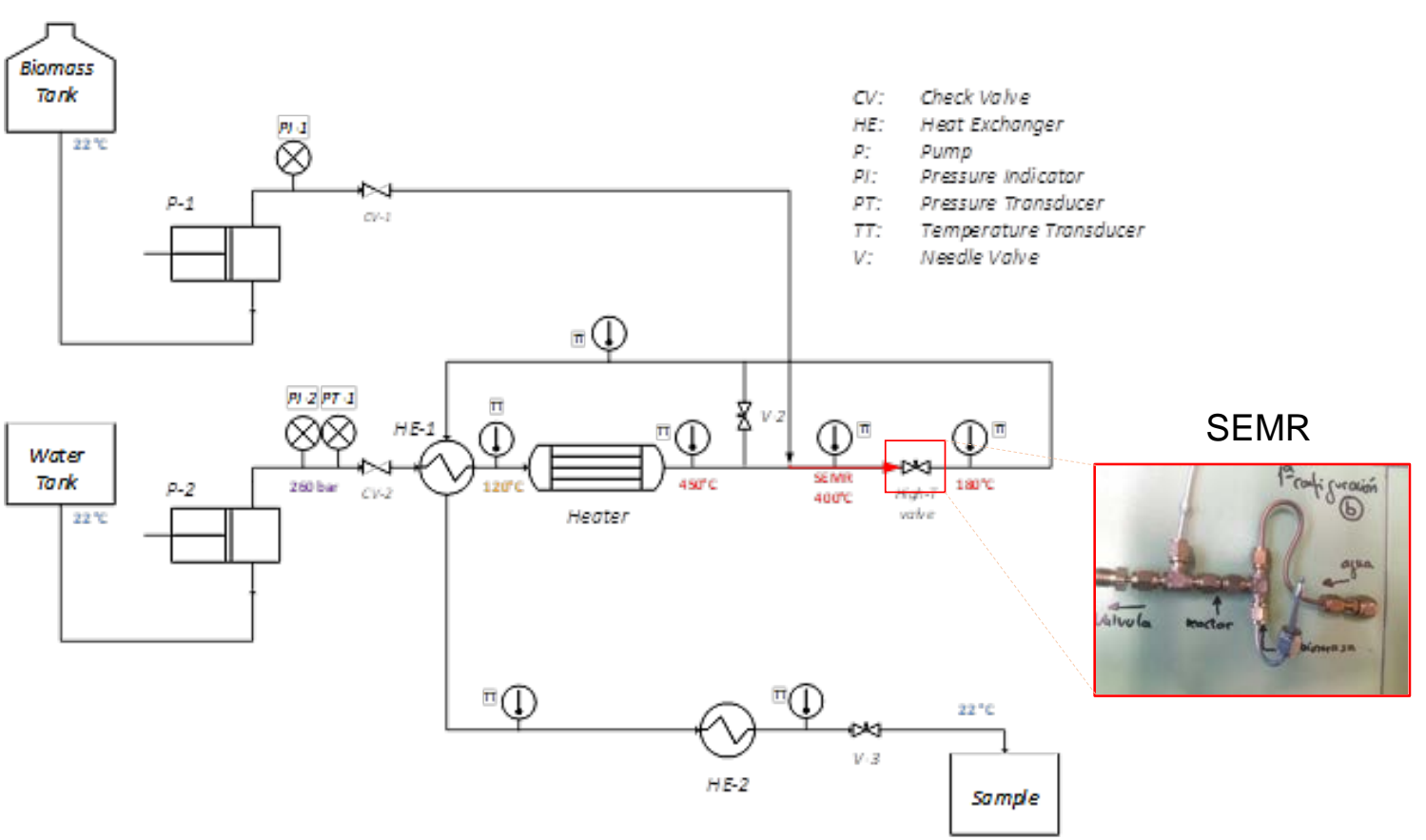

Figura 1. Diagrama de la planta de laboratorio de hidrolisis supercrítica de biomasa, equipada con un Micro Reactor SEMR (sudden expansión micro-reactor)

\subsection{Hidrólisis de agua supercrítica a escala piloto}

La planta piloto continua de hidrólisis supercrítica también fue diseñada y construida por el grupo de investigación y se basa en los mismos principios que la planta de laboratorio. En la Figura 2 se presenta un diagrama de flujo esquemático de la planta piloto. Esta planta permite operar con un flujo de alimentación de hasta $10 \mathrm{~kg} / \mathrm{h}$ de una suspensión de biomasa con tamaños de partículas de biomasa de hasta 0,5 mm. Al igual que en la planta de laboratorio, la reacción se inicia cuando un flujo de agua presurizada precalentada a $450^{\circ} \mathrm{C}$ se mezcla con la suspensión de biomasa, que está a temperatura ambiente. La mezcla tiene lugar en el elemento mezclador $\mathrm{M}$ de la Figura 2, lo que permite un calentamiento casi instantáneo de la suspensión hasta $390{ }^{\circ} \mathrm{C}$. A la salida del reactor, el efluente se despresuriza repentinamente mediante una válvula de aguja, que por efecto Joule-Thomson provoca una reducción de la temperatura hasta los $190{ }^{\circ} \mathrm{C}$ que detiene la reacción de hidrólisis. En la Tabla 2 se presenta una comparación de ambas plantas. 


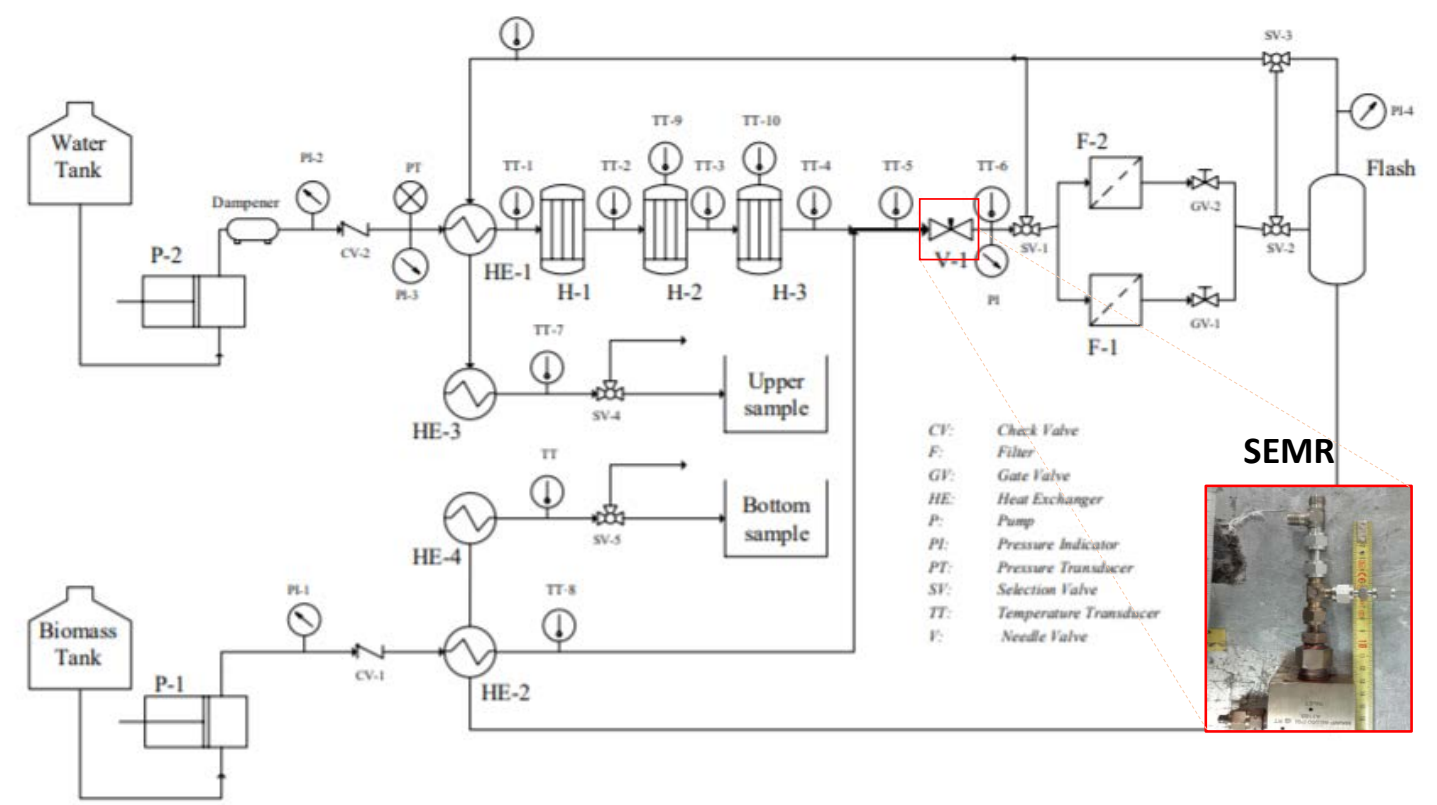

Figura 2. Diagrama esquemático de la Planta Piloto de hidrolisis supercrítica de biomasa

Tabla 2. Comparación entre las plantas escala laboratorio y escala piloto del proceso FASTSUGARS [42]

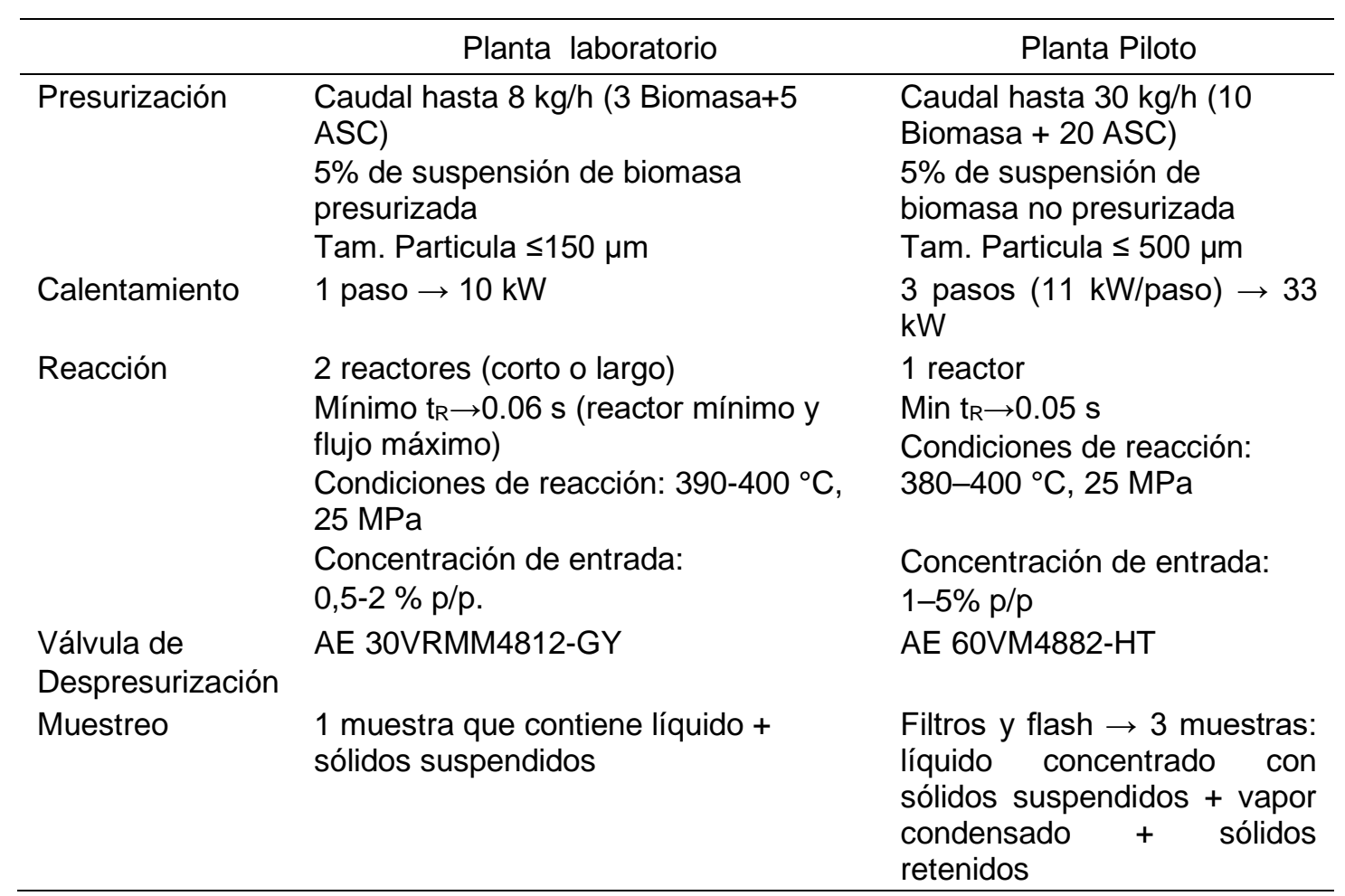




\section{Resultados y discusión}

\subsection{Caracterización de la materia prima}

Los carbohidratos estructurales como la celulosa y la hemicelulosa son las materias primas clave para las biorrefinerías de segunda generación en las que estos compuestos se transforman en azúcares fermentables [21]. En la Tabla 3 se presentan los resultados de los ensayos de composición realizados en las materias primas en este trabajo. Como se presenta en esta tabla, las materias primas presentan cantidades considerables de compuestos extraíbles con agua y extraíbles con etanol. Los compuestos extraíbles con agua incluyen materiales inorgánicos, azúcares libres no estructurales y compuestos de nitrógeno. Los compuestos extraíbles del etanol incluyen clorofila, ceras y gomas. De acuerdo con el protocolo NREL para la determinación de compuestos extraíbles [29], un método de extracción en dos etapas con agua y etanol es útil para analizar materiales con un alto contenido en compuestos solubles en agua, condición que cumplen las materias primas analizadas en este trabajo. Por otro lado, un ensayo de extracción con éter produjo un bajo rendimiento de extracción de aproximadamente el $7 \%$.

Además, un indicador de la calidad de las hojas de tabaco es la relación entre la nicotina y los azúcares [43]. En la Tabla 4 se presentan los resultados de los ensayos de determinación de azúcares libres en las materias primas, recogidos en la literatura [3], [4], [44], [45]. Estos azúcares libres son predominantemente glucosa y fructosa (azúcares reductores), así como sacarosa. Considerando que la glucosa y la fructosa pueden ser sometidas a fermentación y que esos compuestos son fácilmente extraíbles de las materias primas consideradas en este trabajo, como propuesta de trabajo futura se podría considerar la realización de una extracción acuosa para eliminarlas como tratamiento previo a la hidrólisis del carbohidrato estructural. El extracto acuoso así obtenido podría utilizarse directamente para la fermentación, aumentando así la producción de etanol.

Tabla 3. Composición química del scrap y fibra de tabaco Virginia Curado (\%w/w)

\begin{tabular}{cccccccc}
\hline Materia prima & Extraíbles & Humedad & Proteínas & Celulosa & Hemicelulosa & Lignina & Cenizas \\
\hline Scrap & 57,31 & 10,47 & 11,23 & 9,79 & 2,47 & 6,00 & 2,58 \\
Palos & 59,08 & 8,59 & 9,04 & 5,17 & 3,96 & 10,15 & 3,62 \\
\hline
\end{tabular}


Tabla 4.Contenido de azúcares reductores y sacarosa en tabaco Virginia Curado (\% w/w base seca). Datos de bibliografía

\begin{tabular}{ccccc}
\hline Glucosa & Fructosa & Sacarosa & Total & Ref. \\
\hline 10,4 & 7,4 & 5,8 & 23,6 & {$[4]$} \\
14,0 & 9,0 & 6,0 & 29,0 & {$[3]$} \\
8,0 & 8,8 & 7,7 & 24,5 & {$[44]$} \\
17,4 & 12,3 & 4,2 & 25,4 & {$[45]$} \\
\hline
\end{tabular}

\subsection{Hidrólisis de la biomasa en condiciones supercríticas: Experimentos a escala de laboratorio}

Se realizaron experimentos a escala de laboratorio utilizando scrap de tabaco previamente sometida a una extracción supercrítica de $\mathrm{CO}_{2}$, según el procedimiento descrito en un trabajo anterior [26]. Los tallos no se utilizaron en esta etapa de la investigación porque el scrap se produce en mayores cantidades que los tallos y además tiene un mayor contenido de celulosa y un menor contenido de lignina que los tallos $y$, por lo tanto, es más prometedora para un proceso de hidrólisis para la producción de azúcares. Como se presenta en la Tabla 5, se realizaron cuatro experimentos con diferentes tiempos de reacción en el reactor. Como se ha descrito en trabajos anteriores, el tiempo de reacción es un parámetro clave que determina la selectividad de la reacción hacia la glucosa, ya que se producen productos de degradación como la fructosa, la eritrosa o los aldehídos si no se restringe el tiempo de reacción [46]. En la Tabla 4 se presentan los principales resultados experimentales obtenidos, entre los que se incluyen: el rendimiento total de la reacción hacia los azúcares, y los rendimientos hacia los azúcares C6 (celobiosa, glucosa y fructosa), los azúcares C5 (xilosa y arabinosa), los aldehídos (gliceraldehído, piruvaldehído y glicolaldehído) y los ácidos (ácido láctico, ácido fórmico y ácido acético).

Como se presenta en la Tabla 5, en este trabajo se obtuvieron altos rendimientos de aldehídos y ácidos. El alto rendimiento de estos compuestos podría tener su origen en los compuestos solubles en agua presentes en la materia prima, que pueden extraerse de la alimentación sólida por medio del agua antes de entrar en el reactor. Estos compuestos solubles en agua son prácticamente azucares (55\%) y en menor medida proteínas (14\%), sulfatos y ácido urónico (13\%) [47]. El contenido de azúcares reductores en los tallos de tabaco es aproximadamente del $25 \%$ en peso (en base seca), y los polisacáridos solubles más abundantes en los tallos de tabaco son la xilosa (57\%), la glucosa (16\%), la arabinosa (9,6\%), la ramnosa $(9,5 \%)$ y la galactosa (7\%) [48]. En el caso del scrap de tabaco, la fracción soluble en agua está formada por 
glucosa $(57,8 \%)$, galactosa $(13,3 \%)$, xilosa (10\%), arabinosa $(9,6 \%)$, ramnosa $(4,8 \%)$ y manosa $(4,4 \%)[6]$. Por último, la fracción de pectina del tabaco está compuesta en su mayor parte por ácido galacturónico (78,8\%) [17].

Las Figuras 3, 4 y 5 presentan la composición de los productos obtenidos y la composición de las fracciones de aldehído y ácido. Como se presenta en la Figura 4, entre la fracción de aldehído, el compuesto más abundante es el glicolaldehído. Este compuesto se forma por la descomposición de la glucosa en el agua supercrítica [46]. Teniendo en cuenta que la materia prima del tabaco contiene un $13 \%$ en peso de glucosa como azúcar libre, y que la hidrólisis de la celulosa también produce glucosa, se podrían esperar altas cantidades de los productos de la degradación de este azúcar. Dado que el glicolaldehído inhibe el crecimiento celular de la levadura [49], su presencia en los productos de la hidrólisis puede ser perjudicial para su aplicación en la producción de etanol por fermentación. Por otra parte, el glicolaldehído es también un compuesto valioso que se utiliza en la industria para la producción de etilenglicol por fermentación o hidrogenación, para el reticulado de proteínas o como aditivo en la industria alimentaria [50].

Tabla 5. Experimentos realizados en la planta de escala laboratorio. Rendimientos de conversión a diferentes tiempos de reacción

\begin{tabular}{ccccccccc}
\hline Exp. & $\begin{array}{c}\text { Caudal } \\
(\mathrm{L} / \mathrm{h})\end{array}$ & $\begin{array}{c}\text { Tiempo } \\
\text { de } \\
\text { reacción } \\
(\mathrm{s})\end{array}$ & $\begin{array}{c}\text { Azúcares } \\
\text { totales (\%) }\end{array}$ & $\begin{array}{c}\mathrm{C}-6 \\
(\%)\end{array}$ & $\begin{array}{c}\mathrm{C}-5 \\
(\%)\end{array}$ & $\begin{array}{c}\text { Aldehídos } \\
(\%)\end{array}$ & $\begin{array}{c}\text { Ácidos } \\
(\%)\end{array}$ & $\begin{array}{c}\text { Total } \\
(\%)\end{array}$ \\
\hline 1 & 7,37 & 0,18 & 38,5 & 30,4 & 8,1 & 42,4 & 35,2 & 116,1 \\
2 & 7,48 & 0,22 & 30,8 & 24,9 & 5,9 & 26,8 & 34,2 & 91,8 \\
3 & 6,70 & 0,26 & 37,1 & 29,3 & 7,9 & 17,4 & 25,8 & 80,3 \\
4 & 7,73 & 1,13 & 28,6 & 27,6 & 1,0 & 41,6 & 45,0 & 115,3 \\
\hline
\end{tabular}

Entre los productos ácidos, como se presenta en la Figura 5, el ácido acético es el más abundante. Este compuesto se forma por la degradación de los oligómeros que se producen por la descomposición de la hemicelulosa [51]. Una vez más, estos compuestos inhiben el crecimiento celular de la levadura y tienen un efecto perjudicial sobre la fermentación debido a la acidificación de la solución [52], particularmente en el caso del ácido fórmico, que muestra un efecto de inhibición más fuerte que el ácido acético [53]. Si la aplicación prevista de los productos de la hidrólisis es la producción de etanol por fermentación, una extracción acuosa antes de la hidrólisis podría reducir la cantidad de hemicelulosa en la materia prima y, por lo tanto, disminuir la formación de estos compuestos. 
Con respecto a la influencia del tiempo de reacción en el reactor, como se presenta en la Tabla 4, cuando el tiempo de reacción se incrementa de 0,18 s a 1,13 s, la cantidad de azúcares C5 y C6 producidos disminuye considerablemente, mientras que la cantidad de productos de degradación de estos azúcares aumenta, incluyendo aldehídos y ácidos. Como se muestra en la Tabla 5, en algunos experimentos se calcularon rendimientos superiores al 100\%, lo que podría deberse a la presencia de compuestos no cuantificados como la eritrosa, la galactosa y la ramnosa.

\subsection{Hidrólisis de la biomasa en condiciones supercríticas: Experimentos a escala piloto}

Se realizaron experimentos a escala piloto utilizando palos de tabaco y scrap como materias primas. Los principales resultados experimentales se presentan en la Tabla 6 agrupando los rendimientos en las mismas familias de compuestos que se consideraron en los experimentos a escala de laboratorio.

Tabla 6. Contenido de azúcares reductores y sacarosa en tabaco Virginia Curado (\% w/w base seca)

\begin{tabular}{lccccccccc}
\hline Exp & $\begin{array}{c}\text { Materia } \\
\text { Prima }\end{array}$ & $\begin{array}{c}\text { Caudal } \\
(\mathrm{L} / \mathrm{h})\end{array}$ & $\begin{array}{c}\text { Tiempo de } \\
\text { Reacción } \\
(\mathrm{s})\end{array}$ & $\begin{array}{c}\text { Azúcares } \\
\text { totales } \\
(\%)\end{array}$ & $\begin{array}{c}\text { C-6 } \\
(\%)\end{array}$ & $\begin{array}{c}\text { C-5 } \\
(\%)\end{array}$ & $\begin{array}{c}\text { Aldehídos } \\
(\%)\end{array}$ & $\begin{array}{c}\text { Ácidos } \\
(\%)\end{array}$ & $\begin{array}{c}\text { Total } \\
(\%)\end{array}$ \\
\hline 1 & Palos & 20,6 & 0,04 & 18,9 & 15,8 & 3,1 & 2,1 & 8,1 & 29,2 \\
2 & Palos & 21,8 & 0,10 & 30,7 & 20,9 & 9,8 & 5,4 & 17,8 & 53,8 \\
3 & Palos & 15,3 & 0,14 & 39,8 & 31,8 & 8,0 & 4,3 & 20,2 & 64,4 \\
4 & Palos & 20,0 & 0,32 & 22,5 & 19,7 & 2,8 & 2,6 & 13,7 & 38,8 \\
5 & Scrap & 13,7 & 0,15 & 45,8 & 40,2 & 5,6 & 6,6 & 19,7 & 72,1 \\
6 & Scrap & 13,9 & 0,17 & 49,1 & 38,9 & 10,2 & 6,7 & 20,8 & 76,5 \\
7 & Scrap & 14,7 & 0,19 & 46,0 & 40,7 & 5,7 & 5,9 & 22,1 & 74,4 \\
\hline
\end{tabular}

Comparando los resultados obtenidos a escala de laboratorio y a escala piloto, se observa que los resultados son coherentes con respecto a los rendimientos de los azúcares C5 y C6. Sin embargo, a escala piloto se observa una considerable reducción de las cantidades de ácidos y aldehídos producidos. Esta diferencia podría deberse a los mayores tamaños de las partículas de biomasa utilizadas a escala piloto (hasta 500 $\mu \mathrm{m}$, en comparación con los $125 \mu \mathrm{m}$ de los experimentos a escala de laboratorio). Con un tamaño de partícula mayor, la transferencia de masa se ralentiza y, por lo tanto, se necesitan tiempos de reacción más largos para completar la reacción de hidrólisis, por lo que se minimizan las reacciones de degradación de los productos de hidrólisis. Este efecto se observa en los resultados de los experimentos 1, 2 y 3 de la Tabla 6 , que muestran que el rendimiento total de azúcares aumenta cuando se incrementa el tiempo de reacción. 
Además, la planta piloto permite un control más preciso del tiempo de reacción. Mientras que con la planta de laboratorio los tiempos de reacción pueden variar entre 0,18 s y 1,13 s, trabajando con la planta piloto es posible controlar con precisión el tiempo de reacción dentro del intervalo que va de 0,15 s a 0,19 s. Este control es necesario porque los resultados reportados en la Tabla 6 demuestran que una variación del tiempo de reacción de sólo veinte milisegundos, de $0,15 \mathrm{~s}$ a $0,17 \mathrm{~s}$, produce una variación de casi el 5\% en el rendimiento total de azúcar y una reducción de la relación C6/C5 aproximadamente de 8 a 4.

En las Figuras 3, 4 y 5 se comparan las composiciones detalladas de los productos de hidrólisis obtenidos a escala de laboratorio y piloto. Comparando los resultados presentados en la Figura 3, puede observarse que mientras que a escala de laboratorio se produce una reducción gradual de los rendimientos de aldehídos y ácidos producidos a medida que aumenta el tiempo de reacción, a escala piloto estos rendimientos se mantienen casi constantes en todos los tiempos de reacción considerados, pero en valores inferiores a los rendimientos logrados a escala de laboratorio, mientras que en cambio los rendimientos de los azúcares obtenidos a escala piloto son muy superiores a los rendimientos logrados a escala de laboratorio. Como se presenta en estas figuras, tal y como se ha indicado anteriormente, el ácido más abundante obtenido en los experimentos a escala de laboratorio es el ácido acético (que representa un $62 \%$ de la fracción de ácidos) mientras que a escala piloto se obtiene más ácido láctico (que representa un $66,5 \%$ de la fracción de ácidos). Antal y otros [54] describen que el ácido láctico se produce a partir del piruvaldehído, que a su vez se forma a partir del gliceraldehído, y los resultados obtenidos en este trabajo son coherentes con este mecanismo: la concentración de glicolaldehído en el efluente de la planta piloto está por debajo del límite de detección, lo que indica una alta transformación de este compuesto en ácido láctico que, como han descrito Antal y otros [54], puede tener lugar a través del piruvaldehído. En cambio, en los productos de la planta de laboratorio, el ácido láctico sólo representa un $24 \%$ del contenido total de ácidos orgánicos y hay una gran cantidad de aldehídos y, en particular, de glicolaldehído. Con respecto al ácido acético, Jin y otros [55] determinaron dos mecanismos para la formación de ácido láctico a partir de materiales lignocelulósicos. En uno de ellos, el ácido acético es un producto de degradación del ácido láctico, mientras que en el otro se forma a partir del 5-hidrometil furfural y del 2-furaldehído. En los experimentos de la planta piloto se observa que, a mayores tiempos de reacción, la proporción de ácido láctico disminuye del 31\% a una concentración inferior al límite de detección, mientras que la proporción de ácido acético aumenta del $47 \%$ al $66 \%$. Por lo 
tanto, se puede concluir que estos resultados indican que el ácido acético se formó por degradación del ácido láctico.

En el caso de los experimentos realizados con tallos, se puede observar que se lograron bajos rendimientos totales. Este resultado podría deberse al alto contenido de lignina de los tallos, que es casi el doble del contenido de lignina del scrap, con un contenido menor de celulosa y hemicelulosa. Teniendo en cuenta que la lignina actúa como un pegamento de los carbohidratos estructurales, lo que limita la accesibilidad del agua, y los resultados indican un lento progreso de la reacción. Se puede formular la hipótesis de que el rendimiento de la hidrólisis de este material está limitado por la velocidad de transferencia de masa y podría mejorarse reduciendo el tamaño de las partículas. 

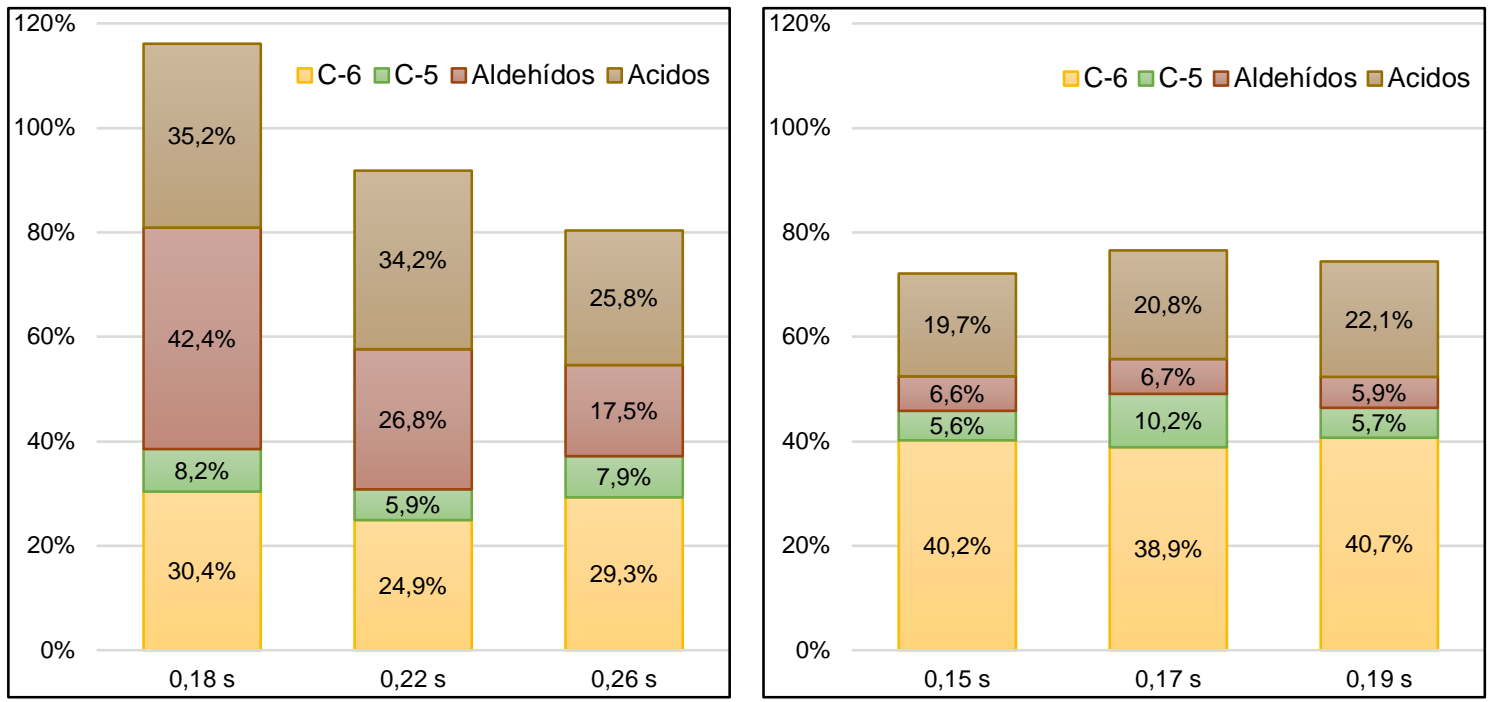

Figura 3. Composición del hidrolizado de scrap en \%,

Planta escala laboratorio (izq.) versus Planta escala Piloto (der.)
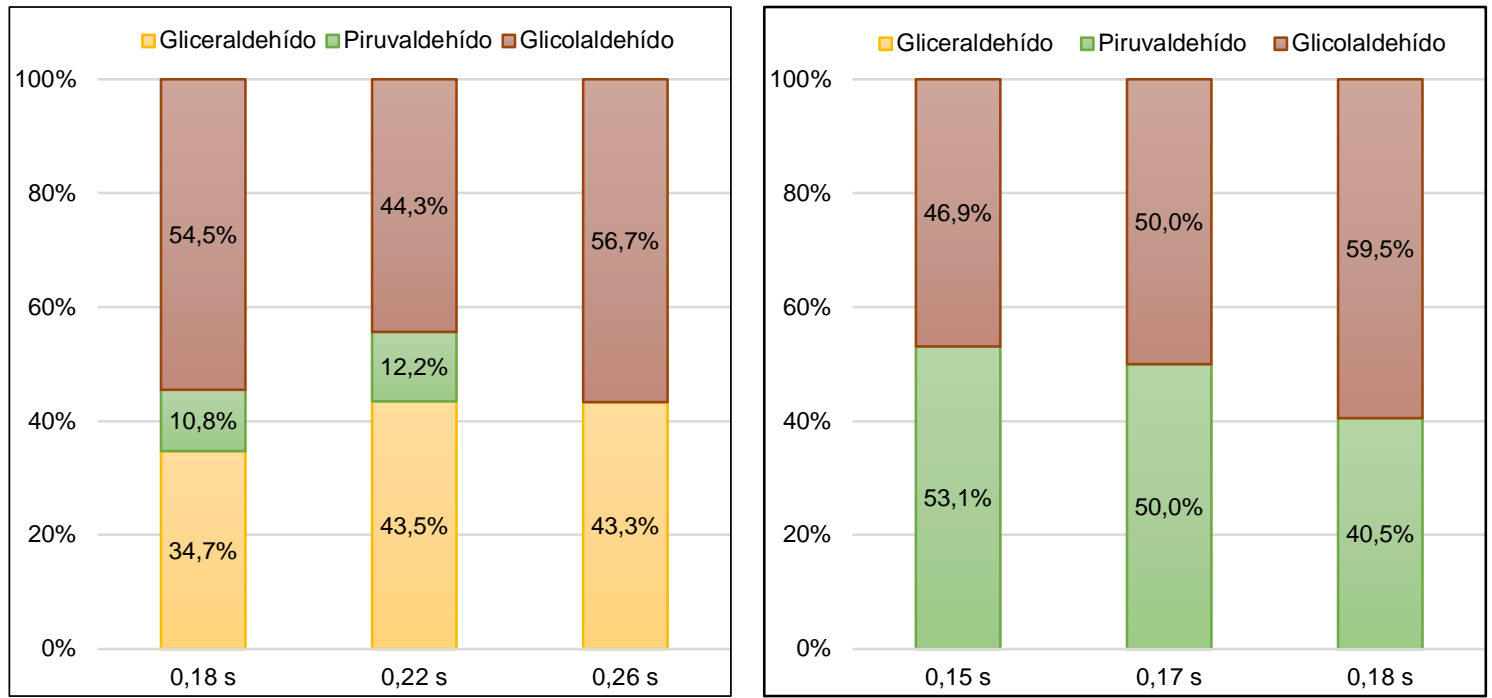

Figura 4. Composición de los aldehídos del hidrolizado de scrap en \%, Planta escala laboratorio (izq.) versus Planta escala Piloto (der.)

El gliceraldehído en la escala piloto no pudo ser medido

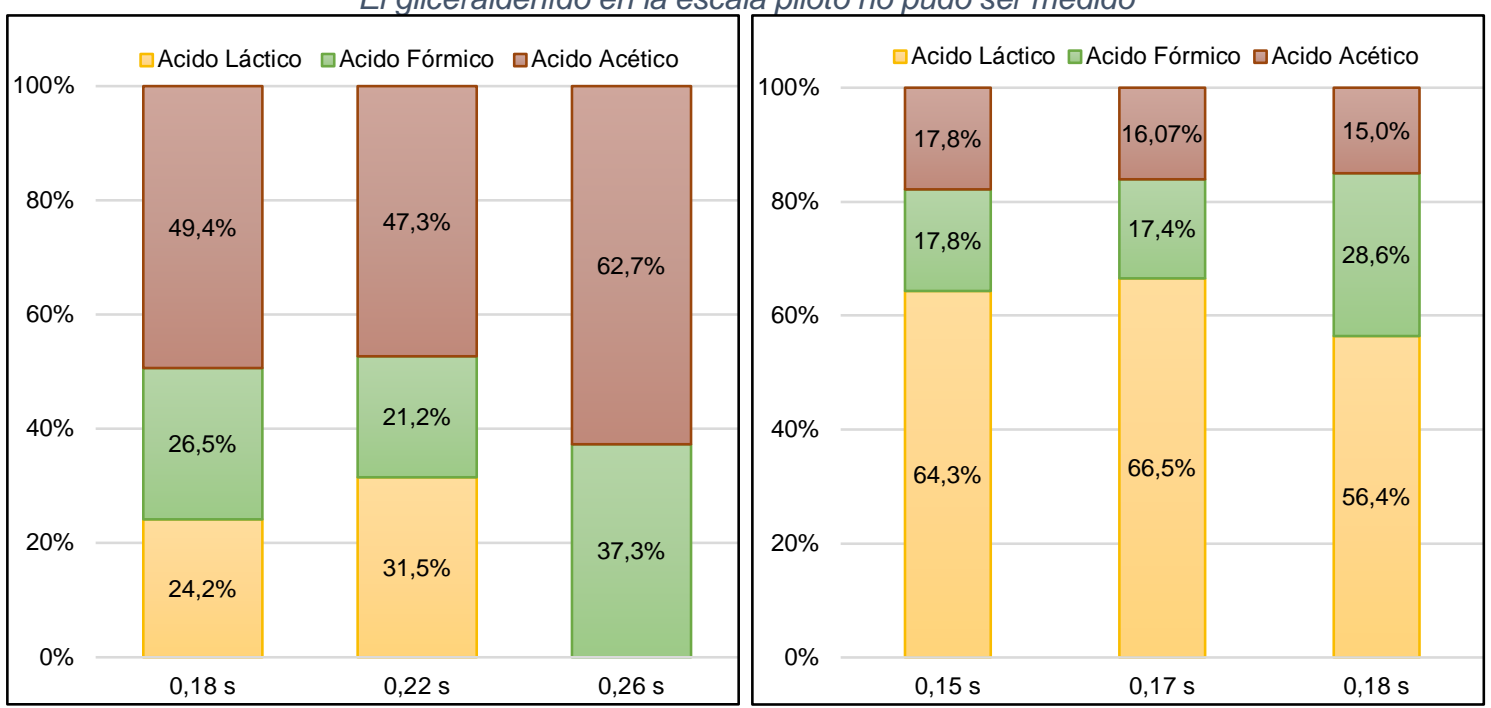

Figura 5. Composición de los ácidos del hidrolizado de scrap en \%, Planta escala laboratorio (izq.) versus Planta escala Piloto (der.) 


\subsection{Análisis del balance de masa}

La Figura 6 presenta el análisis de balance de masa correspondiente al primer escenario discutido en la introducción. El balance de masa se ha elaborado teniendo en cuenta los resultados experimentales obtenidos en este trabajo y tomando como base de cálculo $1000 \mathrm{~kg}$ de materia prima. Como se presenta en la Figura 6, una diferencia clave del enfoque propuesto con respecto a otras alternativas es que sólo se utilizan la biomasa y el agua, sin ningún consumo de ácidos o enzimas.

El primer paso del proceso es la molienda de la materia prima. En esta aplicación, este paso es sencillo porque el scrap de la planta de tabaco utilizada como materia prima ya tiene un tamaño de partícula homogéneo y no se contamina con otras partes de la planta como resultado de su procesado en las fábricas de tabaco. Dado que este material está compuesto por trozos de hojas, el método de molienda más conveniente es un molino de cuchillas seguido de un tamizado. El tamaño final de las partículas debe ser inferior a $1 \mathrm{~mm}$. Después de la molienda, el material se extrae con agua, utilizando una relación agua/materia prima de $20 \mathrm{~L} / \mathrm{kg}$, y la fase acuosa se separa por filtración. Teniendo en cuenta el contenido de compuestos extraíbles en la materia prima descrita en la sección 3.1, se estima que de los 1.000 kg de materia prima (895 kg en base seca) se obtienen $573 \mathrm{~kg}$ de compuestos extraíbles, de los cuales $224 \mathrm{~kg}$ corresponden azucares libres, y el resto son otros compuestos sin cuantificar. La valorización de esta última fracción compuesta por los extraíbles en agua menos los azúcares libres, representa prácticamente el $26 \%$ del peso total de la materia prima, deberá ser considerada en futuros trabajos para evaluar su composición.

Después de la extracción acuosa, la fracción de biomasa restante se somete a una extracción supercrítica de $\mathrm{CO}_{2}$. Basándose en los resultados de trabajos anteriores [26], se estima que serían necesarios $3300 \mathrm{~kg}$ de $\mathrm{CO}_{2}$ (circulando en un circuito cerrado) para obtener $10,625 \mathrm{~kg}$ de extracto, considerando una solubilidad de 0,0032 $\mathrm{kg}$ de extracto/kg de $\mathrm{CO}_{2}$ y asumiendo un rendimiento típico de extracción del $90 \%$. Este paso produce $42,5 \mathrm{~kg}$ de extracto que, como se describe en un trabajo anterior [26], puede fraccionarse en dos compuestos de alto valor añadido: solanesol y nicotina.

Después de estos dos pasos de extracción, la biomasa restante, libre de compuestos solubles en agua y $\mathrm{CO}_{2}$, se somete a una hidrólisis de agua supercrítica. Tomando como referencia los resultados reportados en la sección 3.1, se estima que de los $322 \mathrm{~kg}$ de materia prima que llegan a este paso, el 35 \% es proteína, 30\% es celulosa, el $8 \%$ hemicelulosa, el $16 \%$ lignina y el $9 \%$ es celulosa. Esta composición puede dar lugar a un segundo escenario de una biorrefinería donde esta última fracción se utilice para la obtención de proteínas para consumo animal o humano. En este 
sentido Fantozzi et al [33] evaluaron el perfil de aminoácidos de las proteínas obtenidas del tabaco y su calidad es comparable a las proteínas de la soja. Por otra parte, Fu et al [56] lograron recuperar el 94,5\% de las proteínas del tabaco en un proceso donde se retira totalmente la nicotina.

Con los resultados de rendimiento y composición reportados en la sección 3.3, se estima que después de la hidrólisis se obtienen 158 kg de azúcares fermentables, los cuales pueden ser combinados con los azúcares libres extraídos con agua en el paso inicial de extracción y sometidos a fermentación para producir bioetanol. Suponiendo una eficiencia del $90 \%$ en la etapa de fermentación, esto lleva a la producción de $195 \mathrm{~kg}$ de bioetanol y $187 \mathrm{~kg}$ de CO2 que pueden volver a utilizarse como insumo para la extracción con $\mathrm{CO}_{2}$. Además, de la reacción de hidrólisis supercrítica se obtienen también porcentajes menores de ácidos orgánicos y de aldehídos.

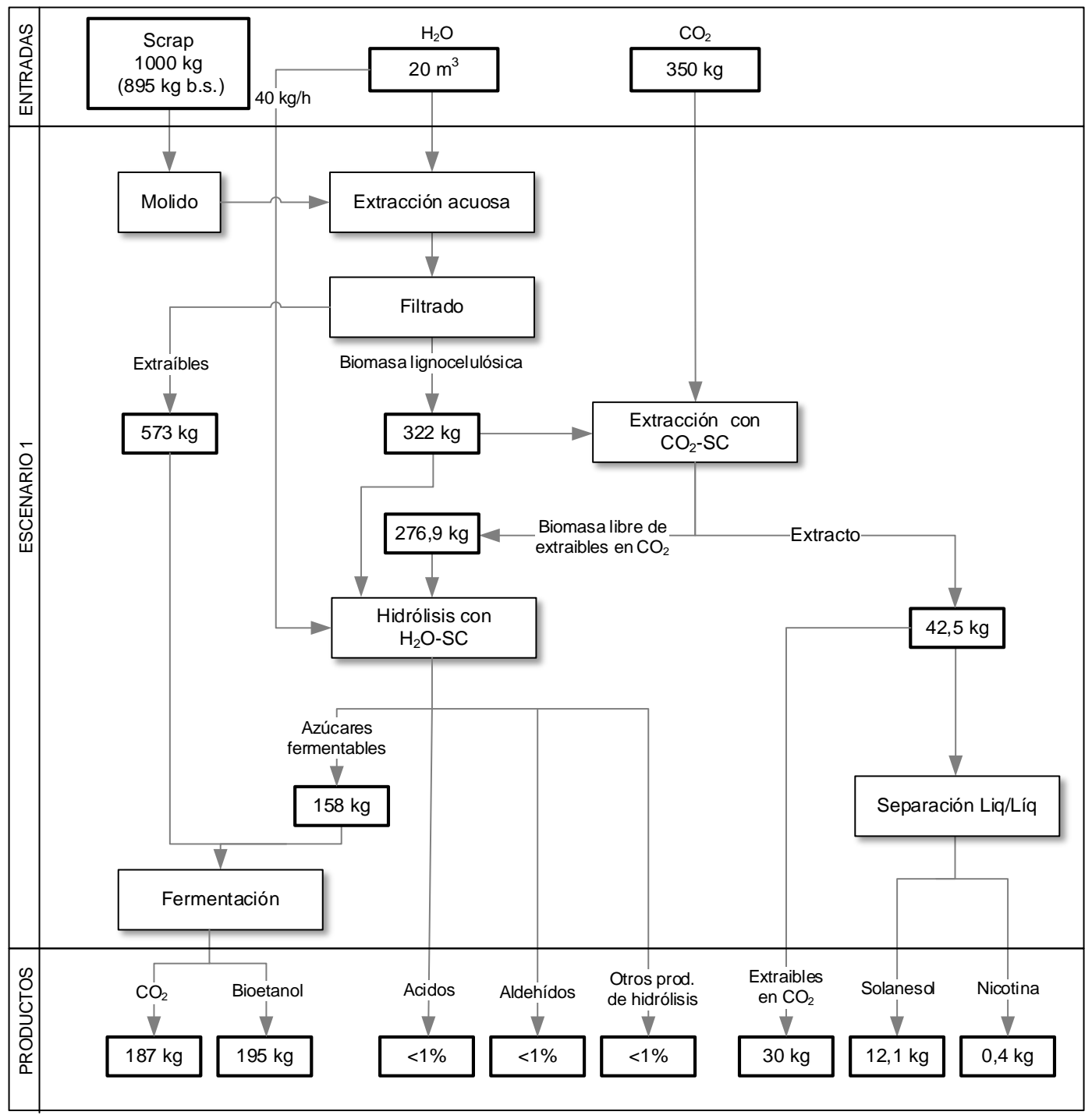

Figura 6. Resultados del balance de masa para el escenario propuesto 


\section{Consumo energético}

En un trabajo previo del grupo se ha estudiado el consumo energético de este proceso y se propuso la integración energética entre la hidrolisis en agua supercrítica y una turbina de gas [57]. En la Figura 7 se presenta el esquema propuesto en ese trabajo. La integración se basa en que el calor requerido por el proceso de hidrolisis es aportado por los efluentes de la turbina de gas y el vapor sobrecalentado que sale del separador flash se inyecta en la entrada de la turbina de gas. La mejora en el funcionamiento de la turbina por la inyección del vapor permite aumentar su producción de trabajo en una cantidad incluso superior a las necesidades del proceso de hidrólisis. Esta estrategia de inyectar vapor en la corriente de entrada de una turbina de gas genera un aumento de la potencia y de la eficiencia térmica y una disminución de las pérdidas generadas por la turbina [58]. El proceso sería energéticamente autosuficiente. Es importante señalar que el efluente líquido que sale de la etapa del flash tiene una concentración en azucares del $40 \%$.

En la Tabla 7 se presentan los requerimientos, caudales y concentración de azúcares de la planta biomasa integrada con la turbina de vapor. El dato más relevante es que el calor necesario para calentar el agua a la temperatura necesaria para la reacción de hidrólisis proviene de la salida de los gases exhaustos de la turbina, por lo tanto, no es necesario generar calor adicional para calentar el agua.

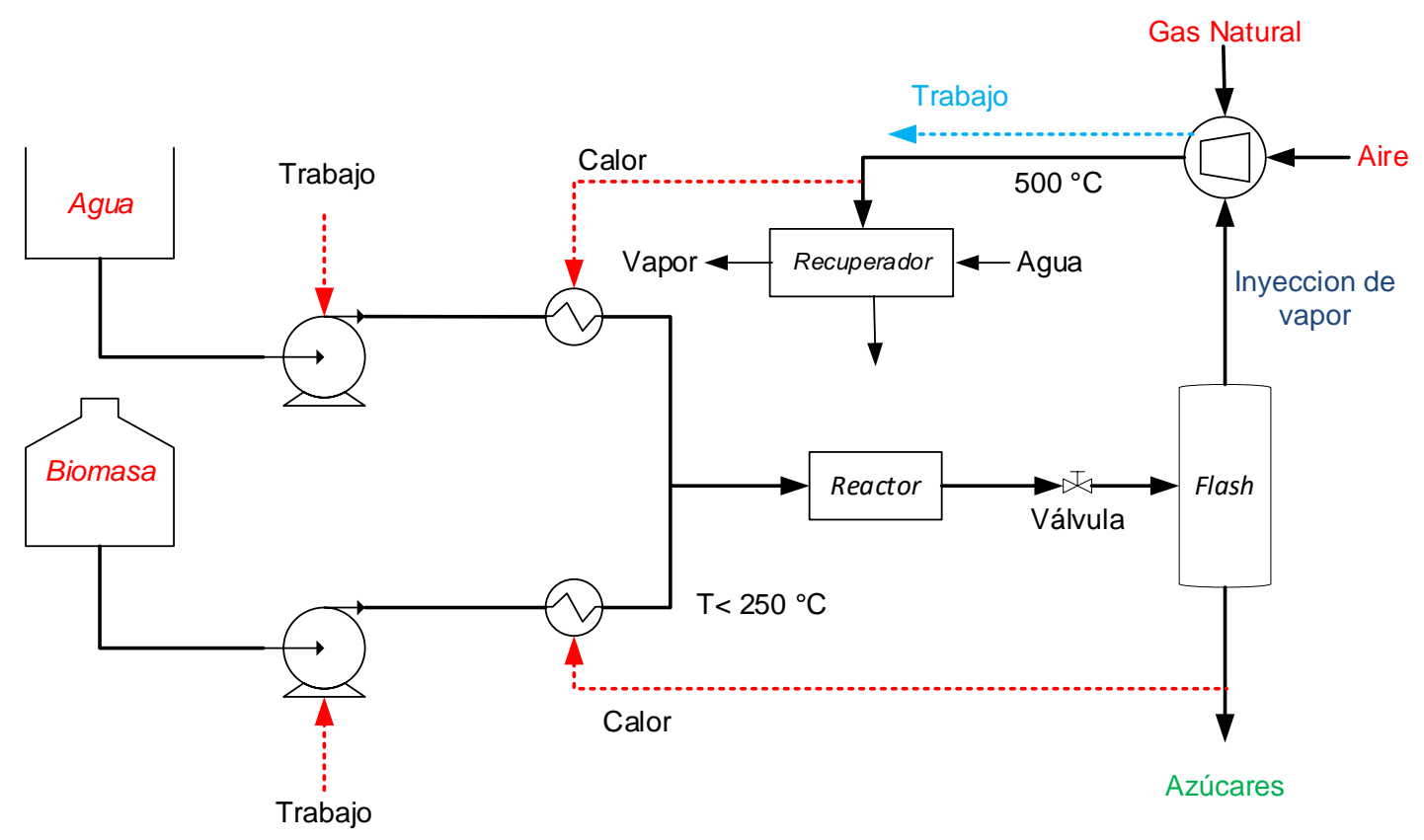

Figura 7. Esquema de la integración del proceso de hidrólisis a una turbina de gas 
Tabla 7. Requerimientos de trabajo, caudales, calor y concentración de azúcares del esquema propuesto[57]

\begin{tabular}{lc}
\hline Trabajo requerido/kg de producto & $19,5 \mathrm{~kW} \mathrm{kg-1}$ \\
Trabajo producido/kg de producto & $28,7 \mathrm{~kW} \mathrm{kg-1}$ \\
Balance de trabajo $/ \mathrm{kg}$ de producto & $9,2 \mathrm{~kW} \mathrm{kg-1}$ \\
$\mathrm{kg}$ de Aire comprimido/kg producto & 131,8 \\
$\mathrm{~kg}$ de Gas Natural/kg producto & 2,22 \\
$\mathrm{~kg}$ producto/kg de azúcar en la corriente de entrada & 0,97 \\
Calor requerido/kg de producto & 0 \\
Concentración de azúcar en la corriente de salida & $0,39 \mathrm{w} \mathrm{w}-1$ \\
\hline
\end{tabular}

\section{Conclusiones}

En este trabajo, se evalúo la hidrólisis con agua supercrítica de scrap y palos, de la industria tabacalera del noroeste argentino. El uso de scrap en los centros de acopio es una ventaja porque permite disponer de la materia prima clasificada y en volúmenes importantes para una biorrefinería, en promedio se pueden disponer de 35.000 tm de scrap por año.

En el estudio de la hidrolisis en ASC se ha operado con dos instalaciones que ha permitido operar en planta laboratorio con partículas de hasta $150 \mathrm{~mm}$, y en planta piloto equipada con una bomba que permitía bombear suspensiones con tamaño de partícula de hasta $500 \mathrm{~mm}$.

- En escala laboratorio se consiguió operar con partículas de tamaño inferior a $150 \mu \mathrm{m}$ se obtuvo un tiempo de reacción optimo del orden de los $170 \mathrm{~ms}$ donde se reducirán las limitaciones a la transferencia de materia aumentando los productos de hidrolisis de los azucares. Con una concentración de 38,5\% de azucares, $42,4 \%$ de aldehídos y $35,2 \%$ de ácidos a un tiempo de 180 milisegundos.

- En la escala piloto, el tamaño de las partículas era de hasta $500 \mu \mathrm{m}$, aumentan las limitaciones a la transferencia de materia y se consigue reducir los productos de hidrólisis de los azucares. Para un tiempo de 170 ms, se consiguió una concentración del 49,1 \% de azucares, con solo un 2,1 \% de aldehídos y 20,8 $\%$ de ácidos.

Los resultados de este capítulo son útiles para la propuesta de una biorrefinería en cascada utilizando como materia prima el scrap y un proceso amigable con el medio ambiente como lo es la hidrólisis con ASC, con las siguientes particularidades: 
Los resultados de este capítulo permiten proponer las etapas de una biorrefinería en cascada utilizando como materia prima el scrap y un proceso amigable con el medio ambiente como lo es la hidrólisis con ASC, con las siguientes particularidades:

- Por cada 1000 kg de scrap, una etapa de extracción con agua permitiría obtener $573 \mathrm{~kg}$ de extractivos ( azucares libres, pectina, proteínas, y otros). Una etapa de separación de proteínas permitiría obtener hasta $112 \mathrm{~kg}$. La etapa de hidrolisis permitiría obtener desde $322 \mathrm{~kg}$ de biomasa libre de extraíbles y proteínas, un efluente liquido con una composición de azucares del $49 \%$, además de aldehídos y ácidos. Este efluente junto a al efluente de la etapa de extracción con agua podrían valorizarse mediante fermentación. 


\section{Bibliografía}

[1] CORESTA, «CRM 38. Determination of Reducing Carbohydrates in Tobacco by Continuous Flow Analysis |». Cooperation Centre for Scientific Research Relative to Tobacco, 2010, Accedido: abr. 14, 2019. [En línea]. Disponible en: https://www.coresta.org/determination-reducing-carbohydrates-tobaccocontinuous-flow-analysis-29164.html.

[2] CORESTA, «CRM89. Determination of the Content of Total Sugars - ContinuousFlow Analysis Method using Hydrochloric Acid / P-Hydroxy Benzoic Acid Hydrazide (PAHBAH)». 2019, Accedido: abr. 14, 2019. [En línea]. Disponible en: https://www.coresta.org/tobacco-determination-content-total-sugars-continuousflow-analysis-method-using-hydrochloric-acid-p.

[3] T. Pang et al., «Determination of Sugars in Tobacco Leaf by HPLC with Evaporative Light Scattering Detection», J. Liq. Chromatogr. Relat. Technol., vol. 29, n. ${ }^{\circ}$ 9, pp. 1281-1289, jun. 2006, doi: 10.1080/10826070600598993.

[4] Z. Švob Troje, Z. Fröbe, y Đ. Perović, «Analysis of selected alkaloids and sugars in tobacco extract», J. Chromatogr. A, vol. 775, n. ${ }^{\circ}$ 1, pp. 101-107, jul. 1997, doi: 10.1016/S0021-9673(97)00281-1.

[5] W. R. Harvey, H. M. Stahr, y W. C. Smith, «Automated determination of reducing sugars and nicotine alkaloids on the same extract of tobacco leaf», Tobacoo Sci. 13, vol. 168, n. ${ }^{\circ} 4$, pp. 48-50, 1969.

[6] W. S. Ryan Jr., «Neutral Sugar Analysis of Tobacco Cell Wall Fractions», Beitr. Zur Tab. Contrib. Tob. Res., vol. 12, n. ${ }^{\circ}$ 3, ene. 1984, doi: 10.2478/cttr-2013-0531.

[7] S. C. Agrupis y E. Maekawa, «Industrial Utilization of Tobacco Stalks (1) Preliminary Evaluation for Biomass Resources», Holzforschung, vol. 53, n. ${ }^{\circ}$, pp. 29-32, 2005, doi: 10.1515/HF.1999.005.

[8] M. Pesevski, B. Iliev, D. Zivkovic, V. Jakimovska-Popovska, M. Srbinoska, y B. Filiposki, «Possibilities for utilization of tobacco stems for production of energetic briquettes», J. Agric. Sci. Belgrade, vol. 55, n. ${ }^{\circ} 1$, pp. 45-54, 2010, doi: 10.2298/JAS1001045P.

[9] O. Akpinar, K. Erdogan, U. Bakir, y L. Yilmaz, «Comparison of acid and enzymatic hydrolysis of tobacco stalk xylan for preparation of xylooligosaccharides», LWT Food Sci. Technol., vol. 43, n. ${ }^{\circ}$ 1, pp. 119-125, ene. 2010, doi: 10.1016/j.Iwt.2009.06.025.

[10] Y. Sun y J. Cheng, «Hydrolysis of lignocellulosic materials for ethanol production: a review», Bioresour. Technol., vol. 83, n. ${ }^{\circ} 1$, pp. 1-11, may 2002, doi: 10.1016/S0960-8524(01)00212-7. 
[11] C. Kasavi et al., «Evaluation of industrial Saccharomyces cerevisiae strains for ethanol production from biomass», Biomass Bioenergy, vol. 45, pp. 230-238, oct. 2012, doi: 10.1016/j.biombioe.2012.06.013.

[12] C. P. Kurtzman y J. W. Fell, Eds., «Part Vb. Descriptions of teleomorphic ascomycetous genera and species», en The yeasts: a taxonomic study, 4th ed., Amsterdam ; New York: Elsevier, 2000, pp. 358-371.

[13] M. Sedlak y N. W. Y. Ho, «Production of ethanol from cellulosic biomass hydrolysates using genetically engineered saccharomyces yeast capable of cofermenting glucose and xylose», Appl. Biochem. Biotechnol., vol. 114, n. ${ }^{\circ} 1-3$, pp. 403-416, mar. 2004, doi: 10.1385/ABAB:114:1-3:403.

[14] L. Fan, M. M. Gharpuray, y Y.-H. Lee, Cellulose Hydrolysis. Berlin Heidelberg: Springer-Verlag, 1987.

[15] C. Martín et al., «Preparation of hydrolysates from tobacco stalks and ethanolic fermentation by Saccharomyces cerevisiae», World J. Microbiol. Biotechnol., vol. 18, n. ${ }^{\circ}$ 9, pp. 857-862, dic. 2002, doi: 10.1023/A:1021258708507.

[16] I. Gutiérrez-Rojas, N. Moreno-Sarmiento, y D. Montoya, «Mecanismos y regulación de la hidrólisis enzimática de celulosa en hongos filamentosos: casos clásicos y nuevos modelos», Rev. Iberoam. Micol., vol. 32, n. ${ }^{\circ} 1$, pp. 1-12, ene. 2015, doi: 10.1016/j.riam.2013.10.009.

[17] Leffingwell, L.C., «Chapter 8. Leaf Chemistry. Basic chemical constituents of tobacco leaf and differences among tobacco types», en Tobacco: Production, chemistry and technology, Oxford; Malden, MA, USA: Blackwell Science, 1999, p. 247.

[18] Harry. Jacin y R. J. Moshy, «Characterization of hemicelluloses in tobacco stems», J. Agric. Food Chem., vol. 16, n. ${ }^{\circ} 4$, pp. 669-672, jul. 1968, doi: 10.1021/jf60158a002.

[19] C. E. Wyman, B. E. Dale, R. T. Elander, M. Holtzapple, M. R. Ladisch, y Y. Y. Lee, «Coordinated development of leading biomass pretreatment technologies», Bioresour. Technol., vol. 96, n. ${ }^{\circ}$ 18, pp. 1959-1966, dic. 2005, doi: 10.1016/j.biortech.2005.01.010.

[20] S. Agrupis, E. Maekawa, y K. Suzuki, «Industrial utilization of tobacco stalks II: preparation and characterization of tobacco pulp by steam explosion pulping», $\mathrm{J}$. Wood Sci., vol. 46, n. ${ }^{\circ}$ 3, p. 222, jun. 2000, doi: 10.1007/BF00776453.

[21] B. Yang, Z. Dai, S.-Y. Ding, y C. E. Wyman, «Enzymatic hydrolysis of cellulosic biomass», Biofuels, vol. 2, n. ${ }^{\circ} 4$, pp. 421-449, jul. 2011, doi: 10.4155/bfs.11.116.

[22] S. Sarbishei, A. Goshadrou, y M. S. Hatamipour, «Mild sodium hydroxide pretreatment of tobacco product waste to enable efficient bioethanol production by 
separate hydrolysis and fermentation», Biomass Convers. Biorefinery, mar. 2020, doi: 10.1007/s13399-020-00644-X.

[23] C. Martin, T. Fernandez, A. Garcia, E. Carrillo, y A. B. Thomsen, «Wet Oxidation Pretreatment of Tobacco Stalks and Orange Waste for Bioethanol Production. Preliminary results», Cellul. Chem. Technol., vol. 42, n. ${ }^{\circ}$ 7-8, pp. 429-434, 2009.

[24] I. Farran, A. F.-S. Millan, M. Ancin, L. Larraya, y J. Veramendi, «Increased bioethanol production from commercial tobacco cultivars overexpressing thioredoxin f grown under field conditions», Mol. Breed., vol. 34, n. ${ }^{\circ}$ 2, pp. 457-469, ago. 2014, doi: 10.1007/s11032-014-0047-x.

[25] S. Kumar, J. L. G. Moscoso, I. Bobe, y P. Majeranowski, «Green process to hydrolyze carbohydrates from tobacco biomass using subcritical water», US20140331993A1, nov. 13, 2014.

[26] G. J. Tita, A. Navarrete, Á. Martín, y M. J. Cocero, «Model assisted supercritical fluid extraction and fractionation of added-value products from tobacco scrap», J. Supercrit. Fluids, submited 2020.

[27] R. Schneider, L. Anacker, M. Szarblewski, L. Silva, M. Moraes, y V. Corbellini, «Bioethanol Production from Residual Tobacco Stalks», Curr. J. Appl. Sci. Technol., vol. 24, n. ${ }^{\circ}$ 6, pp. 1-9, dic. 2017, doi: 10.9734/CJAST/2017/37948.

[28] A. Sluiter, B. Hames, R. Ruiz, C. Scarlata, y J. Sluiter, «Determination of Structural Carbohydrates and Lignin in Biomass Laboratory Analytical Procedure (LAP); Issue Date: 8/3/2012», Tech. Rep., p. 18, 2008.

[29] A. Sluiter, «Determination of Extractives in Biomass: Laboratory Analytical Procedure (LAP); Issue Date 7/17/2005», Tech. Rep., p. 12, 2008.

[30] S. D. Kung y T. C. Tso, «Tobacco as a potential food source and smoke material: soluble protein content, extraction, and amino acid composition», J. Food Sci., vol. 43, n. ${ }^{\circ}$ 6, pp. 1844-1847, nov. 1978, doi: 10.1111/j.1365-2621.1978.tb07428.x.

[31] S. C. Moldoveanu, J. Zhu, y W. A. Scott, «Evaluation of the Content of Free Amino Acids in Tobacco by a New Liquid Chromatography-Tandem Mass Spectrometry Technique», Beitr. Zur Tab. Contrib. Tob. Res., vol. 26, n. ${ }^{\circ}$, ene. 2015, doi: 10.1515/cttr-2015-0023.

[32] NREL, «Nitrogen-to-Protein Factor Calculator», 2019. Nitrogen-to-Protein Factor CalculatorMicrosoft Excel These spreadsheets work best in conj (accedido jul. 09, 2019).

[33] P. Fantozzi y A. Sensidoni, «Protein extraction from tobacco leaves: technological, nutritional and agronomical aspects», Plant Foods Hum. Nutr., vol. 32, n. ${ }^{\circ} 3-4$, pp. 351-368, sep. 1983, doi: 10.1007/BF01091194. 
[34] B. E. Knuckles, G. O. Kohler, y D. De Fremery, «Processing of fresh tobacco leaves for protein fractions», J. Agric. Food Chem., vol. 27, n. ${ }^{\circ} 2$, pp. 414-418, mar. 1979, doi: 10.1021/jf60222a047.

[35] R. Tkachuk, «| Nitrogen-to-Protein Conversion Factors for Cereals and Oilseed Meals.», Cereal Chem., vol. 46, pp. 419-424, 1969.

[36] F. Mariotti, D. Tomé, y P. P. Mirand, «Converting Nitrogen into Protein-Beyond 6.25 and Jones' Factors», Crit. Rev. Food Sci. Nutr., vol. 48, n. ${ }^{\circ} 2$, pp. 177-184, ene. 2008, doi: 10.1080/10408390701279749.

[37] A. Sluiter, «Determination of Sugars, Byproducts, and Degradation Products in Liquid Fraction Process Samples: Laboratory Analytical Procedure (LAP); Issue Date: 12/08/2006», Tech. Rep., p. 14, 2008.

[38] C. M. Martínez, D. A. Cantero, M. D. Bermejo, y M. J. Cocero, «Hydrolysis of cellulose in supercritical water: reagent concentration as a selectivity factor», Cellulose, vol. 22, n. ${ }^{\circ}$, pp. 2231-2243, ago. 2015, doi: 10.1007/s10570-015-06743.

[39] L. Vaquerizo y M. J. Cocero, «Ultrafast heating by high efficient biomass direct mixing with supercritical water», Chem. Eng. J., vol. 378, p. 122199, dic. 2019, doi: 10.1016/j.cej.2019.122199.

[40] D. A. Cantero, M. D. Bermejo, y M. J. Cocero, «Kinetic analysis of cellulose depolymerization reactions in near critical water», J. Supercrit. Fluids, vol. 75, pp. 48-57, mar. 2013, doi: 10.1016/j.supflu.2012.12.013.

[41] D. A. Cantero, M. D. Bermejo, y M. J. Cocero, «Governing Chemistry of Cellulose Hydrolysis in Supercritical Water», ChemSusChem, vol. 8, n. ${ }^{\circ}$ 6, pp. 1026-1033, mar. 2015, doi: 10.1002/cssc.201403385.

[42] C. M. Martínez, T. Adamovic, D. A. Cantero, y M. J. Cocero, «Scaling up the production of sugars from agricultural biomass by ultrafast hydrolysis in supercritical water», J. Supercrit. Fluids, vol. 143, pp. 242-250, ene. 2019, doi: 10.1016/j.supflu.2018.08.017.

[43] T. C. Tso y G. B. Gori, «Leaf Quality and Usability: Theoretical Model I», Beitr. Zur Tab. Contrib. Tob. Res., vol. 8, n. ${ }^{\circ} 4$, ene. 1975, doi: 10.2478/cttr-2013-0375.

[44] C. W. Bacon, R. Wenger, y J. F. Bullock, «Chemical Changes in Tobacco during Flue-Curing», Ind. Eng. Chem., vol. 44, n. ${ }^{\circ}$ 2, pp. 292-296, feb. 1952, doi: 10.1021/ie50506a021.

[45] T. Sakaki, S. Munakata, H. Sakuma, y S. Sugawara, «Gas-liquid Chromatographic Determination of Carbohydrates in Tobacco», Agric. Biol. Chem., vol. 46, n. ${ }^{\circ}$ 3, pp. 827-829, 1982, doi: 10.1271/bbb1961.46.827. 
[46] M. Sasaki, K. Goto, K. Tajima, T. Adschiri, y K. Arai, «Rapid and selective retroaldol condensation of glucose to glycolaldehyde in supercritical water», Green Chem. - GREEN CHEM, vol. 4, pp. 285-287, jun. 2002, doi: 10.1039/b203968k.

[47] Y. Jing et al., «Optimization of the extraction of polysaccharides from tobacco waste and their biological activities», Int. J. Biol. Macromol., vol. 91, pp. 188-197, oct. 2016, doi: 10.1016/j.ijbiomac.2016.05.069.

[48] S. Eda, A. Ohnishi, y K. Kato, «Studies on the chemical structure of tobacco hemicellulose. I. Xylan isolated from the stalk of Nicotiana tabacum.», Agric. Biol. Chem., vol. 40, pp. 359-364, ene. 1976, doi: 10.1271/bbb1961.40.359.

[49] L. N. Jayakody, N. Hayashi, y H. Kitagaki, «Identification of glycolaldehyde as the key inhibitor of bioethanol fermentation by yeast and genome-wide analysis of its toxicity», Biotechnol. Lett., vol. 33, n. ${ }^{\circ} 2$, pp. 285-292, feb. 2011, doi: 10.1007/s10529-010-0437-z.

[50] C. C. Vitasari, «Extraction of bio-based glycolaldehyde from wood-derived pyrolysis oils», 2012, doi: 10.6100/IR738958.

[51] J. C. Parajó, G. Garrote, y H. Domínguez, «Mild autohydrolysis: an environmentally friendly technology for xylooligosaccharide production from wood», J. Chem. Technol. Biotechnol., nov. 1999, doi: 10.1002/(SICl)10974660(199911)74:11<1101::AID-JCTB146>3.0.CO;2-M.

[52] L. Olsson y B. Hahn-Hägerdal, «Fermentation of lignocellulosic hydrolysates for ethanol production», Enzyme Microb. Technol., vol. 18, n. ${ }^{\circ}$ 5, pp. 312-331, abr. 1996, doi: 10.1016/0141-0229(95)00157-3.

[53] S. Larsson et al., «The generation of fermentation inhibitors during dilute acid hydrolysis of softwood», Enzyme Microb. Technol., vol. 24, n. ${ }^{\circ} 3$, pp. 151-159, feb. 1999, doi: 10.1016/S0141-0229(98)00101-X.

[54] M. J. Antal, W. S. L. Mok, y G. N. Richards, «Mechanism of formation of 5(hydroxymethyl)-2-furaldehyde from d-fructose and sucrose», Carbohydr. Res., vol. 199, n. ${ }^{0} 1$, pp. 91-109, may 1990, doi: 10.1016/0008-6215(90)84096-D.

[55] F. Jin, Z. Zhou, A. Kishita, y H. Enomoto, «Hydrothermal conversion of biomass into acetic acid», J. Mater. Sci., vol. 41, n. ${ }^{\circ}$ 5, pp. 1495-1500, mar. 2006, doi: 10.1007/s10853-006-7493-8.

[56] H. Fu, P. A. Machado, T. S. Hahm, R. J. Kratochvil, C. I. Wei, y Y. M. Lo, «Recovery of nicotine-free proteins from tobacco leaves using phosphate buffer system under controlled conditions», Bioresour. Technol., vol. 101, n. ${ }^{\circ} 6$, pp. 20342042, mar. 2010, doi: 10.1016/j.biortech.2009.10.045.

[57] D. A. Cantero, L. Vaquerizo, F. Mato, M. D. Bermejo, y M. J. Cocero, «Energetic approach of biomass hydrolysis in supercritical water», Bioresour. Technol., vol. 179, pp. 136-143, mar. 2015, doi: 10.1016/j.biortech.2014.12.006. 
[58] K. Nishida, T. Takagi, y S. Kinoshita, «Regenerative steam-injection gas-turbine systems», Appl. Energy, vol. 81, n. ${ }^{\circ} 3$, pp. 231-246, jul. 2005, doi: 10.1016/j.apenergy.2004.08.002. 
Capítulo IV.

Estudio sobre el uso del solanesol extraído de scrap de tabaco como precursor de CoQ10 


\section{Introducción}

\subsection{Coenzima Q10, una super-vitamina}

Una coenzima es un cofactor que participa en la función de una enzima aumentando el repertorio de sus capacidades. Sirve, además, para transportar sustratos de un punto a otro dentro de la célula [1]. Una de las coenzimas más estudiadas en los últimos años es la Coenzima Q10 debido principalmente a sus propiedades antioxidantes.

La Coenzima Q10 (CoQ10), o Ubiquinona, juega un rol crucial en la energía celular y la expulsión de los radicales libres en el cuerpo humano. Químicamente es una benzoquinona liposoluble. La letra $Q$ de su nombre refiere al grupo químico quinona y el número 10 al número de subunidades isoprenoides que posee (Figura 18). Su descubrimiento fue el resultado de un arduo trabajo de investigación en los años 50 mientras se estudiaba la función de las mitocondrias en el transporte de energía en las células [2].

La CoQ10 se sintetiza en el cuerpo y está presente naturalmente en todas las células pero, con la edad, la tasa de producción disminuye. Por eso es importante la suplementación en la dieta para la salud. También es conocida como energizante y vitalizante del sistema inmunológico [3]. La CoQ10, administrada oralmente, es beneficiosa para mejorar ciertas patologías en humanos tales como cardiomiopatías, diabetes, encefalomiopatias, ataxias del cerebelo, entre otras. Además, ha ganado creciente popularidad en cosmética como antioxidante previniendo la propagación de la peroxidación de lípidos [4]. Hernández-Camacho et al. [5] relevaron recientemente las enfermedades en humanos, en las cuales la eficacia del uso de la CoQ10 está comprobada. Entre ellas se encuentran las enfermedades cardiovasculares, el síndrome de deficiencia mitocondrial, los procesos inflamatorios crónicos y la protección contra el envejecimiento. En una profunda revisión sobre los efectos de la suplementación en la dieta con CoQ10 contra el envejecimiento, Varela-López et al. [6] recopilaron los antecedentes en los que los investigadores estudiaron los efectos positivos de esta super-vitamina en el aumento de la esperanza de vida, el envejecimiento y las enfermedades relacionadas con la edad.

Además de su función en el transporte de energía en la mitocondria, su gran capacidad antioxidante [7] impactó en el desarrollo de nutraceúticos, suplementos dietarios, y cientos de productos cosméticos como cremas que tienen como función retrasar el envejecimiento de la piel debido al estrés oxidativo, entre otros factores [8], [9]. 


\subsection{Producción de CoQ10}

La CoQ10 puede producirse básicamente por: síntesis química, por síntesis semi-química y conversión microbiana [10].

Shukla y Dubey [4] han publicado una revisión detallada con los antecedentes en síntesis química y biosíntesis mediante microorganismos de CoQ10 concluyendo que el primer método produce una forma de la CoQ10 farmacológicamente menos activa que la producida por los microorganismos. Además, la síntesis química requiere, en algunos casos, de muchas etapas, de temperaturas del orden de $-70{ }^{\circ} \mathrm{C}$ y de varios productos químicos para su elaboración. En cambio, el cultivo de microorganismos se simplifica al cultivo, extracción y purificación, siendo el principal problema desarrollar un proceso de biosíntesis con mayor rendimiento y menores costos. En ese mismo trabajo, los autores manifiestan que para que una cepa de un microorganismo sea comercialmente viable, debe tener un rendimiento mínimo de $500 \mathrm{mg} / \mathrm{L}$ del principio que se busca obtener.

Algunas de las estrategias para aumentar la producción de CoQ10 en microorganismos son: optimización y modificación del potencial de oxidación-reducción del medio de cultivo, estrés oxidativo, aumento de sacarosa y iones Ca+ en el medio de cultivo entre otros [10]. Otra estrategia utilizada tanto en la síntesis química como en la biosíntesis es el uso del solanesol como precursor, tanto de la CoQ10 como de la vitamina $\mathrm{K}$ [11], [12]. Como se mencionó en el capítulo 2, el solanesol es un alcohol terpenoide de cadena abierta, compuesto de nueve unidades isoprenoides, siendo su estructura la misma que la cadena isoprenoide de la CoQ10. En la Figura 1 se puede observar la estructura molecular de la CoQ10, que consta de un anillo de quinona y una cadena de 10 isoprenoides. Esta cadena es aportada por el solanesol en la biosíntesis de la CoQ10 cuando se lo usa como precursor.

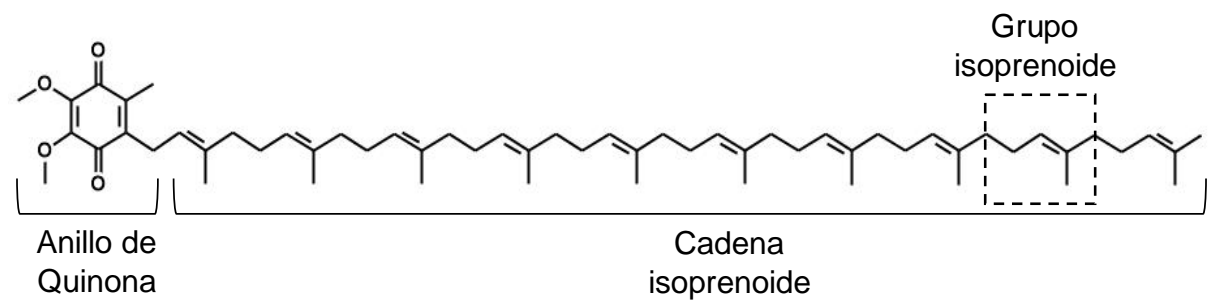

Figura 1. Estructura molecular de la Coenzima Q10

Existen varios antecedentes de producción de CoQ10, usando el solanesol de alta pureza como precursor [11]-[15], sin embargo, existen pocas publicaciones en que utilizan biomasa del tabaco con solanesol o solanesol extraído del tabaco como 
precursor [16], [17]. La desventaja de usar el solanesol de alta pureza es su elevado costo, como lo menciona Lipshutz et al. [14]. Tian et al. [16] demuestran que al agregarle un $20 \%$ de biomasa de tabaco hidrolizada al caldo de cultivo se alcanza un máximo del contenido específico de CoQ10 de 20,4 mg/L contra los 9,8 mg/L del caldo de cultivo control, lo que significa casi un aumento de 2 veces más de producción. A su vez compara el agregado de biomasa de alfalfa y espinaca quienes no aportan mejoras en el rendimiento, si no, que al contrario lo disminuyen. Qie et al. [15] observaron que la cantidad de CoQ10 producida por un cultivo de Sphingonomas llega a un máximo cuando se agota el solanesol utilizado como precursor. Con esta observación desarrollaron una técnica que consiste en adicionar solanesol al caldo de cultivo cada 8 h y logran aumentar casi 10 veces más la cantidad de CoQ10.

Los microorganismos reportados para la producción de CoQ10 incluyen bacterias como Agrobacterium spp, Paracoccus denitrificans, Rhodobacter sphaeroides [18], Sphingonomas sp [15], [19] y levaduras como Rhodotorula glutinis [20] y Sacharomyces cerevisiae [21]. En la tabla 1 se presentan los valores de la producción de CoQ10 por parte de algunos de estos microrganismos. El nombre Agrobacterium tumefaciens fue establecido en 1907 por Smith y Townsend [22] y actualizado por Young [23] en el 2001 a Rhizobium radiobacter siendo esta última denominación la vigente actualmente.

Los principios activos extraídos de las plantas suelen degradarse, oxidarse, o disminuir su eficacia con el paso del tiempo, siendo por eso que suelen formularse con componentes que lo protejan. Para el caso los saborizantes, grasas, aceites y vitaminas se utilizan agentes encapsulantes con una buena resistencia a la oxidación, como por ejemplo almidones modificados químicamente. Además de proteger el principio activo, el agente encapsulante puede tener propiedades que intensifiquen o mejoren la función del mismo y su biodisponibilidad [24]. Como se menciono anteriormente, el solanesol es soluble en etanol, inmiscible en agua y sólido a temperatura ambiente. Disolver este producto en un caldo de cultivo acuoso es un problema que se puede solucionar formulando un producto para su correcta aplicación.

El objetivo de este trabajo es utilizar el solanesol obtenido de la extracción supercrítica con $\mathrm{CO}_{2}$ para elaborar una formulación que facilite el acceso de las células al precursor facilitando su biodisponibilidad, y utilizarlo en un caldo de cultivo acuoso de Rhizobium radiobacter como precursor de la CoQ10. Por último, evaluar el impacto de este precursor en el mejoramiento de la biosíntesis de la CoQ10. . 
Tabla 1. Producción de CoQ10 en distintos microrganismos. Adaptado de [25].

\begin{tabular}{|c|c|c|c|c|c|}
\hline Microorganismo & Precursor & $\begin{array}{l}\text { Incremento de } \\
\text { CoQ10 }\end{array}$ & $\begin{array}{c}\text { CoQ10 } \\
(\mathrm{mg} / \mathrm{l})\end{array}$ & $\begin{array}{c}\text { CoQ10 } \\
(\mathrm{mg} / \mathrm{g} \text { DCW })\end{array}$ & Ref. \\
\hline Pseudomonas N84 & No & - & 2,02 & 1,2 & [10] \\
\hline Protaminobacter ruber & No & - & 2,84 & 1,52 & [10] \\
\hline Rhodospirillum rubrum ATCC 25852 & $\begin{array}{l}\text { Tabaco, alfalfa y } \\
\text { espinaca } \\
\text { hidrolizados }\end{array}$ & Si & 20,40 & 9,21 & [16] \\
\hline Rhodospirillum rubrum ATCC 25852 & Tabaco hidrolizado & Si & 20,16 & - & [17] \\
\hline Escherichia coli BL21/ pACDdsA & No & - & 25,50 & 0,29 & [26] \\
\hline Paracoccus denitrificans ATCC 19367 & No & - & 27,60 & 0,86 & [26] \\
\hline Pseudomonas diminutas NCIM 2865 & Zanahoria/Tomate & Si & 29,22 & - & [27] \\
\hline Spingomonas sp. ZUTEO3 & $\mathrm{PHB}^{*}$ & Si & 441,65 & - & [15] \\
\hline Agrobacterium. tumefaciens KY-8593 & $\mathrm{PHB}^{*}$ & Si & 75 & 1,2 & [28] \\
\hline Agrobacterium tumefaciens ATCC 4452 & No & - & 87,60 & 1,9 & [18] \\
\hline R. sphaeroides FERM-P4675 & No & - & 97,20 & 2,7 & [26] \\
\hline Agrobacterium tumefaciens AU-55 & No & - & 110 & 9,6 & [26] \\
\hline Agrobacterium sp. & No & - & 180 & 1,96 & [10] \\
\hline R. sphaeroides & No & - & 350 & 8,7 & [10] \\
\hline R. spheroides Co-22-11 & $\mathrm{PHB}^{*}$ & Si & 346,80 & 2,6 & [28] \\
\hline R. sphaeroides Co-22-11 & No & - & 347 & 2,5 & [26] \\
\hline $\begin{array}{l}\text { Agrobacterium tumefaciens KCCM } \\
1 \text { K11 }\end{array}$ & No & - & 638 & 9,71 & [29] \\
\hline $\begin{array}{l}\text { Rhodopseudomonas spheroides } \\
\text { ' Nocno }\end{array}$ & No & - & 770 & 8,7 & {$[26]$} \\
\hline Rhizobium rodobacter ATCC 4452 & Solanesol & $\mathrm{Si}$ & 18,5 & 1,3 & Este trabajo \\
\hline
\end{tabular}

*Acido Para-Hidroxibenzoico 


\section{Materiales y Métodos}

\section{$2.1 \quad$ Materiales}

El patrón de CoQ10 (>98\% HPLC) fue provisto por Sigma Alldrich. Se utilizó Cellyctic-B (Sigma-Alldrich) para provocar la lisis de las células y extraer la CoQ10. EI solanesol utilizado fue separado de un extracto obtenido desde residuos de hojas de tabaco Virginia con $\mathrm{CO}_{2}$ supercrítico previamente. La concentración original de solanesol en el extracto fue de 26 \% y luego de una separación líquido-líquido alcanzó el $91 \%$. El solanesol, en estas condiciones de concentración y temperatura ambiente, se encuentra en estado sólido. Para los ensayos, se disolvió solanesol en éter a una concentración de $150 \mathrm{mg} / \mathrm{L}$, usando esta misma solución también para preparar una emulsión. Para esta emulsión se utilizó un agente encapsulante a base de almidón modificado de maíz (N-Lok 1930 ® de Ingredion).

\subsection{Microorganismos y medio de cultivo}

La cepa liofilizada de Rhizobium radiobacter (CECT 4364, ATCC 4452, IAM 1525, IFO 12667) fue provista por la Colección Española de Cultivos Tipo como cultivo activo. Se reconstituyó la cepa en un Erlenmeyer de $100 \mathrm{~mL}$ con un caldo nutritivo número 1 (Sigma Aldrich) compuesto de peptona (15 g/L), extracto de levadura (3 g/L), cloruro de sodio (6 g/L), glucosa ( $1 \mathrm{~g} / \mathrm{L})$. Para obtener un cultivo semilla (Tabla 2$)$, el caldo de cultivo control se formuló con sacarosa (50 g/L), licor de maíz fuerte (40 g/L), $\left(\mathrm{NH}_{4}\right)_{2} \mathrm{SO}_{4}$ (10 g/L), $\mathrm{K}_{2} \mathrm{HPO}_{4}(0,5 \mathrm{~g} / \mathrm{L}), \mathrm{KH}_{2} \mathrm{PO}_{4}(0,25 \mathrm{~g} / \mathrm{L}), \mathrm{MgSO}_{4} .7 \mathrm{H}_{2} \mathrm{O}(0,25 \mathrm{~g} / \mathrm{L}), y \mathrm{CaCl}_{2}(6 \mathrm{~g} / \mathrm{L})$, se reguló el pH a un valor de 7,0 (Tabla 3).

\subsection{Cultivo de Rhizobium radiobacter}

El cultivo semilla se utilizó para inocular $200 \mathrm{~mL}$ de caldo de en frascos Erlenmeyer de $250 \mathrm{~mL}$ previamente esterilizados a $121^{\circ} \mathrm{C}$ durante 15 minutos en una autoclave. Los frascos se incubaron a $32^{\circ} \mathrm{C}$ y 200 rpm en un agitador orbital durante 96 y $122 \mathrm{~h}$ Se realizó un cultivo control y ensayos agregando solanesol disuelto en éter, y una emulsión de solanesol y N-Lok. El peso de células secas (DCW) se determinó secando en estufa $2 \mathrm{~mL}$ de muestra. En los experimentos se utilizó la composición del caldo de cultivo del trabajo de Yoshida et al. [18], en combinación con el trabajo de $\mathrm{Ha}$ et al. [30] quienes al agregarle $40 \mathrm{mM}$ de $\mathrm{CaCl}_{2} .6 \mathrm{H}_{2} \mathrm{O}$ aumentaron la producción específica de CoQ10 en la misma cepa de Rhizobium rodobacter (ATCC 4452) de este trabajo. Este caldo de cultivo fue optimizado para este microorganismo y para la obtención de CoQ10 
en el trabajo de $\mathrm{Ha}$ et al. [31] determinando que la mejor fuente de carbono es la sacarasa y la mejor fuente de nitrógeno es el CSP.

Tabla 2. Composición del caldo semilla ( $g / L)$

\begin{tabular}{ccccc}
\hline Glucosa & Peptona & $\begin{array}{c}\text { Extracto de } \\
\text { levadura }\end{array}$ & Cloruro de Sodio & Ref. \\
\hline 60 & 15 & 15 & 7,5 & {$[29]$} \\
60 & 15 & 15 & 7,5 & {$[31]$} \\
20 & 10 & 10 & 5 & {$[18]$} \\
1 & 15 & 3 & 6 & Este trabajo \\
\hline
\end{tabular}

Tabla 3. Composición del caldo de cultivo (g/L)

\begin{tabular}{cccccccc}
\hline Sacarosa & $\mathrm{CSP} \mathrm{CSL}^{\mathrm{a}}$ & $\left(\mathrm{NH}_{4}\right)_{2} \mathrm{SO}_{4}$ & $\mathrm{~K}_{2} \mathrm{HPO}_{4}$ & $\mathrm{KH}_{2} \mathrm{PO}_{4}$ & $\mathrm{MgSO}_{4} .7 \mathrm{H}_{2} \mathrm{O}$ & $\mathrm{CaCO}_{3}$ & Ref. \\
\hline 50 & $40(\mathrm{CSP})$ & 10 & 0,5 & 0,5 & 0,25 & 2 & {$[29]$} \\
50 & $40(\mathrm{CSP})$ & 10 & 0,5 & 0,5 & 0,25 & - & {$[31]$} \\
$50^{\mathrm{b}}$ & $40(\mathrm{CSL})$ & 0,5 & 0,5 & 0,5 & 0,25 & 20 & {$[18]$} \\
50 & $40(\mathrm{CSL})$ & 10 & 0,5 & 0,5 & 0,25 & - & $\begin{array}{c}\text { Este } \\
\text { trabajo }\end{array}$ \\
\hline
\end{tabular}

\subsection{Emulsión de solanesol}

Se utilizaron $8 \mathrm{~g}$ de N-Lok en $800 \mathrm{~mL}$ de agua, y se le agregaron $200 \mathrm{~mL}$ de la solución de solanesol disuelto en éter, con una concentración de solanesol de 150 mg/L. Esta mezcla se introdujo en un dispersor con camisa refrigerante Ultraturrax 2000/4 (IkaWerke $\mathrm{GmbH} \& \mathrm{Co} . \mathrm{Kg}$ ) para obtener una emulsión con una fase dispersada lipofílica y una fase continua hidrofílica $(\mathrm{O} / \mathrm{W})$. La emulsión se colocó en un rotavapor a $50^{\circ} \mathrm{C}$ para retirar el éter.

\subsection{Extracción de la CoQ10}

Al finalizar el tiempo de cultivo se sacaron $2 \mathrm{~mL}$ de muestra en un tubo eppendorf, la muestra se centrifugó durante 10 minutos, y el sobrenadante se descartó. Se realizó la resuspensión de las células en agua destilada y se centrifugó nuevamente para eliminar residuos del caldo de cultivo. Luego, se agregaron $2 \mathrm{~mL}$ de CelLyctic-B y se mantuvo esta mezcla durante 30 minutos en ultrasonido para provocar la lisis de las células. Luego de la lisis, se agregaron $50 \mathrm{~mL}$ de hexano y se agitó durante 30 minutos. Esta muestra se filtró y se inyecto en HPLC para cuantificar la cantidad de CoQ10.

\subsection{Determinación de CoQ10}

La determinación de la cantidad de CoQ10 se realizó en un equipo HPLC. La columna utilizada fue una Symmetry (Waters $5 \mu \mathrm{m} 4.6$ x 150mm), estando la fase móvil compuesta por una mezcla metanol:hexano (83:17), con un caudal de 0,6 mL/min, manteniendo la temperatura de esta en $30^{\circ} \mathrm{C}$. La longitud de onda del detector UV 
utilizado fue de $275 \mathrm{~nm}$. En la Figura 2 se presenta la recta de calibración obtenida en donde si bien se obtuvo un $\mathrm{R}^{2}$ con un valor de 0,97 se puede observar que en el rango de las muestras obtenidas (<40 ppm) la linealidad es buena.

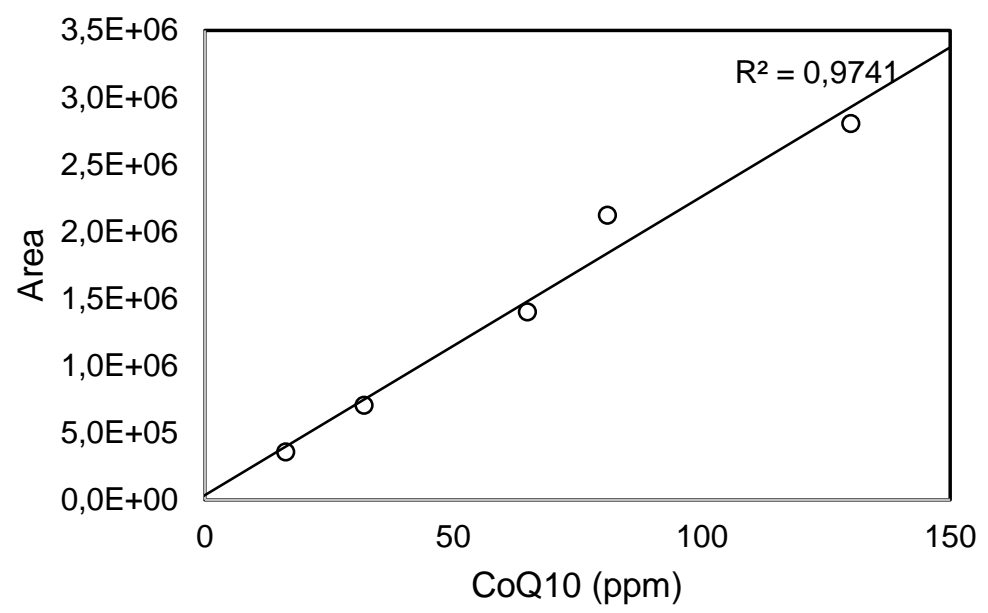

Figura 2. Recta de calibración de la CoQ10 en HPLC

\section{Resultados y discusión}

El cultivo de Rhizobium radiobacter se realizó en un caldo de cultivo acuoso y, debido que el solanesol es soluble en grasas y solventes orgánicos, se buscó aumentar la disponibilidad del solanesol para las bacterias en suspensión. En ensayos preliminares se hicieron pruebas agregando solanesol disuelto en hexano, y agregando una formulación de partículas sólidas generadas con secado por spray con $\mathrm{CO}_{2}$. En el primer caso, la fase orgánica con solanesol se mantuvo separada de la fase acuosa y no hubo aumento de la producción de CoQ10. En el segundo caso, las partículas no llegaban a disolverse y tampoco hubo aumento de la producción de CoQ10, probablemente, la temperatura de cultivo utilizada $\left(32^{\circ} \mathrm{C}\right)$ haya sido muy baja para poder provocar una correcta disolución de las partículas. Los resultados de estos experimentos no se presentan en este trabajo. Luego de estos ensayos preliminares, se eligió utilizar la emulsión O/W que se preparó para el secado por spray para disolver el solanesol en el caldo de cultivo acuoso. Este procedimiento es considerablemente más sencillo y económico que otros presentados en la bibliografía. Por ejemplo, Zhong et al. [19] disuelve dos precursores de la CoQ10, solanesol y acido p-hidroxibenzoico en una mezcla con alcohol isopropílico y luego le agrega las células de los microorganismos previamente cultivada. Este proceso se realiza en un sistema bifásico y solo logra aumentar 1,5 veces la producción de CoQ10 en comparación al cultivo control.

La extracción de la CoQ10 se realizó con el método propuesto por Wu y Tsai [32] quienes compararon distintos métodos de ruptura de células para recuperar la CoQ10 
como: ruptura con enzimas, ruptura térmica, ruptura química y ruptura mecánica. Obteniendo el máximo rendimiento con el uso de CelLyctic $B$.

En la Tabla 2 se presentan 5 ensayos realizados por duplicado, el ensayo control corresponde al caldo de cultivo sin agregados, los ensayos 2 y 3 corresponden al caldo de cultivo al cual se le agregaron 10 y $15 \mathrm{~mL}$ respectivamente de la solución de N-Lok, sin solanesol -para descartar que el aumento de la producción de CoQ10 se deba a este componente- y por último los ensayos 4 y 5 corresponden al agregado de 10 y $15 \mathrm{~mL}$ de la emulsión de N-lok con una concentración de solanesol de $3 \mu \mathrm{g} / \mathrm{mL}$ de solución.

En las Figuras 3 y 4 puede observarse que el agregado de $\mathrm{N}$-lok sin solanesol no provocó ningún cambio en la producción de CoQ10, ni en el crecimiento celular, por lo que no aporta nutrientes para las bacterias. En las mismas, también se observa que una muy pequeña cantidad de solanesol $(30 \mu \mathrm{g})$ provocó un aumento de la producción específica de CoQ10 de 9 y 11 veces en los ensayos a 96 y 122 h de cultivo respectivamente. Si consideramos el aumento de la cantidad de CoQ10 producida por litro de solución, el valor obtenido es 17 y 21 veces mayor en las muestras 4 y 5 que su correspondiente muestra control. La cantidad de CoQ10 producida en los ensayos con 10 y $15 \mathrm{~mL}$ de N-lok y solanesol es similar para los ensayos a 96 y 122 h, como así también el crecimiento celular que, probablemente, se haya encontrado en un punto máximo para la dosificación de esta emulsión de solanesol. Un dato interesante es que la biomasa de células aumentó solo 1,8 veces, entre los ensayos 4 y 5 versus el control. Por lo tanto, se podría decir que el aumento de la producción específica de CoQ10 es muy importante.

Ha et al. [29] observaron en el cultivo de esta bacteria que cuando se consumía toda la sacarosa del caldo de cultivo ocurría una disminución de la tasa de crecimiento celular, de la producción de CoQ10 y un aumento de la producción de subproductos del crecimiento celular como los exopolisacaridos. Al reponer la cantidad original de sacarosa cada 12 h se logró aumentar la cantidad especifica de CoQ10 desde 320 mg/L hasta $638 \mathrm{mg} / \mathrm{L}$ y el crecimiento celular desde 48,4 g/L hasta 67,7 mg/L.

Por último, en la Figura 5, se presentan los cromatogramas obtenidos por HPLC de la muestra control y de la muestra con la mayor producción específica de CoQ10 (muestra 5). Se observa que el área de la CoQ10, relativa a los demás componentes es considerablemente mayor en el cromatograma de la muestra 5. 
Tabla 2. Ensayos de cultivo de Rhizobium rodobacter con solanesol

\begin{tabular}{|c|c|c|c|c|c|}
\hline & Ensayos & $\mathrm{DCW}(\mathrm{g} / \mathrm{L})$ & CoQ10 (mg/L) & $\begin{array}{c}\text { CoQ10 }(\mathrm{mg} / \mathrm{g} \\
\text { DCW })\end{array}$ & Incremento \\
\hline M1 & Control $96 \mathrm{~h}$ & $7,300 \pm 1,626$ & $0,716 \pm 0,026$ & $0,101 \pm 0,026$ & 1 \\
\hline M2 & Control + $10 \mathrm{~mL} \mathrm{~N}$-lok & $7,375 \pm 0,176$ & $0,729 \pm 0,012$ & $0,099 \pm 0,001$ & 1 \\
\hline M3 & Control + $15 \mathrm{~mL} \mathrm{N-lok}$ & $7,650 \pm 0,494$ & $0,739 \pm 0,045$ & $0,097 \pm 0,012$ & 1 \\
\hline M4 & Control + 10 mL N-lok + $30 \mu \mathrm{g}$ solanesol $96 \mathrm{~h}$ & $13,200 \pm 0,141$ & $12,523 \pm 1,335$ & $0,948 \pm 0,091$ & 9 \\
\hline M5 & Control $+10 \mathrm{~mL} \mathrm{N-lok}+30 \mu \mathrm{g}$ solanesol $120 \mathrm{~h}$ & $13,775 \pm 1,025$ & $15,240 \pm 4,553$ & $1,097 \pm 0,249$ & 11 \\
\hline M6 & Control + $15 \mathrm{~mL} \mathrm{N-lok}+45 \mu \mathrm{g}$ solanesol $96 \mathrm{~h}$ & $7,650 \pm 0,495$ & $5,165 \pm 0,577$ & $0,673 \pm 0,032$ & 7 \\
\hline
\end{tabular}

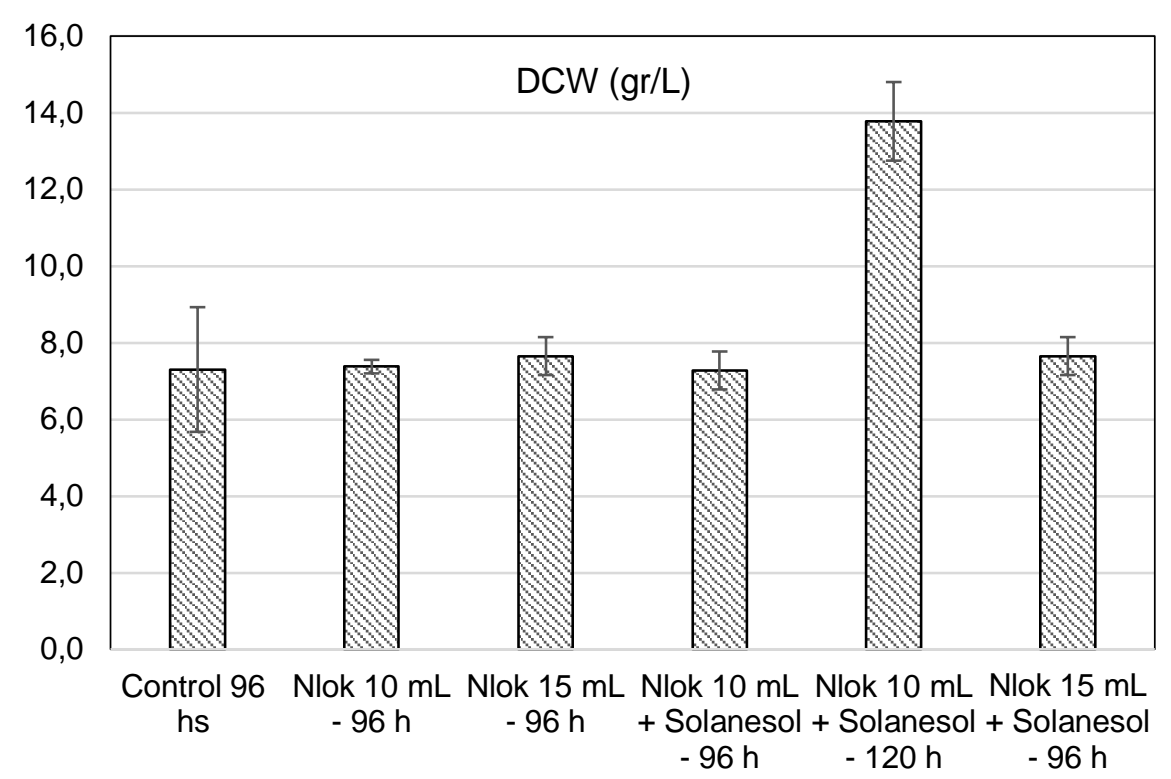

Figura 3. Aumento de la concentración celular en el cultivo de Rhizobium sp.

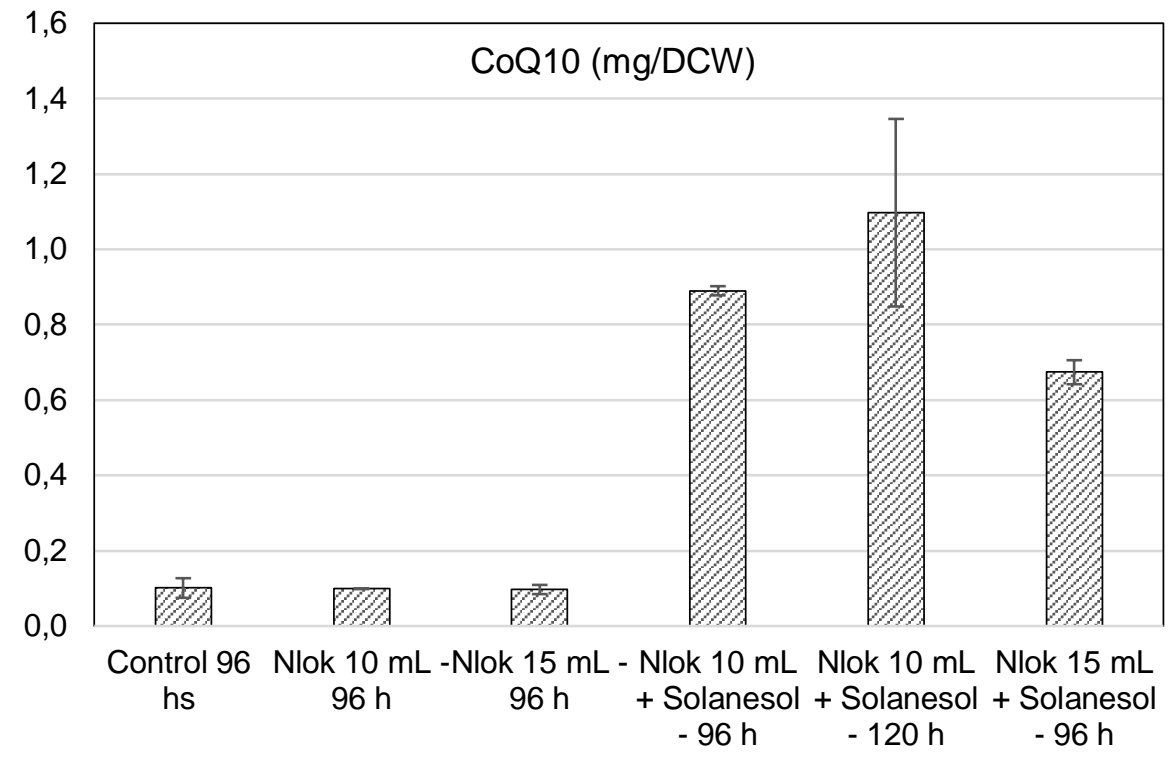

Figura 4. Producción específica de CoQ10 en el cultivo de Rhizobium 

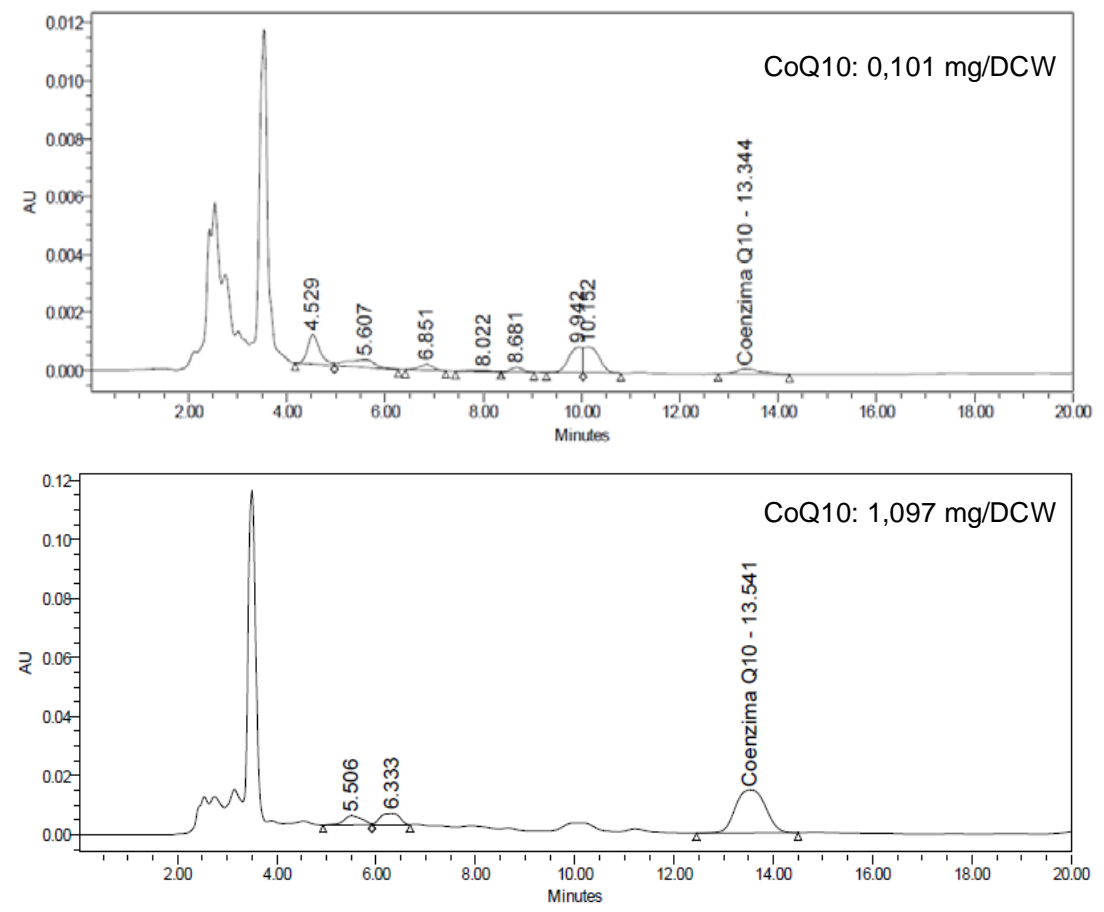

Figura 5. Cromatogramas HPLC. Muestra 1 control (arriba) Muestra 5 (abajo)

Uno de los aspectos mas importantes que se puede observar en las Figuras 3 y 4 , particularmente en los ensayos a 96 y 120 h, es que además de haber un aumento de la cantidad específica de CoQ10 por parte de las bacterias, también se observa un aumento del crecimiento celular al pasar de 96 a 120 h de cultivo. Para la muestra de $96 \mathrm{~h}$ y con agregado de $10 \mathrm{~mL}$ de $\mathrm{N}$-Lok con solanesol la cantidad de células es similar al cultivo sin solanesol pero con mayor producción específica de CoQ10. Ha et al. [31] estudiaron la influencia de la temperatura, el pH, las fuente de nitrógeno y de carbono y el oxigeno disuelto en el cultivo de esta misma bacteria y todas estas variables tienen impacto en la producción de CoQ10. Por esta razón, ensayos mas profundos son necesarios para optimizar la producción de CoQ10 con solanesol del tabaco virginia como precursor.

De los resultados de la tabla 2, se puede observar que el error en las muestras con mayor contenido de CoQ10 es mayor en comparación con las muestras control que tienen muy poco error. Wu y Tsai [32] observaron que, si bien el método de extracción con enzimas es el de mayor rendimiento, tiene poca reproducibilidad y esto se podría deber a la baja estabilidad de las enzimas. Este método de extracción de la CoQ10 no es recomendable para escalas mas grandes debido a su costo. Bule y Singhal [33] compararon la extracción de CoQ10 con hexano y $\mathrm{CO}_{2} \mathrm{SC}$ desde una biomasa de Pseudomonas diminuta y obtuvieron el $100 \%$ con hexano y el $96,2 \%$ con $\mathrm{CO}_{2} \mathrm{SC}$ usando 
etanol como solvente. Presentándose la extracción con $\mathrm{CO}_{2} \mathrm{SC}$ como una buena opción para la extracción de este principio activo.

\section{Conclusiones.}

Como se expresó en el punto 1, el presente trabajo tiene como objetivo utilizar el extracto obtenido desde scrap de tabaco Virginia con $\mathrm{CO}_{2}$ supercrítico para comprobar su eficacia como precursor de la CoQ10. Con los resultados obtenidos, se pudo comprobar el uso del solanesol como precursor por medio del cultivo de Rhizobium radiobacter. Además:

- Se logró aumentar la producción específica de CoQ10 en un factor de 11 veces la concentración en el cultivo control.

- Con una simple y económica emulsión O/W se logró disolver el precursor lipofílico solanesol, haciéndolo soluble en el caldo de cultivo acuoso.

- Se descartó que el aumento de la producción específica de CoQ10 sea consecuencia del almidón modificado para la emulsión.

Para futuros trabajos podría trabajarse en aumentar el crecimiento celular (optimizando el medio de cultivo), realizar dosificaciones periódicas del precursor durante el cultivo cada 8 h y optimizar la concentración del solanesol en la emulsión. 


\section{Bibliografía}

[1] R. K. Murray, H. A. Harper, y B. Rivera Muñoz, Harper: bioquímica ilustrada. México [etc.: McGraw-Hill, 2013.

[2] F. L. Crane, «Discovery of ubiquinone (coenzyme Q) and an overview of function», Mitochondrion, vol. 7, Supplement, pp. S2-S7, jun. 2007, doi: 10.1016/j.mito.2007.02.011.

[3] X.-L. Cao, Y.-T. Xu, G.-M. Zhang, S.-M. Xie, Y.-M. Dong, y Y. Ito, «Purification of coenzyme Q10 from fermentation extract: High-speed counter-current chromatography versus silica gel column chromatography», J. Chromatogr. A, vol. 1127 , n. ${ }^{0} 1-2$, pp. 92-96, sep. 2006, doi: 10.1016/j.chroma.2006.05.083.

[4] S. Shukla y K. K. Dubey, «CoQ10 a super-vitamin: review on application and biosynthesis», 3 Biotech, vol. 8, n. ${ }^{\circ}$ 5, may 2018, doi: 10.1007/s13205-018-12716.

[5] J. D. Hernández-Camacho, M. Bernier, G. López-Lluch, y P. Navas, «Coenzyme Q10 Supplementation in Aging and Disease», Front. Physiol., vol. 9, p. 44, feb. 2018, doi: 10.3389/fphys.2018.00044.

[6] A. Varela-López, F. Giampieri, M. Battino, y J. Quiles, «Coenzyme Q and Its Role in the Dietary Therapy against Aging», Molecules, vol. 21, n. ${ }^{\circ} 3$, p. 373, mar. 2016, doi: 10.3390/molecules21030373.

[7] F. L. Crane, «Biochemical functions of coenzyme Q10», J. Am. Coll. Nutr., vol. 20, n. ${ }^{\circ} 6$, pp. 591-598, dic. 2001.

[8] A. Knott et al., «Topical treatment with coenzyme Q10-containing formulas improves skin's Q10 level and provides antioxidative effects», Biofactors Oxf. Engl., vol. 41, n. ${ }^{\circ}$ 6, pp. 383-390, nov. 2015, doi: 10.1002/biof.1239.

[9] S. S. Parmar, A. Jaiwal, O. P. Dhankher, y P. K. Jaiwal, «Coenzyme Q10 production in plants: current status and future prospects», Crit. Rev. Biotechnol., vol. 35, n. ${ }^{\circ}$ 2, pp. 152-164, abr. 2015, doi: 10.3109/07388551.2013.823594.

[10] M. Jeya, H.-J. Moon, J.-L. Lee, I.-W. Kim, y J.-K. Lee, «Current state of coenzyme $\mathrm{Q}(10)$ production and its applications», Appl. Microbiol. Biotechnol., vol. 85, n. ${ }^{\circ}$ 6, pp. 1653-1663, feb. 2010, doi: 10.1007/s00253-009-2380-2.

[11] Y. Naruta, «Regio- and stereoselective synthesis of coenzymes Qn ( $n=2-10)$, vitamin K, and related polyprenylquinones», J. Org. Chem., vol. 45, n. ${ }^{\circ} 21$, pp. 4097-4104, oct. 1980, doi: 10.1021/jo01309a006.

[12] K. Hamamura et al., "Synthesis of [3'-14C] coenzyme Q10», J. Label. Compd. Radiopharm., vol. 45, n. ${ }^{\circ}$ 10, pp. 823-829, 2002, doi: 10.1002/jlcr.588. 
[13] B. H. Lipshutz, P. Mollard, S. S. Pfeiffer, y W. Chrisman, «A Short, Highly Efficient Synthesis of Coenzyme Q10», J. Am. Chem. Soc., vol. 124, n. ${ }^{\circ} 48$, pp. 1428214283, dic. 2002, doi: 10.1021/ja021015v.

[14] B. H. Lipshutz, A. Lower, V. Berl, K. Schein, y F. Wetterich, «An Improved Synthesis of the "Miracle Nutrient" Coenzyme Q ${ }_{10}$ », Org. Lett., vol. 7, n. ${ }^{\circ}$ 19, pp. 4095-4097, sep. 2005, doi: 10.1021/ol051329y.

[15] L. Qiu et al., «Coenzyme Q10 production by immobilized Sphingomonas sp. ZUTE03 via a conversion-extraction coupled process in a three-phase fluidized bed reactor», Enzyme Microb. Technol., vol. 50, n. ${ }^{\circ}$ 2, pp. 137-142, feb. 2012, doi: 10.1016/j.enzmictec.2011.11.006.

[16] Y. Tian et al., «Tobacco biomass hydrolysate enhances coenzyme Q10 production using photosynthetic Rhodospirillum rubrum», Bioresour. Technol., vol. 101, n. ${ }^{\circ} 20$, pp. 7877-7881, oct. 2010, doi: 10.1016/j.biortech.2010.05.020.

[17] Y. Tian, P. Machado, H. Fu, T.-S. Hahm, C.-I. Wei, y Y. Lo, «Photosynthetic Bioconversion of Coenzyme Q(10) Using Agrowaste Generated from Tobacco Biorefinery for Nonsmoking Applications: A Review», J. Food Drug Anal., vol. 20, pp. 173-178, 2012.

[18] H. Yoshida, Y. Kotani, K. Ochiai, y K. Araki, «Production of ubiquinone-10 using bacteria», J. Gen. Appl. Microbiol., vol. 44, n. ${ }^{0}$ 1, pp. 19-26, feb. 1998.

[19] W. Zhong, J. Fang, H. Liu, y X. Wang, «Enhanced production of CoQ10», J. Ind. Microbiol. Biotechnol., vol. 36, n. ${ }^{0}$ 5, pp. 687-693, feb. 2009, doi: 10.1007/s10295009-0538-7.

[20] P. A. Balakumaran y S. Meenakshisundaram, «Modeling of Process Parameters for Enhanced Production of Coenzyme Q10 From Rhodotorula glutinis», Prep. Biochem. Biotechnol., vol. 45, n. ${ }^{\circ} 4$, pp. 398-410, may 2015, doi: 10.1080/10826068.2014.923447.

[21] S. I. Vicas, L. Vasile, y D. Uivarosan, «Stimulation of biosynthesis of coenzyme Q10 by Sacharomyces cerevisiae under the influence of vitamin B1.», Analele Univ. Din Oradea Fasc. Ecotoxicologie Zooteh. Și Tehnol. Ind. Aliment., pp. 693700, 2009.

[22] «ITIS Standard Report Page: Agrobacterium tumefaciens». https://www.itis.gov/servlet/SingleRpt/SingleRpt?search_topic=TSN\&search_valu e=967928\#null (accedido nov. 18, 2019).

[23] J. M. Young, L. D. Kuykendall, E. Martínez-Romero, A. Kerr, y H. Sawada, «A revision of Rhizobium Frank 1889, with an emended description of the genus, and the inclusion of all species of Agrobacterium Conn 1942 and Allorhizobium 
undicola de Lajudie et al. 1998 as new combinations: Rhizobium radiobacter, $\mathrm{R}$. rhizogenes, R. rubi, R. undicola and R. vitis.», Int. J. Syst. Evol. Microbiol., vol. 51, n. ${ }^{\circ} 1$, pp. 89-103, 2001, doi: 10.1099/00207713-51-1-89.

[24] Á. Martín, S. Rodríguez-Rojo, A. Navarrete, E. de Paz, J. Queiroz, y M. J. Cocero, «CHAPTER 8:Post-extraction Processes: Improvement of Functional Characteristics of Extracts», en Natural Product Extraction, 2013, pp. 285-313.

[25] J. de D. Ndikubwimana y B. H. Lee, «Enhanced production techniques, properties and uses of coenzyme Q10», Biotechnol. Lett., vol. 36, n. ${ }^{\circ}$ 10, pp. 1917-1926, oct. 2014, doi: 10.1007/s10529-014-1587-1.

[26] Jin-Ho Choi, Yeon-Woo Ryu, y Jin-Ho Seo, «Biotechnological production and applications of coenzyme Q10», Appl. Microbiol. Biotechnol., vol. 68, n. ${ }^{\circ}$ 1, pp. 915, jul. 2005, doi: 10.1007/s00253-005-1946-x.

[27] M. V. Bule y R. S. Singhal, «Use of carrot juice and tomato juice as natural precursors for enhanced production of ubiquinone- 10 by Pseudomonas diminuta NCIM 2865», Food Chem., 2009, Accedido: dic. 04, 2019. [En línea]. Disponible en: http://agris.fao.org/agris-search/search.do?recordID=US201301622158.

[28] C. P. Cluis et al., «Identification of bottlenecks in Escherichia coli engineered for the production of CoQ(10)», Metab. Eng., vol. 13, n. ${ }^{\circ}$ 6, pp. 733-744, nov. 2011, doi: 10.1016/j.ymben.2011.09.009.

[29] S.-J. Ha, S.-Y. Kim, J.-H. Seo, H.-J. Moon, K.-M. Lee, y J.-K. Lee, «Controlling the sucrose concentration increases Coenzyme Q10 production in fed-batch culture of Agrobacterium tumefaciens», Appl. Microbiol. Biotechnol., vol. 76, n. ${ }^{\circ} 1$, pp. 109-116, ago. 2007, doi: 10.1007/s00253-007-0995-8.

[30] S.-J. Ha et al., «Ca2+ increases the specific coenzyme Q10 content in Agrobacterium tumefaciens», Bioprocess Biosyst. Eng., vol. 32, n. ${ }^{\circ}$ 5, pp. 697700, ago. 2009, doi: 10.1007/s00449-009-0318-9.

[31] S.-J. Ha, S.-Y. Kim, J.-H. Seo, D.-K. Oh, y J.-K. Lee, «Optimization of culture conditions and scale-up to pilot and plant scales for coenzyme Q10 production by Agrobacterium tumefaciens», Appl. Microbiol. Biotechnol., vol. 74, n. ${ }^{\circ}$ 5, pp. 974980, abr. 2007, doi: 10.1007/s00253-006-0744-4.

[32] H.-S. Wu y J.-J. Tsai, «Separation and purification of coenzyme Q10 from Rhodobacter sphaeroides», J. Taiwan Inst. Chem. Eng., vol. 44, n. ${ }^{\circ}$ 6, pp. 872878, nov. 2013, doi: 10.1016/j.jtice.2013.03.013.

[33] M. V. Bule y R. S. Singhal, «Development of a protocol for supercritical carbon dioxide extraction of ubiquinone-10 from dried biomass of Pseudomonas 
diminuta», Bioprocess Biosyst. Eng., vol. 35, n. ${ }^{\circ}$ 5, pp. 809-816, jun. 2012, doi: 10.1007/s00449-011-0661-5.

[32] Martín, Á., Rodríguez-Rojo, S., Navarrete, A., Paz, E. de, Queiroz, J., Cocero, M.J., 2013. CHAPTER 8:Post-extraction Processes: Improvement of Functional Characteristics of Extracts, in: Natural Product Extraction. pp. 285-313. 
Conclusiones 
Las aportaciones de este trabajo pueden contribuir a la transformación del sistema productivo lineal actual de la industria tabacalera del noroeste argentino hacia un nuevo sistema productivo que se enmarca de mejor manera en el concepto de economía circular. ¿De qué manera?, valorizando los residuos utilizándolos como materia prima, generando nuevos recursos económicos, nuevos productos y apertura a nuevos mercados y generando nuevas fuentes de empleo. Los resultados de los estudios realizados en esta tesis se pueden concretar en las siguientes conclusiones.

1. Los subproductos o residuos de la industria de transformado del tabaco aportan 35000 t por año biomasa. En el Capítulo I se detallan las particularidades sobre el scrap y los palos. Estos subproductos aportan compuestos activos como el solanesol, y la nicotina que se han podido valorizar mediante una tecnología limpia como es la extracción con $\mathrm{CO}_{2} \mathrm{SC}$. Además, el scrap contiene compuestos extraíbles como $22 \%$ de azúcares libres, 11,2 \% de proteínas, 9,79 \% de celulosa, $2,47 \% \mathrm{~kg}$ de hemicelulosa y $6 \%$ de lignina. Compuestos que se pueden separar mediante tecnologías limpias como es la extracción con agua, y el subproducto generado fraccionar con una tecnología limpia como es la hidrólisis en ASC

Resaltar, el impacto económico y social que tiene este cultivo en esta región por la cantidad de mano de obra directa e indirecta que emplea (21.389 cultivadores, 50.000 empleados directos y 500.000 empleados indirectos) y la cantidad de recursos económicos que aporta al estado por impuestos hacen que el posible aporte de los resultados de este trabajo a la sostenibilidad de esta actividad tenga un alto potencial.

2. La extracción supercrítica del scrap ha permitido obtener un extracto enriquecido en solanesol y nicotina. Que se pude fraccionar mediante una extracción liquido-liquido con éter y etanol para obtener dos corrientes enriquecidas en cada uno de estos compuestos.

- La presión es la variable de operación que permite operar con altas densidades de $\mathrm{CO}_{2}$, y fraccionar el extracto en función de la diferencia de solubilidad en el $\mathrm{CO}_{2}$ del solanesol y la nicotina. El mayor rendimiento en nicotina $(2,10 \mathrm{~g}$ de nicotina/kg de biomasa) se obtuvo a la mayor presión de operación $37 \mathrm{MPa}$ y $58^{\circ} \mathrm{C}$, y el mayor rendimiento en solanesol $(33,33 \mathrm{~g}$ de solanesol $/ \mathrm{kg}$ de materia prima) se obtuvo a una presión de $15 \mathrm{MPa}$ y $40^{\circ} \mathrm{C}$. 
Estos resultados permiten proponer una extracción a alta presión seguida de una despresurización en dos etapas, recuperándose en cada etapa fracciones ricas en nicotina y solanesol.

- El modelado fenomenológico del proceso de extracción ha permitido obtener los perfiles de concentración en el extractor y su variación con el tiempo. Información necesaria para plantear el escalado a un extractor industrial. Así como determinar que la solubilidad es la etapa controlante del proceso.

- En el proceso de extracción líquido-líquido del extracto crudo, se obtuvieron dos fracciones de productos: una fracción de éter que contiene el 91\% del solanesol extraído y una fracción alcohólica que contiene el 75\% de la nicotina. Ambos solventes orgánicos se retiraron, quedando solanesol en estado sólido y nicotina disuelta en la fase acuosa.

3. El subproducto que queda luego de la extracción con $\mathrm{CO}_{2} \mathrm{SC}$ es una biomasa con alta concentración de extractivos, proteínas, celulosa, hemicelulosa y lignina. Su valorización se pude realizar con un pretratamiento para separar las fracciones solubles en agua como extractivos, y la fracción de proteínas.. En este trabajo no se realizó este pretratamiento por lo que la fracción liquida de la hidrolisis presenta concentraciones más altas de ácidos y otros productos de reacciones secundarias. De esta etapa se pude concluir:

- Los resultados muestran las limitaciones a la transferencia del agua a través de la partícula. Las partículas de hasta $500 \mu \mathrm{m}$ presentan una disminución en los productos de hidrolisis de los azúcares, solo un 2,1 \% de aldehídos y 20,8 \% de ácidos, con un tiempo de 170 milisegundos y con una transformación de azucares estructurales del $49 \%$.

- Las altas concentraciones de ácidos y otros productos de hidrolisis en el efluente líquido se deben a que no se ha sometido a la biomasa a un proceso previo de separación de extractivos y proteínas. Compuestos que están en concentraciones elevadas y sus productos de hidrolisis están presentes junto al los productos de hidrolisis de los carbohidratos estructurales.

4. El solanesol producido en la etapa de fraccionamiento del extracto se ha utilizado con éxito en el proceso de fermentación para la obtención de CoQ10. La encapsulación del solanesol en N-Lok ${ }^{\circledR}$ permitió mejorar su solubilidad en el caldo de cultivo de las 
bacterias de Rhizobium radiobacter, y aumentar la producción específica de CoQ10 en un factor de 11 veces la concentración en el cultivo control.

5. Las aportaciones de esta tesis permiten proponer una biorrefinería en cascada para valorizar de una forma eficaz los subproductos de la industria de transformado del tabaco, con las siguientes etapas: Con una base de cálculo de $1000 \mathrm{~kg}$ de scrap tal como sale de los centros de acopio (base húmeda).

- Etapa de extracción con $\mathrm{CO}_{2} \mathrm{SC}$ para obtener principios activos como solanesol y nicotina. Por cada tonelada de scrap, se obtienen $12,1 \mathrm{~kg}$ de solanesol y 0,4 $\mathrm{kg}$ de nicotina. El solanesol se propone su uso para mejora el proceso de producción de CoQ10, y la nicotina tiene su mercado para industria farmacéutica. El subproducto de este proceso es la biomasa lignocelulósica libre de los extraíbles con $\mathrm{CO}_{2}$ sin degradación, ni cambios en la composición estructural. Por cada tonelada de scrap, se obtienen aproximadamente $980 \mathrm{~kg}$ de este subproducto (scrap libre de extraíbles con $\mathrm{CO}_{2}$ )

- Etapa de extracción con agua caliente. Debido al alto porcentaje de azucares libres y otros carbohidratos como pectinas y proteínas en la fracción de extraíbles se propone que su uso directo como para alimentar un proceso de fermentación. Permitiría obtener hasta una fracción líquida con 573 kg de extraíbles por cada tonelada de scrap en base húmeda.

- Etapa de extracción de proteínas. La concentración de proteínas en el scrap permitiría su separación, y posterior valorización, obteniéndose hasta 112 kg por tonelada de scrap original

- Etapa de hidrólisis ultra rápida en ASC. Las etapas de extracción acuosa y de proteínas generará un subproducto con una composición de $47 \%$ de celulosa, $11,8 \%$ hemicelulosa, 28,8 \% lignina y 12,3 \% de cenizas. Esta fracción se utiliza como alimentación de un proceso de hidrolisis ultra rápida en ASC. Este proceso permite obtener, desde $322 \mathrm{~kg}$ de una biomasa libre de extraíbles y proteínas, un efluente liquido con una composición de azúcares, del $49 \%$, además de ácidos y aldehídos. Se puede valorizar mediante un proceso de fermentación. 
Anexo 


\section{Planta Piloto de Extracción con $\mathrm{CO}_{2} \mathrm{SC}$ de la Universidad Católica de Salta}

En el año 2007, comencé a trabajar como técnico en un proyecto de investigación de la Universidad Católica de Salta que tenía como objetivo la construcción de una planta piloto de extracción con $\mathrm{CO}_{2}$ supercrítico para la obtención de oleorresina de pimentón. El armado de esta planta piloto tuvo una serie de particularidades que permitieron abaratar los costos de construcción. Por ejemplo, el extractor, el tanque buffer y el separador fueron donados por la empresa Aceros Zapla S.A. (ex Fabricaciones Militares de la Nación Argentina), siendo fabricado con los restos de un cañón de un tanque militar. El material de este extractor es un acero SAE 4340 y su cuerpo está formado por un tubo sin costura de $30 \mathrm{~mm}$ de espesor. Además, se utilizó una bomba neumática a pistón para presurizar el $\mathrm{CO}_{2}$ desde el tanque buffer al extractor. Este tipo de bombas, si bien no son la opción más eficiente, tienen un costo del orden de una décima parte de una bomba a diafragma.

En la Figura 1 se puede observar la primera versión de la planta piloto que puse en marcha por primera vez en el año 2008. La presión máxima de trabajo era de 50 MPa y $80^{\circ} \mathrm{C}$. La planta contaba con un extractor de $5 \mathrm{~L}$ y un separador de $2,5 \mathrm{~L}$ ambos calefaccionados por resistencias eléctricas; un tanque buffer de $25 \mathrm{~L}$ con un sistema de enfriamiento para condensar el $\mathrm{CO}_{2}$, y una bomba neumática a pistón Haskel. Su funcionamiento era íntegramente manual y no contaba con caudalímetro, pero extraía oleorresina de pimentón que era su función. Hasta ese momento, en Argentina solo existía una planta de extracción con $\mathrm{CO}_{2}$ supercrítico en la Universidad Nacional de Rio Cuarto a cargo del Ing. Alejandro Ambrogi. Una vez que la planta piloto fue puesta en funcionamiento, el Ing. Alejandro Ambrogi se hizo cargo de la dirección de la planta y de los inicios de mi formación en investigación.

Cuatro años más tarde, y como mi trabajo final de la carrera de Ingeniería Industrial, pude hacer un rediseño y mejoras en la planta piloto con financiamiento de la Facultad de Ingeniería de la Universidad Católica de Salta. Inaugurándose el laboratorio de Fluidos Supercríticos en el año 2012. En la Figura 2 se puede observar una imagen del aspecto actual de la planta. Entre las mejoras realizadas se puede mencionar: la instalación de un medidor de caudal másico tipo Coriolis, el reemplazo del tanque buffer de acero 4340 por un nuevo tanque de acero inoxidable con una camisa de refrigeración por agua, el reemplazo del separador, también de acero 4340 por uno de acero inoxidable, la instalación de un sistema de enfriamiento de agua y un rediseño de las cañerías para minimizar el uso de uniones. 
Desde la creación de este laboratorio, se prestaron servicios a terceros para la extracción de diversas matrices vegetales, de biomasa de bacterias y se hicieron pruebas con biomateriales. Además, se utilizó la planta para la formación de alumnos y elaboración de otros trabajos finales de ingenieria.

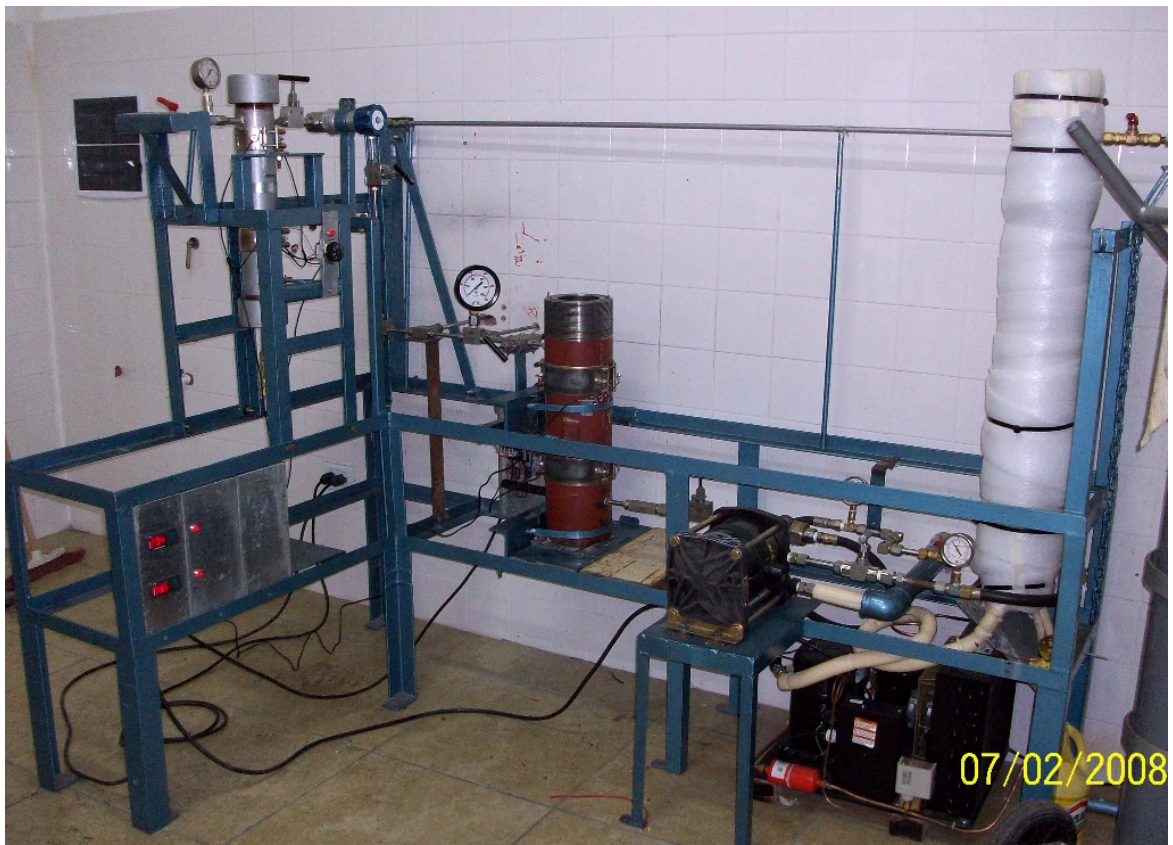

Figura 1. Primera versión de la planta piloto de extracción con $\mathrm{CO}_{2} \mathrm{SC}$ de la Universidad Católica de Salta

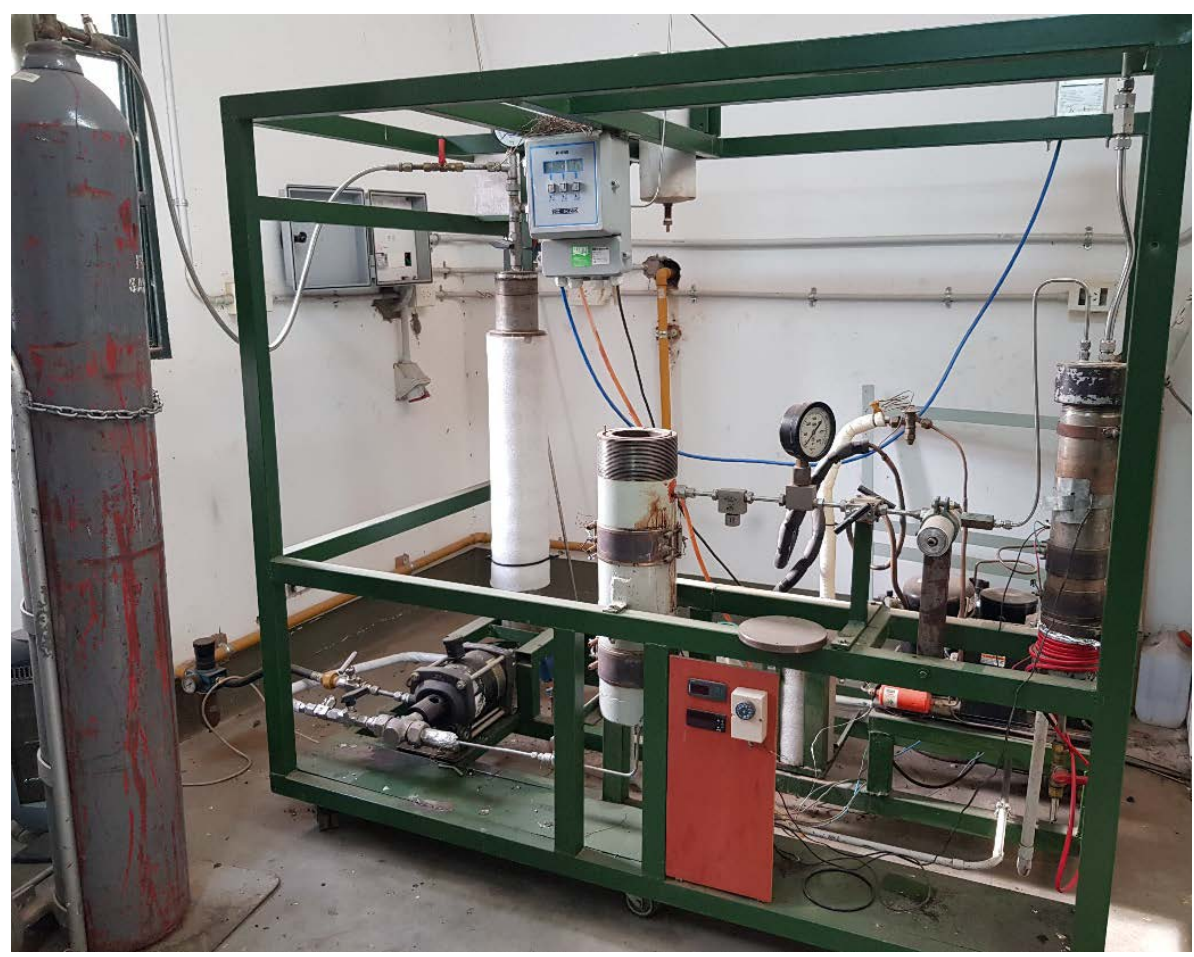

Figura 2. Segunda versión de la planta piloto de extracción con $\mathrm{CO}_{2} \mathrm{SC}$ 


\section{Extracción de Oleorresina de pimentón}

El cultivo de pimiento para pimentón esa una de las llamadas economías regionales del noroeste argentino.. En el año 2009, el 65 \% de la producción argentina se realizó en Salta y el resto en las provincias de Catamarca y Tucumán. La mayoría de los productores tienen menos de 5 hectáreas de producción y la producción es baja (1100 kg/ha) en comparación con otros países como Perú que son exportadores (3.000 a $6.000 \mathrm{~kg} / \mathrm{ha}$ ). Por otra parte, uno de los parámetros de la calidad del pimiento para pimentón es el color que se mide en grados ASTA, y el pimentón de esta región apenas llega al mínimo que son 70 grados ASTA.

El objetivo del primero proyecto que financió la construcción de la planta piloto era darle valor agregado al pimentón cultivado en esta región extrayendo la oleorresina con este proceso. Debido a la baja calidad de la materia prima, la oleorresina extraída no fue de interés para los potenciales compradores que se contactaron. Sin embargo, las pruebas fueron útiles para evaluar el desempeño de la planta piloto y optimizar su funcionamiento.

En la Figura 3 se muestra una de las curvas de extracción de oleorresina (OR) de pimentón con los datos experimentales y los datos obtenidos con el simulador desarrollado en la Universidad de Valladolid, que se encuentra descripto en el Capítulo II de esta tesis.

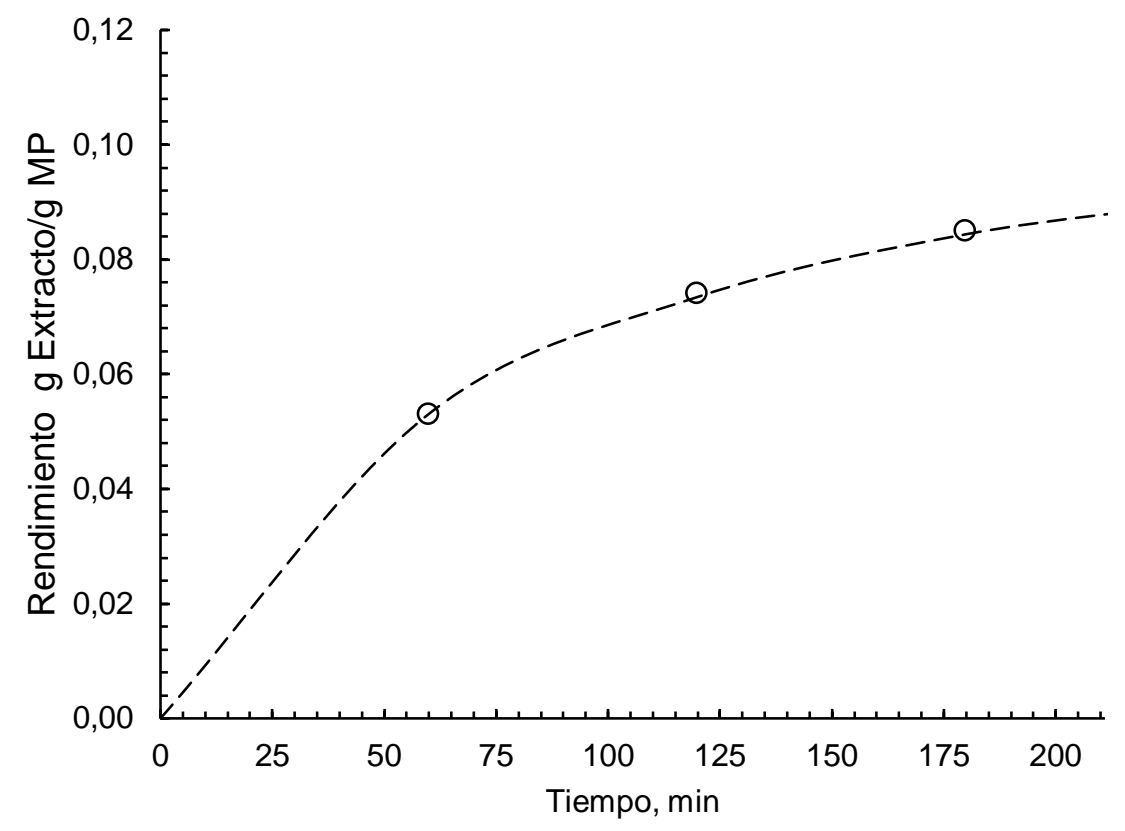

Figura 3. Curva de extracción de OR de pimentón (25 MPa y $\left.55^{\circ} \mathrm{C}\right)$. ---- Datos del modelo ${ }^{\circ}$ Datos experimentales 
La extracción se llevó a cabo con 1 kg del pimentón seco y molido, a una presión de $25 \mathrm{MPa}$ y $55^{\circ} \mathrm{C}$ y con un caudal de $\mathrm{CO}_{2}$ de $10 \mathrm{~kg} / \mathrm{h}$. El tamaño de partícula de la materia prima fue de $450 \mu \mathrm{m}$. y la humedad del $10 \%$. El contenido de OR original se determinó mediante una extracción Soxhlet obteniéndose un valor de 0,1 g OR/g Materia Prima.

En la Figura 4 se muestra uno de los gráficos que aporta el simulador arriba mencionado, en él se puede ver la concentración del extracto en el líquido a lo largo del lecho. En esta figura se puede observar, por ejemplo, que a los 120 minutos se ha extraído el $80 \%$ del contenido de OR de la materia prima y que la concentración de extracto en el extremo superior del cartucho es de aproximadamente el $0,001 \mathrm{~kg} / \mathrm{m}^{3}$ y en el extremo inferior es cero. Esta situación puede observarse mejor en la Figura 5, donde se muestras 3 imágenes con el estado del lecho del cartucho luego de la extracción. La imagen 1 muestra la parte inferior del cartucho donde se ve claramente que el pimentón ha perdido todo su color, la imagen 2 muestra la parte superior donde todavía queda un resto de color por extraer y la imagen 3 muestra el aspecto del lecho completo. En trabajos anteriores se determinó que un tamaño de partícula muy fino (menor que $150 \mu \mathrm{m}$ ) genera un efecto negativo en la cinética de la extracción debido a una compactación del lecho. El uso de esta materia prima es una buena oportunidad para usarlo en capacitaciones de extracción con $\mathrm{CO}_{2}$ supercrítico.

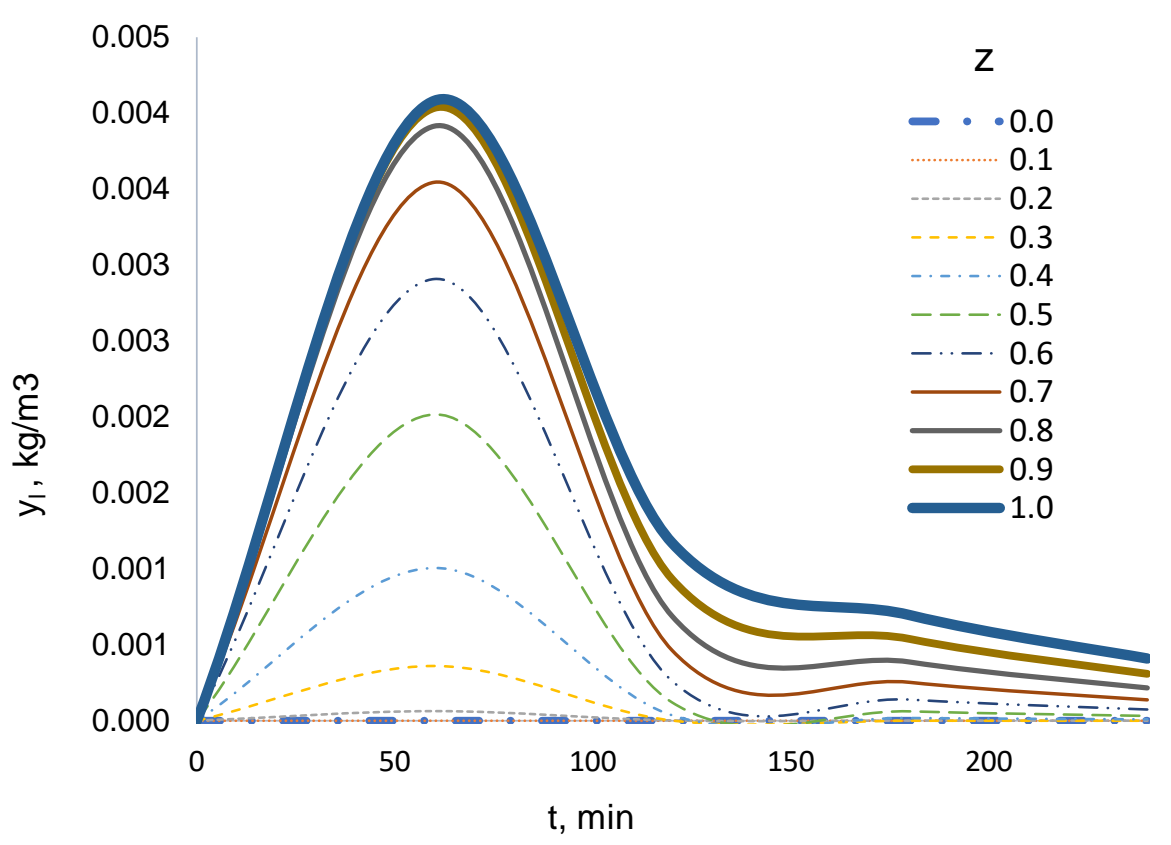

Figura 4. Concentración del Extracto a lo largo del lecho (z) en función del tiempo 


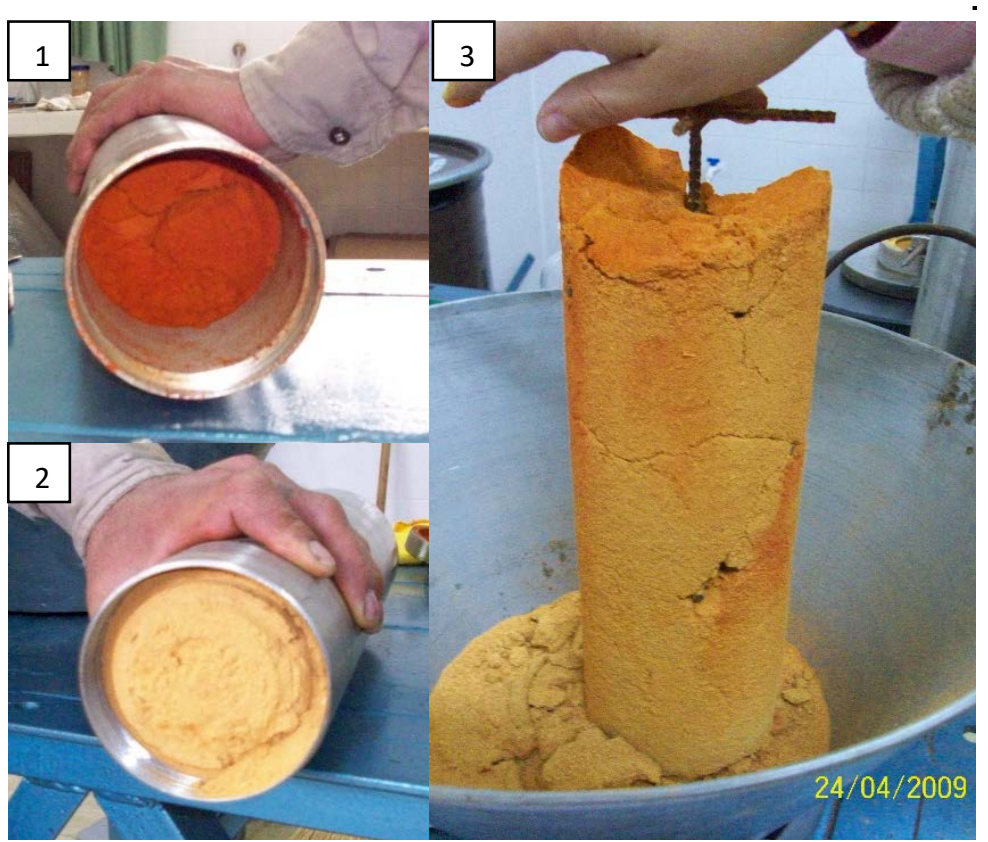

Figura 5. Aspecto del lecho de pimentón luego de una extracción. 1. Parte superior. 2. Parte inferior. 3. Lecho completo.

\section{Conclusiones}

La planta piloto de la Universidad Católica de Salta fue construida por el autor de este trabajo y se mantiene funcionando hasta el día de hoy. Se armó una primera versión en el año 2008 y un rediseño en el año 2012 que mejoró considerablemente su desempeño.

Esta planta es una fuente genuina de generación de conocimiento y una herramienta muy útil para generar relaciones con el medio en el que está inserta la Universidad. Al prestar servicios y posibilidades de incorporación de valor agregado a distintos sectores productivos que hoy no lo tienen. Además de ser un proceso sustentable y amigable con el medio ambiente. 
Trabajos a Futuro 
Los fluidos supercríticos como $\mathrm{CO}_{2}$ y $\mathrm{H}_{2} \mathrm{O}$, para la extracción de principios activos y para la hidrólisis de biomasas lignocelulósicas respectivamente, se presentan como la mejor opción para un futuro cercano en un contexto en el que se busca que los procesos sean sustentables y amigables con el medio ambiente.

Los resultados de este trabajo dejan abiertas una serie de posibilidades para futuros trabajos utilizando estos procesos con fluidos supercríticos como:

- Extracción con $\mathrm{CO}_{2}$ y purificación de otros componentes de interés como rutina, escualeno, vitamina E, etc. Si bien, están en bajos porcentajes, se podría formular algún producto con fines cosméticos con el extracto supercrítico de tabaco. El alto volumen de biomasa disponible anualmente mejora las posibilidades de obtener una cantidad económica de un producto de alto valor.

- Estudio de una etapa previa a la hidrólisis donde se separe y aísle la fracción proteica del tabaco. Debido a la calidad de sus proteínas como potencial uso alimenticio humano o animal.

- Debido al alto contenido de extraíbles en agua, se puede estudiar y evaluar de una extracción acuosa de la biomasa de tabaco, como pretratamiento de la hidrólisis.

- Evaluación de fermentaciones de los productos de hidrólisis para la obtención de bioetanol. Utilizando levaduras que metabolicen C-5 y C-6.

- Ampliación de los experimentos de biosíntesis de CoQ10 usando solanesol como precursor. Optimización de las condiciones de cultivo.

- Extracción supercrítica de la CoQ10 desde la biomasa de bacterias a escala piloto.

- Evaluación de la factibilidad económica de instalar una pequeña biorrefinería con fluidos supercríticos en el mismo lugar donde se generan los subproductos. 


\section{Summary}


The tobacco production of Argentina is concentrated in the northern provinces of the country, due to the favorable climatic conditions. The provinces of Salta and Jujuy together produce an average of 70,000 tn/year of tobacco leaf, which generates 35,000 tn of by-products or residues. In this work, research is contributed to develop a sustainable biorefinery using the by-products of the tobacco industry, employing supercritical fluids such as $\mathrm{CO}_{2}$ and $\mathrm{H}_{2} \mathrm{O}$ as solvents and reaction media. It is proposed to add value to the by-products, expanding the current value chain and contributing to the sustainability of this important industry in the provinces of Northwest Argentina.

Among the advantages identified to valorize these by-products are:

- The chemical composition, high yield of biomass in $\mathrm{kg} / \mathrm{ha}$

- High level of knowledge in the agricultural cultivation

- Abundant research background in alternative uses to the existing one

- Economy of scale in the industrial production

- Access to by-products and waste in high volumes centralized in collection centers, which favors the homogeneity and accessibility of the product.

This report presents the characteristics of the by-products generated in the tobacco processing industry, to be used as raw material in a biorefinery. This work provides the experimental results that demonstrate the viability of the extraction of solanesol and nicotine from the byproducts obtained in the processing of tobacco leaves, with supercritical $\mathrm{CO}_{2}\left(\mathrm{SCCO}_{2}\right)$. The effect of the operation variables (pressure, temperature, extraction time) were analyzed and a phenomenological model of the extraction was applied to obtain the solubility and mass transfer coefficients.

The results show that different conditions are required depending on the purpose of the extraction: low pressure (15 MPa) to increase the yield of the extracts in solanesol, and high pressure $(37 \mathrm{MPa})$ to promote nicotine extraction, while the model results indicate that the best results were obtained under conditions where the extraction was controlled by the solubility (rather than mass transfer). These results provide the necessary information for the valorization of the extractive compounds in $\mathrm{SCCO}_{2}$ from the waste produced by the tobacco industry.

The by-product obtained from the extraction stage with $\mathrm{SCCO}_{2}$, still contains valuable fractions: close to $60 \%$ of water-soluble compounds, such as glucose, fructose and sucrose, pectins and others. In addition to $10 \%$ protein, $10 \%$ cellulose, $6 \%$ lignin, $10 \%$ moisture and in lesser proportion hemicellulose and ash. The scrap of the tobacco plant coming from the extraction stage with $\mathrm{SCCO}_{2}$, has been treated in a hydrolysis process 
with supercritical water (SCW) at both laboratory and pilot plant scale. The operating conditions included temperatures between $374-400^{\circ} \mathrm{C}$, pressures of $25 \mathrm{MPa}$ and reaction times below $1 \mathrm{~s}$. The results show that the controlling stage of this process is the mass transfer. Thus, the lab scale plant was operated using a particle size of $150 \mu \mathrm{m}$ and a reaction time of $170 \mathrm{~ms}$. Given the increased surface area the sugars degradation in SCW is fast which results in a high concentration of hydrolysis products, aldehydes $42.4 \%$ and acid $35.2 \%$. On the other hand, at the pilot plant the bigger particles (up to $500 \mu \mathrm{m}$ ) present greater resistance to SCW attack resulting in a higher concentration of sugars $(49,1 \%)$ and a much lower concentration of aldehydes (2.1\%) and acids (20.8\%). This pilot plant was operated using a reaction time of $180 \mathrm{~ms}$.

The last chapter of this thesis is dedicated to study an application of the solanesol obtained from tobacco scrap by supercritical extraction in chapter 2. Specifically, its use as a precursor in a Rhizobium radio bacteria culture in order to obtain CoQ10. Here, the Solanesol extract is first encapsulated in N-Lok, forming an emulsion that facilitates its dissolution in the culture medium. The results show that the production of CoQ10 is 10fold larger than that obtained in the control.

The results obtained allow us to propose a cascade biorefinery concept. In a first stage, the fraction of reducing sugars can be obtained by water extraction for a subsequent fermentation stage. The remnant concentration of proteins is appropriate for their use. Finally, the remaining residue can be fractionated by a hydrolysis process in SCW. This effluent can be recovered by fermentation. 
Agradecimientos 
En primer lugar, quiero agradecer a María José Cocero por su enorme generosidad, por ayudarme y alentarme a terminar mi tesis doctoral a la distancia, por su tiempo y sabiduría y por haberme echo sentir como en casa durante los meses que estuve en Valladolid. Sin su acompañamiento y su dirección, probablemente no hubiese terminado. Hoy siento que gran parte de mi doctorado es gracias a ella. A María José Cocero Alonso mi mas sincera y enorme gratitud. ¡Gracias!

Quiero agradecer también a Alexander Navarrete Muñoz, mi tutor y guía durante mi estancia en Valladolid, quien me ayudo a diseñar los experimentos y a insertarme en el trabajo diario, me abrió las puertas de su hogar y me permitió conocer a su hermosa familia, gracias por la calidez latinoamericana y tu buena onda. Quiero agradecer también a Angel Martín, quien fue el golpe de óxido nitroso que necesitaba para poder llegar a la meta logrando publicar mi primer paper. Sos un grande Angel!.

Gracias a Celia, quien me dio una ayuda enorme para la caracterización de la materia prima, los análisis de los productos de hidrólisis y pude ayudarla un poquito en poner en marcha la planta piloto de hidrólisis de la UVa.

Del otro lado del charco, está mi institución de origen. Donde me formé como Ingeniero y trabajé desde el segundo año de mi carrera en varios proyectos que salieron muy bien. Mi agradecimiento a las autoridades de la Universidad Católica de Salta quienes me apoyaron para crear un laboratorio en la Facultad de Ingeniería con la planta de extracción con $\mathrm{CO}_{2}$ supercrítico que construí. Han pasado 12 años desde que empecé, las autoridades cambiaron, pero el apoyo continúo. Agradezco a los ex vicerrectores, Ing. Manuel Cornejo Torino y al Dr. Gerardo Vides Almonacid. Excelentes personas que dejaron una huella de integridad y honestidad en mi formación. Agradezco también al actual rector Ing. Rodolfo Gallo Cornejo y al vicerrector de investigación Dr. Federico Colombo Speroni quienes eligieron dar continuidad en el cambio de gestión. Hoy les agradezco con palabras y con el doctorado que les prometí terminar.

En la Facultad de Ingeniería, tengo que agradecer al Dr. Javier Alberto Moya, quien me dirigió durante los cinco años de mi beca doctoral del CONICET, me enseñó los primeros pasos en investigación, los primeros trabajos en congresos, y un montón de cosas más que aprendí de él. Fue y es un excelente consejero, y una persona de las que vale la pena cruzarse en la vida. ¡Gracias Javier!. Al decano de la Facultad, Ing. Néstor Lesser y a la Dra. Lia Orozco, Jefa de Investigación, gracias por todo el apoyo que me dieron en tiempos en los que se necesitaba.

Todos los experimentos de esta tesis no hubiesen sido posible sin el apoyo de las autoridades de la Cooperativa de Productores Tabacaleros de Salta. Agradezco al 
entonces Gerente de la Cooperativa, Sr. Carlos Robbio, quien en el año 2014 me recibió en su oficina diciéndome: Tenes 3 minutos para convencerme de porque te debería escuchar y nos quedamos 2 horas hablando en esa reunión. La Cooperativa financió el envío de muestras de tabaco desde Salta a España, con los que se hicieron todos los ensayos, además compraron insumos y una bomba de repuesto para la planta piloto. Mi agradecimiento también se extiende al Ing. Jorge Alderete, Gerente de Negocios de la cooperativa quien se encargó de ejecutar las gestiones para todo el financiamiento recibido. Sin duda, es mi mas grande deseo que los resultados de esta tesis sirvan para darle sustentabilidad a esta tan importante industria de Salta y que se puedan llevar a cabo en escala industrial.

No quiero olvidarme de agradecer a mis compañeros de doctorado de la Universidad de Valladolid. Al recordarlos, se me dibuja una enorme sonrisa por la cantidad de momentos divertidos y risas juntos. Gracias a Danilo y Joao, los primeros dos que conocí dos personas gigantes, gracias por tantos momentos latinoamericanos. Gracias a Oscar, Miriam, Lara, Teresa, Irene, Cristina, Luis Miguel, Vito, Florencia, Sergio, Gyuri, Anna, Alberto, Marta, Reinal, Nuria, Gianluca, Nerea, Inés, Vanessa, Johana y Sebastiano. Los recordaré siempre.

Gracias al todo el personal de apoyo del Grupo de Procesos de Alta Presión: Dani, Isa, Sergio, Alvaro, Enrique y Carlotta.

A mi madre Maria de los Ángeles, mis hermanos Antonio, Esteban, Giselda y Luciana, a quienes los extrañé muchísimo mientras estuve lejos y siempre recibí los mejores deseos de su parte. Junto con cada una de sus familias me hicieron muy feliz. Gracias Paula, Jazmín y Lucia; Cecilia y Julieta; Federico, Enzo y Sofía.

A mis amigos de toda la vida, Sebastián, Juan José, Miguel y Gabriel. A mis más viejos y queridos amigos Marcelo y todos los guardianes del vaso.

Por último, y por ser lo mas importante para mí, al amor de mi vida. Agustina, gracias por ser el puntal que me mantuvo en pie. Gracias por comprenderme, por ayudarme, gracias por hacerme sentir amado. ¡Gracias por todo! 
Sobre el Autor 


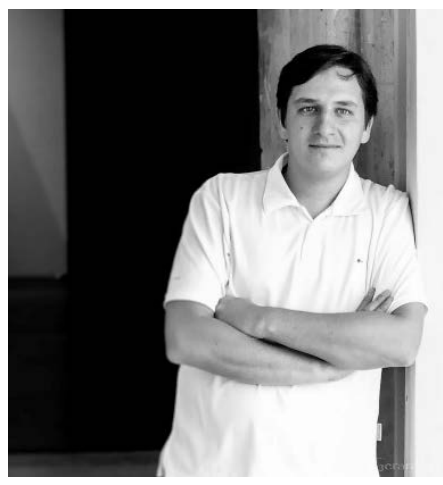

Gerardo Joaquin Tita, nació el 24 de agosto de 1982 en Villa Regina, provincia de Rio Negro. Se formó en una escuela secundaria de educación técnica obteniendo el título de Técnico en Automotores. Luego ingresó a la carrera de Ingenieria Industrial en la Universidad Católica de Salta, donde comenzó a trabajar en la construcción de equipos para los laboratorios de Física mientras cursaba la carrera. En el año 2008 se incorporó a un proyecto donde fue el encargado de construir y poner en funcionamiento una planta piloto de extracción con $\mathrm{CO}_{2}$ supercrítico. Al terminar su carrera como ingeniero obtuvo una beca de 5 años del Consejo Nacional de Ciencia y Tecnología de la Nación Argentina (CONICET) para cursar sus estudios doctorales. Mientras, recibió una beca para Jóvenes Profesores Investigadores del Banco Santander para realizar una estancia de 3 meses en el Grupo de Procesos de Alta Presión de la Universidad de Valladolid donde comenzó a trabajar en la extracción con $\mathrm{CO}_{2}$ supercrítico de solanesol y nicotina desde el tabaco. Unos meses después de regresar a Argentina recibió una beca Erasmus Mundus para una nueva estancia en Valladolid de 22 meses que le permitió complementar los experimentos de extracción con un proceso de conversión de la celulosa del tabaco en azucares fermentables para darle forma al concepto de una Biorrefinería a base de residuos de tabaco, siendo este último el tema de su tesis doctoral. 